\title{
Involvement of Two Novel GRF-Type Zinc Finger Nodulins during Rhizobial Symbiotic Establishment in Medicago truncatula Nodules
}

Lucas Gontijo Silva Maia

Follow this and additional works at: https://researchrepository.wvu.edu/etd

\section{Recommended Citation}

Maia, Lucas Gontijo Silva, "Involvement of Two Novel GRF-Type Zinc Finger Nodulins during Rhizobial Symbiotic Establishment in Medicago truncatula Nodules" (2018). Graduate Theses, Dissertations, and Problem Reports. 6142.

https://researchrepository.wvu.edu/etd/6142

This Dissertation is protected by copyright and/or related rights. It has been brought to you by the The Research Repository @ WVU with permission from the rights-holder(s). You are free to use this Dissertation in any way that is permitted by the copyright and related rights legislation that applies to your use. For other uses you must obtain permission from the rights-holder(s) directly, unless additional rights are indicated by a Creative Commons license in the record and/ or on the work itself. This Dissertation has been accepted for inclusion in WVU Graduate Theses, Dissertations, and Problem Reports collection by an authorized administrator of The Research Repository @ WVU.

For more information, please contact researchrepository@mail.wvu.edu. 


\title{
INVOLVEMENT OF TWO NOVEL GRF-TYPE ZINC FINGER NODULINS DURING \\ RHIZOBIAL SYMBIOTIC ESTABLISHMENT IN MEDICAGO TRUNCATULA NODULES
}

\section{LUCAS GONTIJO SILVA MAIA}

\author{
Dissertation submitted to the Davis College of Agriculture, \\ Natural Resources and Design \\ at West Virginia University \\ in partial fulfillment of the requirement of the degree of \\ Doctor of Philosophy \\ in \\ Genetics \& Developmental Biology \\ Vagner Augusto Benedito, Ph.D. Committee Chairperson \\ Jianbo Yao, Ph.D. \\ Nicole Waterland, Ph.D. \\ Teiya Kijimoto, Ph.D. \\ Alexander Valentine, Ph.D. \\ Department of Plant and Soil Sciences
}

\section{Morgantown, West Virginia}

2017

KEYWORDS: Symbiotic Nitrogen Fixation, Nodulation, Bacteroid Differentiation, Genetic Network, Transcription Factors, Legumes

Copyright 2017 Lucas Gontijo Silva Maia 


\author{
ABSTRACT \\ INVOLVEMENT OF TWO NOVEL GRF-TYPE ZINC FINGER NODULINS \\ DURING RHIZOBIAL SYMBIOTIC ESTABLISHMENT IN MEDICAGO \\ TRUNCATULA NODULES
}

\author{
Lucas Gontijo Silva Maia
}

In legumes, symbiotic nitrogen fixation (SNF) occurs through a cooperative relationship established with rhizobial diazotrophic bacteria. This association triggers the de novo development of a highly specialized organ from root, called nodule. In this dissertation, we explore the molecular functional genetics of nodulation in the model legume Medicago truncatula in the scope of knowledge. Followed by a linearization of the current knowledge about the roles of Transcription Factors in legume nodule symbiosis. In an attempt of understanding the orchestration dynamics of nodulation and processes that generate SNF. Legumes evolved novel genes related with nodule development, symbiosis establishment and nitrogen fixation, which are exclusively expressed at different stages of nodule development, and during nitrogen reduction per se. In the model legume Medicago truncatula, two genes encoding GRF-type zinc finger proteins present high and distinct expression pattern during symbiotic nitrogen fixation in root nodules. Both genes encode for very similar protein, part on a non-characterized protein family, GRF-type zinc finger, with putative function as transcriptional factor. The gene expression data present high and distinct transcription for both genes in specific zones of the indeterminate nodule: MtGRF1/MtN20 (Medtr7g086040.1) is highly expressed in an area below the nodule meristem (zone II, where endosymbiosis occurs), while MtGRF2 (Medtr1g064350.1) is expressed in the interzone, where bacteroid differentiation occurs. MtN20 is exclusively present in the distal-zone II of nodules, in tissue where the plant cells become colonized and bacteroids start to differentiate in SNF "organelles". And a Tnt1insertional line for MtN20 was genotyped and phenotype. Nodules of $m$ tn20 present normal nodule formation but disruption in nitrogen fixation, showing early senescence, and loss of the rhizobial maturation, required in this process. MtGRF2 present expression pattern in the interzone of nodules, in a tissue where the and bacteroids pass through a singular differentiation stage to become a in SNF "organelles". A genetic network for each gene of interest highlight high correlated genes that possible play essential roles on distinct stages of symbiotic nitrogen fixation and bacteroid differentiation, await to be functional characterized. This information contributes to understanding of symbiotic nitrogen fixation and emphasize important questions to be investigated and make possible to explore root nodulation in nonlegumes. 


\section{DEDICATION}

In dedication to my family, in special to my parents, for making me who I am, and my wife for supporting me all the way! 


\section{ACKNOWLEDGEMENTS}

I thank the Coordination for the Improvement of Higher Level Personnel - CAPES (Brazil) for granting a scholarship during 4 years of my studies.

Foremost, I would love to express my deepest gratitude to my advisor Dr. Vagner Augusto Benedito for his belief, patience, support and enlightening guidance during my $\mathrm{Ph}$. D. study. I could not imagine how fortunate I would be to have such a wonderful, supportive and positive mentor.

I am sincerely grateful to my committee members Dr. Nicole Waterland, Dr. Jianbo Yao, Dr. Teiya Kijimoto and Dr. Alexander Valentine for serving on my graduate committee and providing me all the learning and challenge throughout my graduate study.

My great appreciation for WVU DAVIS college faculty and staff, for the warm friendship and opportunity, in special Dr. Daniel Panaccione, Dr. Kenneth Blemings, Dr. Lee Kass, Dr. Domingo Jose Mata Padrino, Dr. Eugenia M. Pena-Yewtukhiw, Dr. Brett Kenney, Dr Scott Bowdridge, Dr. David Davis, Barton Baker, Sue Myers, Gail Sikorsky and Dr. Yong-Lak Park.

My sincere appreciation and deepest gratitude to my lab mates Lina Yang, Christina Wyman, Roshan Abeyratne, Delini Samarasinghe, Victor Adelanwa and visitor researcher Adolfo Santos, Samuel Silva, Maísa Siqueira and Nelson Tavares.

My frank thankful to my friends, Prasanthi Koganti, Roshan Abeyratne and family, Suejin Park, Sarah Mills, Gabriela and Charlie, Sandy and Big Charlie, Deborah and Brandon, Brandon's family, Rafael and Ângela, WVU Brazilian Student Association friends, Dr. DiFázio, Dr. Dale, and my rock climb friends for such important and distinguish presence in my life, which make everything flows more pleasurable.

Lastly, and most importantly, I would like to thank my family for accepting my time and distance, even contribute with continuous love, understanding and encouragement that have been crucial for this accomplishment. My sincere thankfulness to my wife to be by my side all the time, accepting the difficulty of the distance and time and understanding to postpone our plans.

I would like to thank all you that contribute directly or indirectly for this achievement. 


\section{TABLE OF CONTENTS}

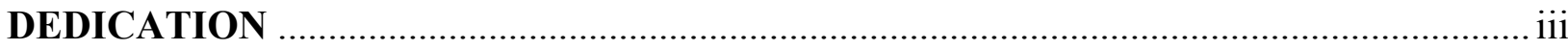

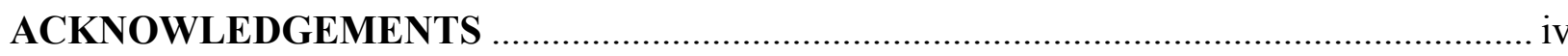

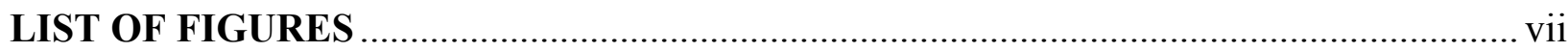

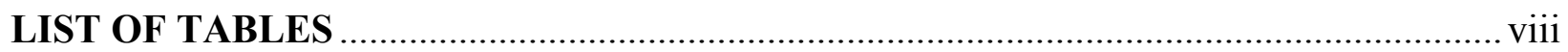

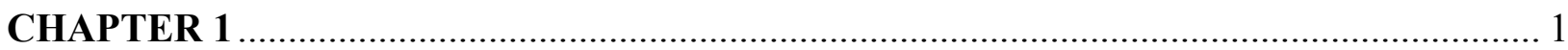

OF LEGUMES AND SYMBIOTIC NITROGEN FIXATION: EXPLORING THE MOLECULAR GENETICS OF NODULATION IN THE MODEL LEGUME

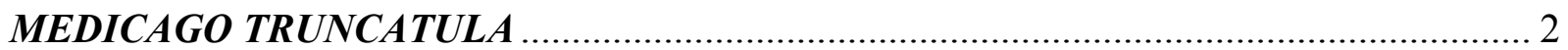

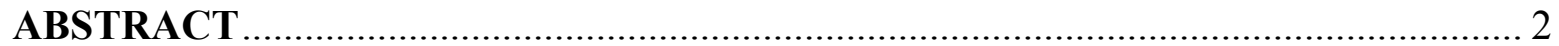

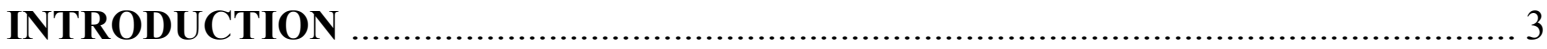

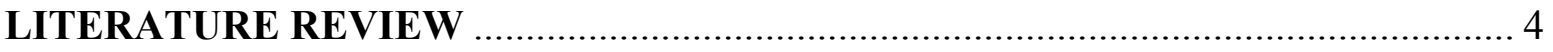

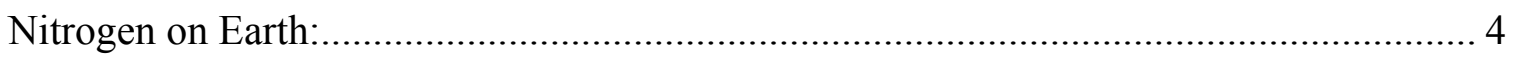

Diazotrophs and symbiotic nitrogen fixation:........................................................ 4

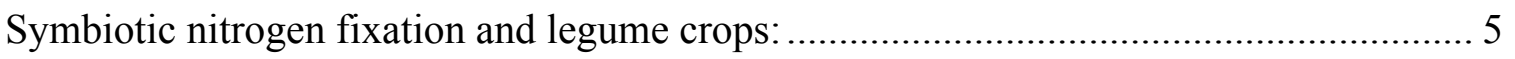

Evolution of symbiotic nitrogen fixation in legumes: .................................................. 5

Rhizobium recognition and nodule development initiation:.............................................. 6

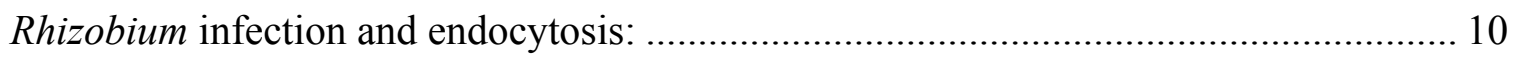

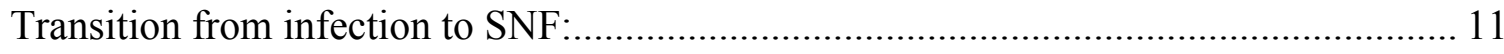

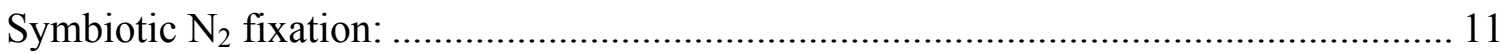

Medicago truncatula as a model legume system:...................................................... 12

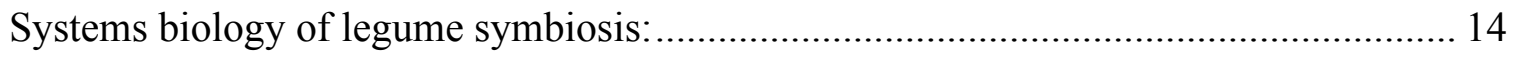

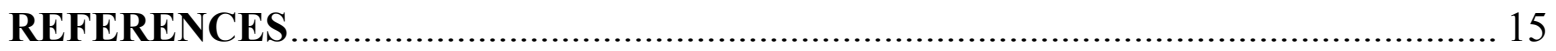

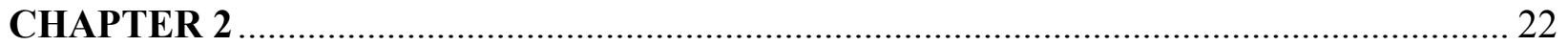

THE MAKING OF THE LEGUME NODULE: TRANSCRIPTION FACTORS, REGULATORY GENE NETWORKS AND THE NOVEL GRF-TYPE ZINC FINGER

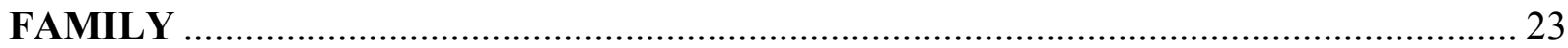

ABSTRACT

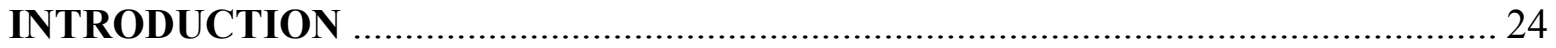

The making of the nodule at the molecular level........................................................... 24

Hubs of nodule development: identification of nodule-specific transcription factors...... 31

Transcriptional regulomics of the Medicago truncatula nodule and symbiotic nitrogen

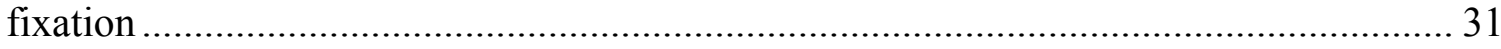

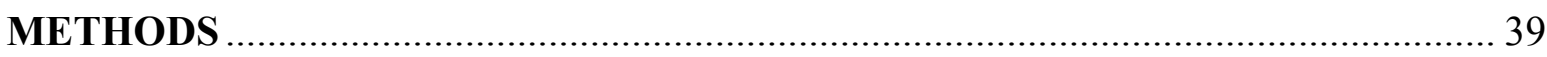

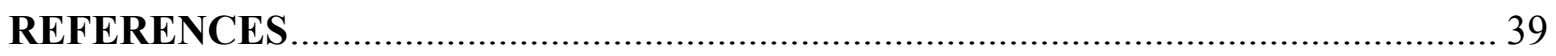


CHAPTER 3

MTN20 IS AN ESSENTIAL GRF-TYPE ZINC FINGER NODULIN FROM MEDICAGO TRUNCATULA INVOLVED IN THE FIRST STAGE OF BACTEROID DIFFERENTIATION 46

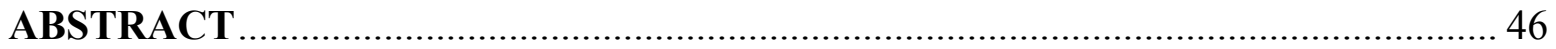

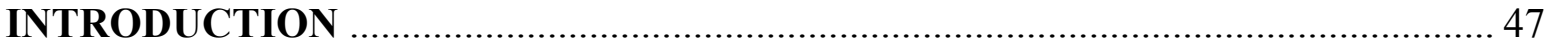

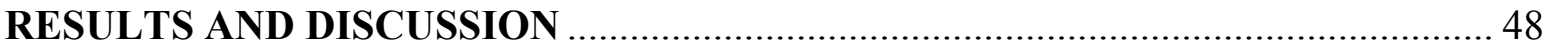

Nodulin 20 (MtGRF1) is an elusive protein recurrently identified in early transcriptomic

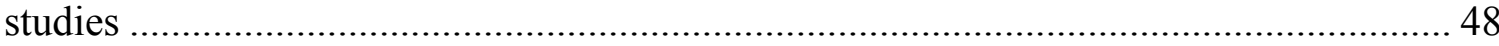

MtN20 is potentially a novel nuclear protein 49

MtN20 function may be essential for symbiotic nitrogen fixation but not for nodule

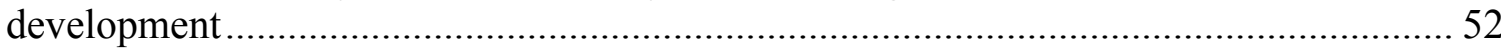

MtN20 expression occurs specifically in the very early stages of bacterial infection ...... 54 The MtN20 transcriptional network correlates with the development of the early infection

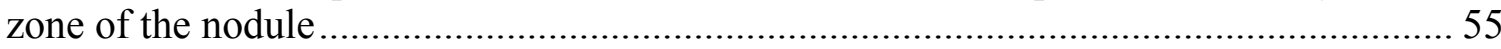

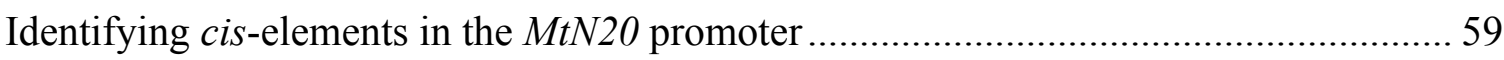

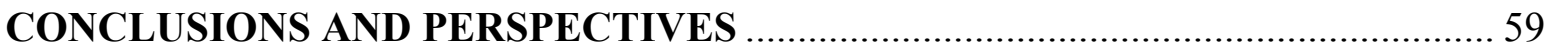

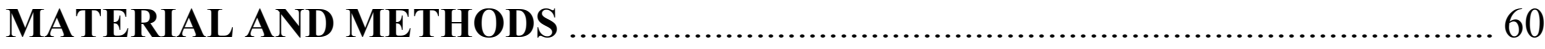

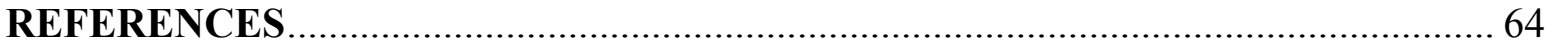

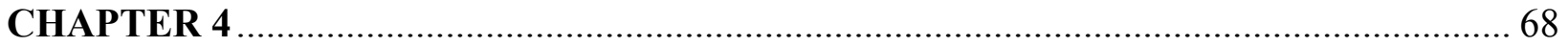

MTGRF2 IS A GRF-TYPE ZINC FINGER NODULIN FROM MEDICAGO TRUNCATULA POTENTIALLY INVOLVED IN BACTEROID DIFFERENTIATION

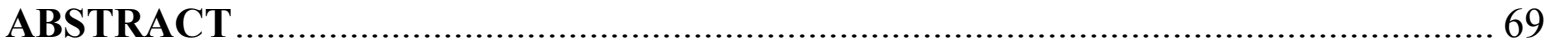

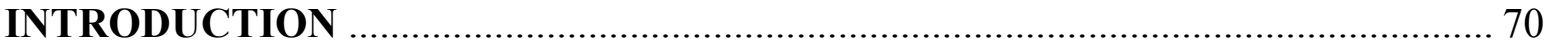

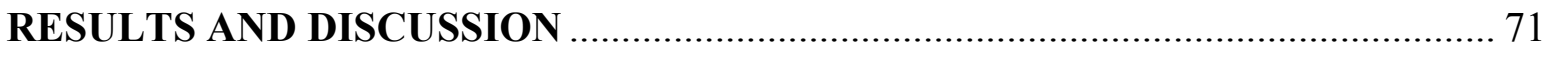

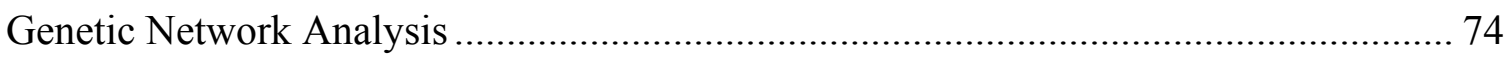

Analysis of $c i s$-elements in the $M t G R F 2$ gene promoter ........................................ 79

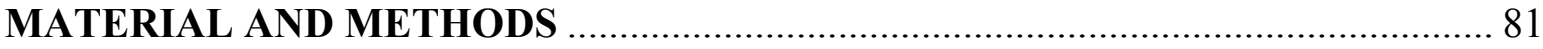

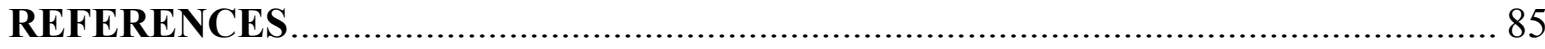

CHAPTER 5

INVOLVEMENT OF TWO NOVEL GRF-TYPE ZINC FINGER NODULINS DURING RHIZOBIAL SYMBIOTIC ESTABLISHMENT IN MEDICAGO TRUNCATULA

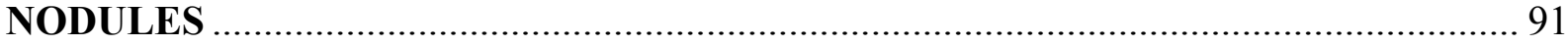

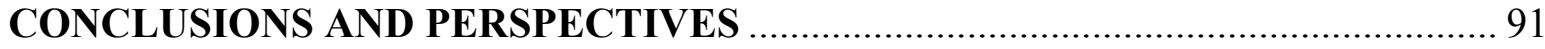

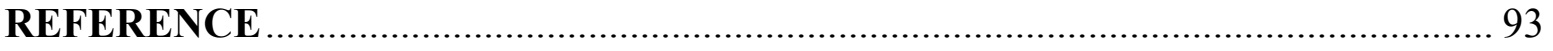




\section{LIST OF FIGURES}

CHAPTER 1 - Figure 1. Nodule organogenesis in Medicago truncatula ............................6

CHAPTER 1 - Figure 2. The indeterminate nodule of Medicago truncatula ........................14

CHAPTER 2 - Figure 1. Characterized transcription factors involved in the common symbiotic pathway as well as the Rhizobium-specific nitrogen fixation symbiosis in legumes..........................26

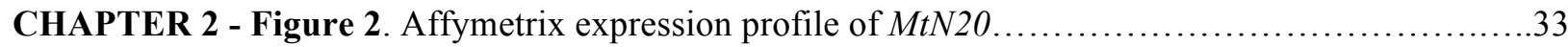

CHAPTER 2 - Figure 3. Phylogenetic reconstruction of GRF-type zinc finger proteins in select legume species and Arabidopsis and expression profile of the Medicago truncatula genes........................34

CHAPTER 2 - Figure 4. Protein GRF-type zinc finger alignments.............................. 35

CHAPTER 2 - Figure 5 Expression profile of GRF-type zinc finger family members (IPR010666) in

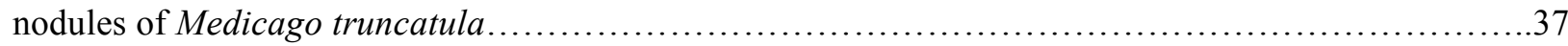

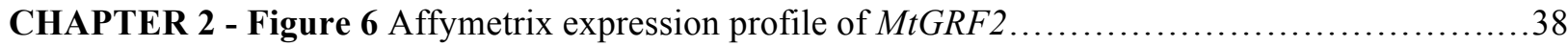

CHAPTER 3 - Figure 1. MtN20 protein sequence retrieved data from Medicago truncatula Proteome compendium.

CHAPTER 3 - Figure 2. MtN20/MtGRF1 quantification in the Medicago truncatula Compendium proteome (Marx et al., 2016).

CHAPTER 3 - Figure 3. Position and gene structure of Medtr7g086040 (MtGRF1/MtN20) in Medicago

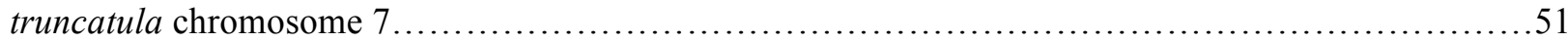

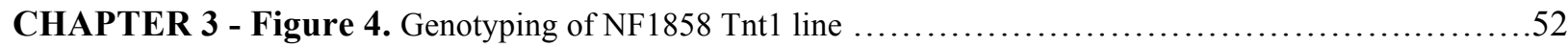

CHAPTER 3 - Figure 5. Phenotype of NF1858 Tnt1 insertion line of Medtr7g086040.1 (MtN20).....53

CHAPTER 3 - Figure 6. MtN20 (Medtr7g086040) function and gene expression of roots inoculated with

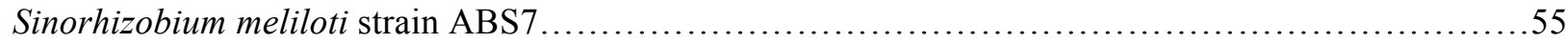

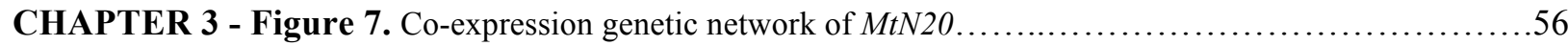

CHAPTER 3 - Figure 8. Cis-regulatory elements identified in promoter region of MtN2O (Medtr7g086040.1).

CHAPTER 4 - Figure 1. MtGRF2 quantification in the Medicago truncatula Compendium proteome (Marx et al., 2016).....

CHAPTER 4 - Figure 2. The MtGRF2 protein sequence was retrieved from Medicago truncatula Proteome Compendium..................................................................... 72

CHAPTER 4 - Figure 3. Gene structure of Medtr1g064350 (MtGRF2) ........................72

CHAPTER 4 - Figure 4. MtGRF2 (Medtr1g064350) gene expression in nodules and roots inoculated with Sinorhizobium meliloti.....................................................................

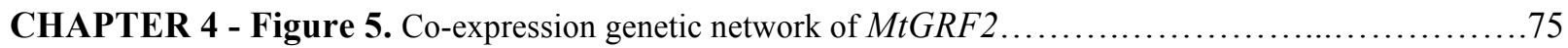

CHAPTER 4 - Figure 6. Cis-regulatory elements identified in the promoter region of MtGRF2 (Medtr1g064350).... 


\section{LIST OF TABLES}

CHAPTER 1 - Table 1. Characterized genes involved in nodulation of Medicago truncatula.............8 CHAPTER 2 - Table 1. Transcription factors and transcriptional regulators identified in the proteome of

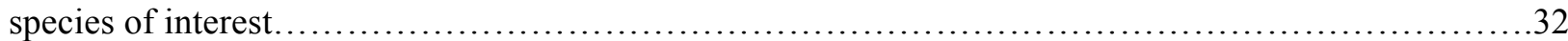

CHAPTER 2 - Table 2. Abundancy of and GRF type-ZF proteins in the proteome of species of interest, holds or not additional domains.

CHAPTER 2 - Table 3. Gene expression of the GRF-type zinc finger nodulins Medtr7g086040 and Medt1g064350 in nodule zones by RNA-Seq of laser capture microdissection (LCM).................38

CHAPTER 3 - Table 1. First and second degree of correlated expression genes with MtN20/MtGRF1..58

CHAPTER 4 - Table 1. First- and second- correlation degree of co-expression genes with MtGRF2 ...76

CHAPTER 4 - Table 2. Comparative analysis of promoter cis-elements of $M t N 20 / M t G R F 1$ and $M t G R F 2$ genes. 


\section{CHAPTER 1}




\title{
OF LEGUMES AND SYMBIOTIC NITROGEN FIXATION: EXPLORING THE MOLECULAR GENETICS OF NODULATION IN THE MODEL LEGUME MEDICAGO TRUNCATULA
}

\begin{abstract}
In legumes, symbiotic nitrogen fixation (SNF) occurs through a cooperative relationship established with rhizobial diazotrophic bacteria. This association triggers the de novo development of a highly specialized organ from the root, called nodule. Legumes evolved novel genes related to nodule development, symbiosis establishment and nitrogen fixation, which are exclusively expressed at different stages of nodule development, and during nitrogen reduction per se. In the model legume Medicago truncatula, we identified two GRF-type zinc finger genes as expressed specifically in nodules and were chosen for characterization of their molecular roles during symbiotic nitrogen fixation. Gene expression levels are high for both genes in specific zones of the indeterminate nodule: MtGRF1/MtN20 (Medtr7g086040) is highly expressed in an area below the nodule meristem (zone II, where cell infection or endosymbiosis occurs), whereas MtGRF2 (Medtr1g064350) is expressed in the interzone, where bacteroid differentiation occurs. Understanding their functions is of paramount importance to enhance our basic knowledge about how nodules develop and establish symbiotic nitrogen fixation. Therefore, in order to functionally characterize the role of these genes, this research aims to: 1) Further detail their expression patterns during nodule development and in specific zones of the mature indeterminate nodule of $M$. truncatula; 2) Assess the essentiality of these genes for symbiotic nitrogen fixation; 3) Generate regulatory gene networks centered on these nodulins. In this chapter, we review modern concepts of legume biology and symbiotic nitrogen fixation in the light of genetics and genomics studies using model species, and especially the recent advances in the body of scientific knowledge based on studies with the model legume Medicago truncatula.
\end{abstract}




\section{OF LEGUMES AND SYMBIOTIC NITROGEN FIXATION: EXPLORING THE MOLECULAR GENETICS OF NODULATION IN THE MODEL LEGUME MEDICAGO TRUNCATULA}

\section{INTRODUCTION}

Legume (Fabaceae) species occupy an indisputable place in modern agriculture, not only as food and feed crops but also as key players of natural systems and essential components of sustainable agriculture due to its capability of naturally injecting fixed nitrogen into the soil through root symbiosis with rhizobia. Nutritionally, pulses are a substantial source of protein, vitamins, fibers and minerals as food and feed. Legume crops contribute also to enrich and restore nitrogen fertility in farming fields (Graham, 2003; Herridge et al., 2008; Peoples et al., 2009). In natural ecosystems, legume species are vital to nitrogen (N) cycling and soil fertility. Most legumes can associate with diazotrophic bacteria, Rhizobium spp. and make indirect use of atmospheric $\mathrm{N}_{2}$ for their metabolism (Sprent and James, 2007; Den Herder and Parniske, 2009; Oldroyd et al., 2011). Diazotrophic bacteria have an enzyme (nitrogenase) that under hypoxic conditions captures dinitrogen and reduces it into ammonia. This trait, which evolved independently at least six times in the Rosids I clade, and most remarkably in the legume family (Leguminosae or Fabaceae), making this family capable of establishing in nitrogen-poor environments. Ultimately, legumes radiated globally and became one of the most successful botanical families, currently encompassing 689 genera and over 19,000 species (Doyle, 2016). Besides legumes, Parasponia (Cannabaceae) can also associate with Rhizobium and develop nodules for nitrogen fixation (A. D. L. Akkermans, 1978). Moreover, eight more families of the Rosid I clade contain species that are capable of symbiotically fix nitrogen with Frankia bacteria through actinorrhizal association (Rosaceae, Casuarinaceae, Myricaceae, Rhamnaceae, Elaeagnaceae, Datiscaceae, Coriariaceae), including alder (Alnus spp., Betulaceae) and Trema spp. (Ulmaceae) (Soltis et al., 1995). Both, rhizobial and actinorhizal intracellular associations occur in an organ that is developed de novo from root tissues, called nodule (Oldroyd and Downie, 2008; Oldroyd et al., 2011).

The legume-Rhizobium symbiosis (i.e., nodulation and symbiotic nitrogen fixation, SNF) has been co-evolving for circa 58 million years (Sprent, 2008). In order to be viable and sustainable, SNF requires balanced physiological conditions and chemical exchanges between the plant and rhizobia. For example, a source of direct $\mathrm{N}$ for the plant or lack of a finely-tuned genetic coordination between the symbionts can inhibit this mutualistic relationship (Oldroyd and Downie, 2008; Valentine et al., 2010).

Although large datasets have been amounting in the last decade on the molecular genetics of SNF in legumes, we still do not have a complete understanding of how genes are regulated in the root and nodule 
cells in order to develop the nodule and sustain SNF. Transcription factors are proteins that bind to specific DNA sequences to control the rate of transcription, thus directly controlling growth, development, and metabolism in living organisms (Udvardi et al., 2007; Yamasaki et al., 2013). By exploring the gene expression atlas of the legume model Medicago truncatula (Benedito et al., 2008), we identified two novel putative transcription factors that are highly and specifically expressed in nodules, each with a unique expression pattern within nodule zones. They belong to the largely uncharacterized GRF-type zinc finger family of (putative) transcription factors (Brown, 2005; Gamsjaeger et al., 2007).

\section{LITERATURE REVIEW}

Nitrogen on Earth: Nitrogen $(\mathrm{N})$ is a macroelement essential for all living organisms. It constitutes a key element necessary to sustain life, participating in the composition of amino acids, nucleic acids, coenzymes, signals, and secondary metabolites (e.g., alkaloids). In agriculture, $\mathrm{N}$ is often the most limiting nutrient to crop yields and one of the most costly inputs (Smil, 1999; Vitousek et al., 2002). On the other hand, $\mathrm{N}$ is very abundant in the Earth's atmosphere, composing approximately $78 \%$ as a very stable gas, dinitrogen $\left(\mathrm{N}_{2}\right)$. This molecule has a triple covalent bond between the two $\mathrm{N}$ atoms that requires $200 \mathrm{~kJ} \cdot \mathrm{mol}^{-}$ ${ }^{1}$ of energy to split in order to generate an accessible form to plants, such as ammonia $\left(\mathrm{NH}_{3}\right)$ (Peoples et al., 2009; Valentine et al., 2010). $\mathrm{N}_{2}$ can be converted into $\mathrm{NH}_{3}$ naturally by lightning, industrially by the HaberBosch process, or enzymatically via the nitrogenase present in diazotrophic prokaryotes (Smil, 2001; Herridge et al., 2008).

Diazotrophs and symbiotic nitrogen fixation: Diazotrophs can be "free-living" or "symbiotic" prokaryotic organisms that have the nitrogenase, an enzymatic multi-unit complex that catalyzes this highly energetically reaction to reduce $\mathrm{N}_{2}$ into $\mathrm{NH}_{3}$ (Graham, 2003). Nitrogenase has iron (Fe) and iron/molybdenum (MoFe) protein cofactors. While the Fe-protein complex hydrolyzes ATP, the MoFecomplex carries out the $\mathrm{N}_{2}$ reduction into $\mathrm{NH}_{3}$ (Kim and Rees, 1992; Anderson et al., 2013). Importantly, the nitrogenase active site can also interact with dioxygen $\left(\mathrm{O}_{2}\right)$, which generates an oxidation damage to the MoFe-protein site and irreversibly inactivates the enzyme (Robson and Postgate, 1980; Ott et al., 2005). Therefore, nitrogenase must work in an anoxic or hypoxic cellular environment. The mechanisms that evolved to deal with $\mathrm{N}_{2}$ fixation in the presence of our oxygenic atmosphere by lowering the $\mathrm{O}_{2}$ pressure through an extracellular polysaccharide protection layer that hinders $\mathrm{O}_{2}$ diffusion and allocating nitrogenase into a heterocyst with low $\mathrm{O}_{2}$ pressure and anaerobic metabolism as seen in cyanobacteria, or confining SNF in nodule cells that contain leghemoglobin, which is a protein with high affinity to oxygen and allows for an aerobic metabolism and SNF to happen concomitantly, as seen in legumes (Robson and Postgate, 1980). Symbiotic diazotrophs, such as Rhizobium and Sinorhizobium bacteria, are capable of interacting 
and associating endosymbiotically with legume roots, develop the nodule anew and create ideal conditions for SNF to happen (Lodwig et al., 2003; Udvardi et al., 2007; Den Herder and Parniske, 2009; Libault et al., 2009; Oldroyd et al., 2011).

Symbiotic nitrogen fixation and legume crops: Legumes are recognized as essential to agricultural sustainability (Graham, 2003; Herridge et al., 2008; Peoples et al., 2009). Legumes are also an important component of human and animal diets and the main source of primary proteins. Pulses, which are grain legumes used for human consumption and comprise of dry beans, peas, lentils, chickpeas, cowpeas, lupins and vetches. Pulse reached a global production of 4.5 million tons in 2014 (FAOSTAT, 2017). N corresponds to 3-4\% of organic matter in legumes and SNF performed by pulses and other legume crops were estimated to fix annually over 20 tons of $\mathrm{N}, 10.7-23 \mathrm{~kg} \mathrm{~N}_{2}$ per metric ton of biomass produced, depending on the species (Unkovich et al., 2010). Thus, legumes are a major factor of $\mathrm{N}$ input in agricultural systems and significantly contributing to low-cost and sustainable $\mathrm{N}$ fertilization (Herridge et al., 2008; Peoples et al., 2009). During the evolution of $\mathrm{N}_{2}$-fixing nodules, Rhizobium root colonization has been presented by at least three different ways, intercellular infection, crack entry and the most complex root hair infection thread (Madsen et al., 2010). Beside those difference, the nodule growth also diverged in two types, such as determinate growth present in Phaseoloid legumes clade (such as soybean, peanut, Phaseolus and Lotus japonicus), and indeterminate growth, present in Medicago truncatula (barrel medic, henceforth called just Medicago) (Sprent and James, 2007; Sprent, 2008). The indeterminate nodule, even when fully mature, maintains all developmental tissue stages from meristem in the apex to a senescence zone proximal to the root. M. truncatula and Lotus japonicus are models for legume nodulation along with other important crop legumes, such as soybean (Glycine max), bean (Phaseolus vulgaris), pea (Pisum sativum) and lentil (Lens culinaris), which present inconveniences for adoption as models, due to large genomes and low transformation rates.

Evolution of symbiotic nitrogen fixation in legumes: SNF rose circa 58 million years ago (Lavin et al., 2005; Sprent and James, 2007; Sprent, 2008), just about two million years after the Fabaceae family emerged (Doyle and Luckow, 2003; Sprent, 2007). The appearance of SNF provided a distinguished evolutionary advantage during the evolution of legumes, and this trait is thought to have provided the opportunity to conquer otherwise inhospitable, N-poor habitats and radiate globally (Sprent and James, 2007; Yokota and Hayashi, 2011; Geurts et al., 2016; Mus et al., 2016).

Unsurprisingly, legumes coopted existing as well as evolved novel genes to enable the establishment of the symbiotic relationship, which encompasses a continued "molecular communication" and exchange of metabolites between legumes and rhizobia (Udvardi and Day, 1997; Prell and Poole, 2006; Benedito et al., 2010; Udvardi and Poole, 2013). This association triggers the development of a new specialized organ from root tissues, the nodule, to intracellularly host the rhizobia and capacitate SNF 
(Figure 1) (Lodwig et al., 2003; Oldroyd and Downie, 2008; Den Herder and Parniske, 2009; Oldroyd et al., 2011).

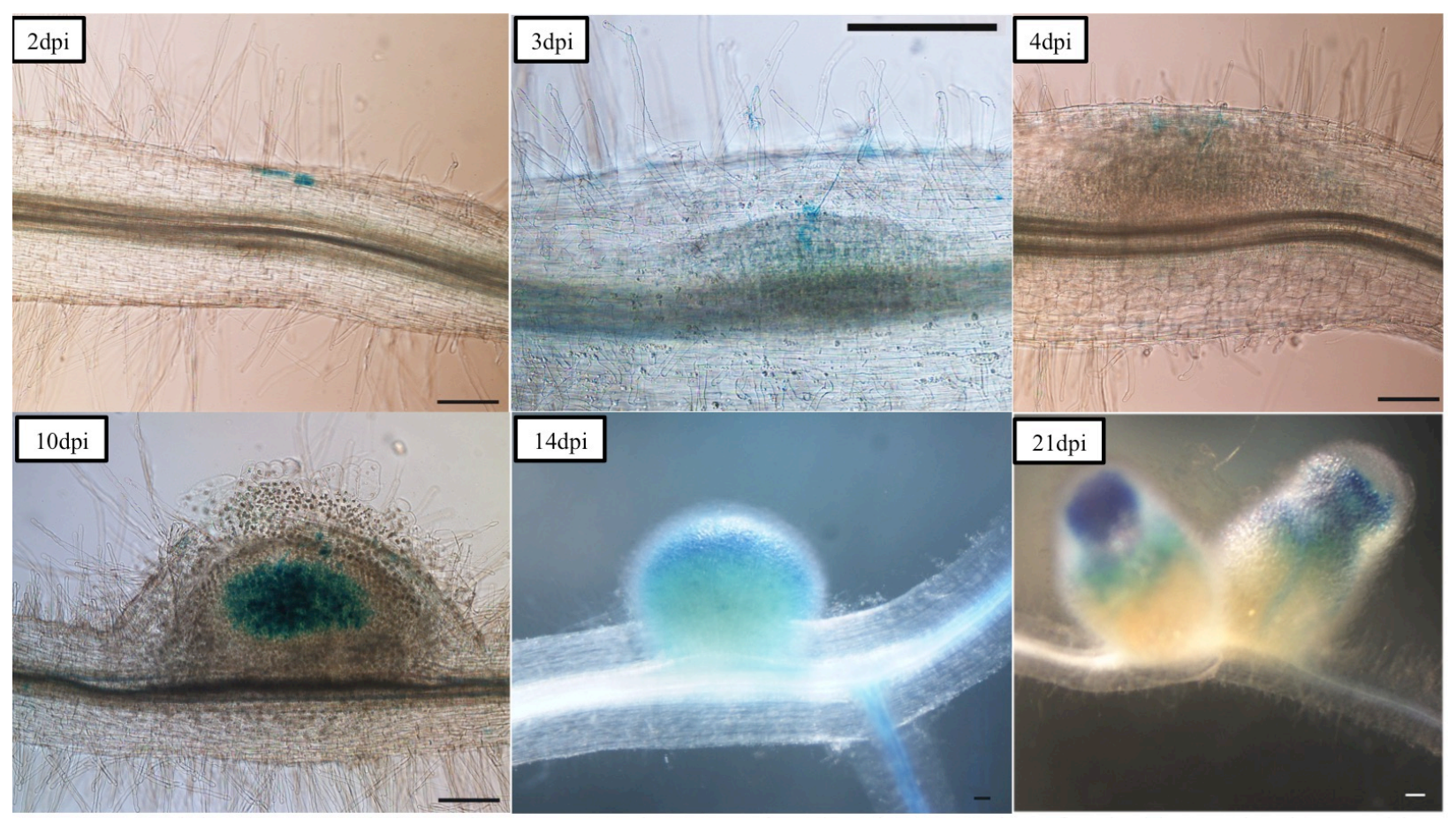

Figure 1. Nodule organogenesis in Medicago truncatula. Roots of 10-day plants were inoculated with Sinorhizobium meliloti strain Sm-1021 constitutively expressing the beta-galactosidase (lacZ) gene. Roots were stained with X-gal and the blue color reveals the bacteria. At 2 dpi, S. meliloti interact with root epidermis, 3 dpi S. meliloti form the infection thread inducing cortex cells to divide, 4 dpi $S$. meliloti start to colonize the nodule primordia, 10 dpi nodule presents a bump in the root, establishs the fixation zone, 14 dpi nodule is completed development of a nodule and at 21 dpi nodules keep growing indeterminately. Scale bars in all images represent $100 \mu \mathrm{m}$.

Rhizobium recognition and nodule development initiation: Before nodulation starts, a nitrogenstarving legume plant begins a chemical communication with free-living Rhizobium in the rhizosphere by exuding flavonoids from its root system via unknown efflux transporters at the plasma membrane of root cells. Flavonoid transporters in plant species so far identified include MULTIDRUG AND TOXIC COMPOUND EXTRUSION (MATE) efflux in Arabidopsis thaliana, ATP-BINDING CASSETTE (ABC) transporter in soybean and RESISTANCE-NODULATION-CELL DIVISION (RND)-type efflux in Lotus japonicus (Wasson et al., 2006; Sugiyama et al., 2008; Thompson et al., 2010). Firstly, flavonoids/isoflavonoids exuded by low nitrogen root, are recognized by free-living Rhizobium in the rhizosphere and induces synthesis and exudation of lipo-chitooligosaccharides (LCOs), called Nod-factors (NFs), with the expression of common nodABC and species-specific nodD Rhizobium ssp. genes (Peters et al., 1986; Hartwig et al., 1990; Limpens, 2003; Limpens and Bisseling, 2003; Radutoiu et al., 2003).

In legumes, NFs are recognized species-specifically by constitutive membrane receptors localized in the root hairs, such as M. truncatula NOD-FACTOR PROTEIN (MtNFP) and Lotus japonicus NODFACTOR RECEPTOR (LjNFR1) and LjNFR5 in Lotus japonicus. These receptors are dimeric LYSIN 
MOTIF (LysM) receptor-like kinases that act upstream of the "Common Symbiotic Signaling (SYM) Pathway" that is shared between arbuscular mycorrhizal fungi (AMF) and root nodule symbiosis (RNS). Nodulation, therefore, occurs by the association between a legume root and species-specific rhizobial bacteria, in which the Rhizobium commonly enters through the root epidermis (root hairs), where it forms an infection thread (IT) to colonize the root cortex (Vernié et al., 2015).

In an attempt to better illustrate the nodulation process, we present the characterized genes involved in each developmental event of the M. truncatula indeterminate nodules (Table 1). 


\begin{tabular}{|c|c|c|c|}
\hline Nodulation and symbiosis nitrogen fixation event: & Genes: & Medicago gene ID: & References: \\
\hline Nitrogen Starving Plant & Flavonoids transmembrane efflux & & Peter et al., 1986 \\
\hline Rhizobium spp. NodFactor synthesis genes & NFs (nod $A B C$ and nod $D)$ & & Hartwig et al., 1990 \\
\hline $\begin{array}{l}\text { Pre-infection genes - Rhizobium ssp. } \\
\text { ITs }\end{array}$ & $\begin{array}{l}\text { MtNFP (LysM-RLK), LjNFR1 and LjNFR5 (MtNFP) } \\
\text { MtLYK3 (entry receptor-later signaling) }\end{array}$ & $\begin{array}{l}\text { Medtr5g019040 } \\
\text { Medtr5g086130 }\end{array}$ & \begin{tabular}{|l|} 
Amor et al., 2003; Radutoiu S, et al., 2003 \\
Smit P, et al., 2007 \\
\end{tabular} \\
\hline $\begin{array}{l}\text { A) Common Pathway AMS and RNS } \\
\text { Activation of Ca2+ spiking signaling (root hair) and ITs } \\
\text { Mainteinance of Ca2+ spiking signaling } \\
\text { Phospholipase C (PLC) transduction of responses to NFs } \\
\text { Perception of Ca2+ spiking signaling (nuclei) } \\
\text { CCaMK-CYCLOPS } \\
\text { early stages of the nodulation programme - activation of gene } \\
\text { expression } \\
\text { MtNSP1-(MtENOD11, MtERN1, MtNIN, MtCRE1(root cortex)) } \\
\text { Infection thread propragation } \\
\text { LjNSP2 induces } \\
\text { Cytokinin } \\
\text { Auxins } \\
\text { MtNSP2, MtERN1 and MtNIN and PIN activates } \\
\text { Ethylene }\end{array}$ & $\begin{array}{l}\text { MtDMI2 and LjSYMRK (NORK) } \\
\text { MtDMI1 (Lj. CASTOR and POLLUX) } \\
\text { G-protein (MAPK) } \\
\text { MtDMI3 (CCAMK) } \\
\text { MtIPD3, CYCLOPS (Lotus japonicus) } \\
\text { MtNSP1; CERBERUS } \\
\text { MtNSP2, LjNSP2 } \\
\text { MtNIN, LjNIN (epidermis) } \\
\text { MtCBS1; MtCBS2 } \\
\text { LjENOD4O - LjNIN } \\
\text { MtRR4 and MtNSP2 } \\
\text { MtPIN (auxin efflux) MtLAXs (MtPINs and MtPAT) } \\
\text { MtCLE13 } \\
\text { EFD1 (ERNs-ERFs) } \\
\text { MtNIN in cortex }\end{array}$ & $\begin{array}{l}\text { Medtr5g030920 } \\
\text { Medtr2g005870 } \\
\text { Medtr4g005830 } \\
\text { Medtr8g043970 } \\
\text { Medtr5g026850 } \\
\text { Medtr8g020840 } \\
\text { Medtr3g072710 } \\
\text { Medtr5g099060 } \\
\text { Medtr6g052300 }\end{array}$ & $\begin{array}{l}\text { Limpens et al., } 2005 \\
\text { Riely et al., } 2007 \\
\text { Miles, G. P., et al., } 2004 . \\
\text { Lévy J, et al., } 2004 \\
\text { Messinese et al., } 2007 \\
\text { Smit P, et al., } 2005 \\
\text { Kaló P, et al., } 2005 \\
\text { Vernié, et al., } 2015 \\
\text { Sinharoy, et al., } 2016 \\
\text { Murakami, Y., et al., } 2006 \\
\text { Murakami, Y., et al., } 2006 \\
\text { Sanko-Sawczenko, et al., } 2016 \\
\text { Mortier et al., } 2010 \\
\text { Vernié et al., 2008 } \\
\text { Vernié, et al., 2015 }\end{array}$ \\
\hline $\begin{array}{l}\text { B) Nodule Meristema (ZI) } \\
\text { ENODs (bona fide marker following mechanisms) }\end{array}$ & $\begin{array}{l}\text { WUS/WOX-CLV (WOX5) } \\
\text { MtCRE1 (cytokinin receptor 1) } \\
\text { MtN13 } \\
\text { MtCLE12 } \\
\text { MtROP2 } \\
\text { CYCA2;4 } \\
\text { MtLYK3 } \\
\text { NOOT/COCH } \\
\text { MtSPK1 } \\
\text { MtNF-YA1 (HAP2.1) } \\
\text { MtNF-YA2 } \\
\text { MtRR4 }\end{array}$ & \begin{tabular}{|l|} 
Medtr5g081990 \\
Medtr8g106150 \\
Medtr4g120950 \\
Medtr4g079630 \\
Medtr6g087980 \\
Medtr2g102520 \\
Medtr5g086130 \\
Medtr7g090020 \\
Medtr4g129010 \\
Medtr1g056530 \\
Medtr7g106450 \\
Medtr5g036480
\end{tabular} & $\begin{array}{l}\text { Osipova, et al., } 2012 \\
\text { Gonzalez-Rizzo, et al., 2006; Laffont et al., } 2015 \\
\text { Gamas et al., } 1998 \\
\text { Popp and Ott, } 2011 \\
\text { Limpens et al., } 2013 \\
\text { Roudier et al., } 2003 \\
\text { Limpens et al., } 2005 \\
\text { Couzigou, } 2012 \\
\text { Andrio et al., } 2013 \\
\text { Combier et al., } 2006 \text {; Laporte et a., } 2014 \\
\text { Laloum et al., } 2014 \\
\text { Plet et al., 2011 }\end{array}$ \\
\hline C) Rhizobium Infection Specific (ZII-d) & $\begin{array}{l}\text { MtAnn1 } \\
\text { ENOD11 } \\
\text { MtERN1 (NFs activator) } \\
\text { MtN6 } \\
\text { MtENOD12 } \\
\text { MtN1 } \\
\text { MtERN2 (NFs activator) } \\
\text { MtERN3 (putative NFs repressor-ENOD11) } \\
\text { NCR- } \alpha \text { (NFS1) } \\
\text { NCR- } \beta \text { (NFS2) } \\
\text { LjAPN1 }\end{array}$ & \begin{tabular}{|l|} 
Medtr8g038210 \\
Medtr3g415670 \\
Medtr7g085810 \\
Medtr1g062710 \\
Medtr3g415650 \\
Mtr.37500.1.S1_at \\
Medtr6g029180 \\
Medtr8g085960 \\
Medtr8g073380 \\
Medtr8g465280
\end{tabular} & $\begin{array}{l}\text { de Carvalho Niebel F, et al., } 1998 \\
\text { Journet E-P, et al., } 2001 \\
\text { Cerri, 2012 } \\
\text { Mathis et al., } 1999 \\
\text { Limpens et al., } 2013 \\
\text { Gamas et al., } 1998 \\
\text { Cerri et al., } 2012 \\
\text { Adriankaja, } 2007 \\
\text { Yang et al., } 2017 \\
\text { Wang et al., } 2017 \\
\text { Yamaya-ito et al., } 2017\end{array}$ \\
\hline $\begin{array}{l}\text { D) Nodule maturation - Early Bacteroid D\ifferentiation (ZII-p) } \\
\text { CLE peptides } \\
\text { NCRs }\end{array}$ & \begin{tabular}{|l|} 
MtENOD20 (ZIId-IZ) \\
MtMMPL1/MtN9 \\
MtNCR247 \\
MtCP1 (TrX S1) \\
MtIRE \\
NAC1 (ZIId-ZIII) \\
MtENOD16 (ZIId-ZIII) \\
MtSYMREM1 (ZIId-ZIII) \\
MtDNF1 (ZIId-ZIII) \\
MtDNF2 (ZIId-ZIII) \\
MtCKX1 (ZIId-ZIII) \\
MtKNOX3 (downregulate MtIPT3 and MtLOG2) \\
\end{tabular} & \begin{tabular}{|l|} 
Medtr4g130800 \\
Medtr5g036087; Me \\
Medtr5g056815;Me \\
Medtr2g079400 \\
Medtr5g069000 \\
Medtr2g064470 \\
Medtr4g130780 \\
Medtr8g097320 \\
Medtr3g027890 \\
Medtr4g085800 \\
Medtr1g015410 \\
Medtr1g012960 \\
\end{tabular} & $\begin{array}{l}\text { Vernoud et al., } 1999 \\
\text { Combier et a., } 2007 \\
\text { Farkas et al., } 2014 \\
\text { Ribeiro et al., } 2017 \\
\text { Pislariu and Dickstein } 2007 \\
\text { D'haeseleer, } 2011 \\
\text { Catalano et al., } 2004 \\
\text { Lefebvre et al., } 2010 \\
\text { Wang et al., 2010; Van de Velde et al., } 2010 \\
\text { Bourcy et al., } 2013 \\
\text { Moreau et al., } 2011 \\
\text { Azarakhsh, } 2015\end{array}$ \\
\hline E) Nodule maturation - Bacteroid Late Differentiation (IZ) & $\begin{array}{l}\text { MtPUB1 } \\
\text { NCR035 (IZ-ZIII) } \\
\text { NCR001 (IZ-ZIII) } \\
\text { HSP70 (Symbiosome) } \\
\text { MtNip1 (Symbiosome) (IZ-ZIII) } \\
\text { RSD (C2H2) } \\
\text { MtNACO74 } \\
\text { MtCCS52a } \\
\end{array}$ & $\begin{array}{l}\text { Medtr5g083030 } \\
\text { Mtr.10684.1.S1_at } \\
\text { Medtr6g463200 Me } \\
\text { Medtr4g130540 } \\
\text { Medtr8g087710 } \\
\text { Medtr7g063220 } \\
\text { Medtr7g085220.1 } \\
\text { Medtr3g067940 } \\
\end{array}$ & $\begin{array}{l}\text { Mbengue et al., } 2010 \\
\text { Van de Velder et al., } 2010 \\
\text { Van de Velder et al., } 2010 \\
\text { Catalano et al., } 2004 \\
\text { Catalano et al., } 2004 \\
\text { Sinharoy, et al.,2013 } \\
\text { Vidyadhar Karmarkar, } 2014 \\
\text { Vindardell et al., } 2003\end{array}$ \\
\hline $\begin{array}{l}\text { F) Nitrogen Fixation (ZIII) } \\
\text { leghemoglobin } \\
\text { Anparagine Synthetases (4) }\end{array}$ & \begin{tabular}{|l} 
bHLH1 \\
MtIP3 (interacts with DMI3) \\
MtENOD8.1 \\
MtRBOHA \\
MtENOD8.2 \\
Krüppel-like zinc finger (Mszpt2-1) \\
GmNAT2 \\
\end{tabular} & $\begin{array}{l}\text { Medtr3g150170 } \\
\text { Medtr5g026850 } \\
\text { Medtr1g030275 } \\
\text { Medtr1g083290 } \\
\text { Medtr1g030268 }\end{array}$ & $\begin{array}{l}\text { Godiard, } 2011 \\
\text { Messinese et al., } 2007 \\
\text { Coque et al., } 2008 \\
\text { Marino et al., } 2011 \\
\text { Dickstein et al., 2002; Limpens et al., } 2013 \\
\text { Frugier, } 2000 \\
\text { Laursen, } 1994 \\
\end{array}$ \\
\hline G) Nodule Senescence (IV) & $\begin{array}{l}\text { MtATB2 (bZIP) } \\
\text { MtNAC969 } \\
\text { MtNAC920 }\end{array}$ & \begin{tabular}{|l|} 
Medtr4g070860 \\
Medtr4g081870 \\
Medtr3g096920.2
\end{tabular} & $\begin{array}{l}\text { D'haeseleer et al., } 2010 \\
\text { de Zelicourt et al., } 2012 \\
\text { Vidyadhar Karmarkar, } 2014\end{array}$ \\
\hline
\end{tabular}

Table 1. Characterized genes involved in nodulation of Medicago truncatula. Genes noted in bold genes are transcription factors. 
Notwithstanding, in a distinguished way, rhizobium recognition elicits membrane depolarization and causes root hair curling (Amor et al., 2003; Madsen et al., 2003; Radutoiu et al., 2003). In Lotus japonicus, at least seven genes (SYMRK, CASTOR, POLLUX, SYM3, SYM6, SYM15, and SYM24) were found essential for both, RNS and AMF (Kistner et al., 2005). Another membrane receptor with a LysM domain, M. truncatula DOES NOT MAKE INFECTIONS (MtDMI2), is present on the plasma membrane of cells surrounding the ITs and share the common SYM pathway that is needed for the formation of symbiosomes (Bersoult et al., 2005). In Lotus, this recognition elicits $\mathrm{Ca}^{2+}$ spiking at the perinuclear boundary via SYMRK receptor kinases homologous to MtDMI2, downstream of NFP/NFR under recognition of Rhizobium NFs (Limpens et al., 2005).

This signaling cascade is marked by calcium spiking ripple through the cell cytoplasm to reach the nucleus in order to induce transcriptional changes to drive nodule development via a dramatic rewiring of the genetic networks (Kistner et al., 2005; Czaja et al., 2012; Moreau et al., 2014). In the nuclear envelope, a similar signaling characterized by $\mathrm{Ca}^{2+}$ spiking is induced by MtDMI1 in Medicago or POLLUX in Lotus, which are membrane-spanning proteins that participate in the formation of a symbiotic receptor complex (Ané et al., 2004; Riely et al., 2007). In the nucleus, $\mathrm{Ca}^{2+}$ signaling is produced by a $\mathrm{Ca}^{2+} /$ calmodulindependent protein kinase (CCaMK), MtDMI3 in Medicago and CYCLOPS in Lotus, which ultimately activates the gene expression of transcription factors involved in the nodulation signaling pathway, such as NODULE INCEPTION (NIN), NODULATION SIGNALING PATHWAY (NSP1), NSP2, ETHYLENE RESPONSIVE FACTOR (ERF) REQUIRED FOR NODULATION (ERN1) and EARLY NODULIN (ENOD11).

As primary transcriptional regulator induced by NF signaling is the GRAS TF NSP1 (MtNSP1) in Medicago and CERBERUS (CER) in Lotus, which share RNS and AMF pathway and essential for the symbiosis transcriptional change (Smit, 2005; Nagae et al., 2014). A second GRAS-type transcriptional regulator, MtNSP2, cannot bind directly to DNA, but it acting by forming a heterodimer with MtNSP1, which has a DNA-binding activity to TA-rich cis elements in many promoters of nodulation genes, such as MtERN1 (Kalo, 2005; Cerri et al., 2012a). Indeed, ENOD11 expression is a bona fide marker for early nodule organogenesis (Lévy et al., 2004; Boisson-dernier et al., 2005; Kalo, 2005; Smit, 2005; Marsh et al., 2007; Cerri et al., 2012; Soyano et al., 2013; Vernié et al., 2015). Interestingly, nodulation that is independent of Rhizobium interaction can occur by CCaMK auto-inhibition, proving that DMI3 in Medicago (and CYCLOPS in Lotus) is a central regulator of nodulation (Lévy et al., 2004; Gleason et al., 2006; Yano et al., 2008).

The nodulation signal cascade travels from the root epidermis to the inner cortex and stimulates the nodule primordia formation while the "shepherd's crook" forms at the tip of the root hair (Oldroyd et al., 2011). Induced and maintained by NIN and high cytokinin levels, nodule primordia formation starts at the 
root cortex via cell division (Vernié et al., 2015). Besides its symbiotic role in initiative nodule primordia development, the $M$. truncatula CYTOKININ RESPONSE (MtCRE1) also has positive effects on root architecture and resistance to different stress conditions, such as salinity and some pathogens (Laffont et al., 2015). Cytokinin signaling also regulates transcription via M. truncatula RESPONSE REGULATOR (MtRR1), a response regulator that interacts with RR binding sites found in RR4 and NSP2 promoters (Kalo, 2005; Vernie et al., 2008; Ariel et al., 2012).

Rhizobium infection and endocytosis: After the symbiotic recognition occurs and the concurrent nodule primordia formation starts, the micro-symbiont is entrapped at the root hair, which tip curls under bacterial recognition and forms the "shepherd's crook" (Stougaard et al., 1999; Veereshlingam, 2004; Marsh et al., 2007; Pislariu and Dickstein, 2007; Laporte et al., 2014). This recognition enable the bacterial entrance via endocytosis and trigger nodule primordia formation in the inner root cortex, where cells start to multiply to form the nodule meristem, while Rhizobium colonization initiates at the root hair epidermis via the IT formation towards the developing nodule meristem (Limpens, 2003; Oldroyd and Downie, 2008; Farkas et al., 2014; Laloum et al., 2014).

During rhizobial infection, the plant defense apparatus against pathogens is locally "placed on hold" and a symbiotic status takes place, providing conditions for the Rhizobium to colonize the root cortical cells (Domonkos et al., 2013; Sinharoy et al., 2013). During this process, the plant cell wall is locally digested, the cytoskeleton reorganizes in response to NF perception, directing root hair curling and formation of an IT, culminating with rhizobium endocytosis by the plant plasma membrane, and creating a new organelle, the symbiosome, which interface (the symbiosome or peribacteroid membrane) forms both a structural as well as functional boundary between both symbionts (Veereshlingam, 2004; Prell and Poole, 2006; Zhao et al., 2012).

Driven by a $\mathrm{Ca}^{2+}$ gradient and guided by the plant nucleus, the IT forms by aligning the plant cell cytoskeleton and creating cytoplasmic bridges that invaginate towards the nodule meristem (van Brussel et al., 1992; Timmers et al., 1999). In some instances, the nodule meristem and active bacterial infection zone are maintained in the mature nodule, which allows the nodule to grow indeterminately and contain four spatially distinct zones: the meristem (zone I), cell infection (zone II), bacteroid differentiation (zone II-III or interzone, IZ), nitrogen fixation (zone III), and senescence (zone IV) (Franssen et al., 1992; Mergaert et al., 2006). On the other hand, in determinate nodules, the cortical cells of the developing nodule rather go through these phases synchronously. In temperate legumes, such as pea and alfalfa, the primordium is formed from cells of the root inner cortex and develop indeterminate nodules (Timmers et al., 1999). Meanwhile, tropical legumes, such as soybean and common beans, develop the nodule primordium from the root outer cortex and present nodules with determinate growth (Popp and Ott, 2011; Suzaki et al., 2012). 
Transition from infection to SNF: Some nodule cells become colonized by Rhizobium, which becomes specialized in SNF and nutritionally dependent on the plant metabolism (Wienkoop and Saalbach, 2003; Oldroyd et al., 2011). During cell infection, the Rhizobium is engulfed by the plant cell through an endocytosis process (Timmers et al., 2006) and receives a membrane derived from the plasma membrane (PM), called symbiosome (or peribacteroid) membrane (SM). This membrane encompasses a physical barrier between the bacteria and the plant cytosol and is specialized in signaling and transport of substances in and out of the symbiosome to maintain and regulate the symbiosis (Udvardi and Poole, 2013). After endocytosis, the bacteria will redefine its transcriptional program to become able to fix (i.e., reduce) $\mathrm{N}_{2}$ into $\mathrm{NH}_{3}$. During bacteroid differentiation, the Rhizobium passes through five well-defined differentiation stages (cell division, cell elongation, maximum bacteroid elongation with invaded cells with starch accumulation in plastids, bacteroid cytoplasmic heterogeneity with DNA endoreduplication, and synthesis and organization of the SNF apparatus) (Vasse et al., 1990; Udvardi and Day, 1997). Meanwhile, the Rhizobium undergoes a differentiation process, such as DNA endoreduplication up to 64C (Cebolla, 1999), cell elongation, repression of some essential biosynthesis pathways, which thereon needs to be supplied by the host (Hosie et al., 2002; Prell et al., 2009), and synthesis of the SNF apparatus, thus becoming mature bacteroids capable of fixing $\mathrm{N}_{2}$ (Oldroyd and Downie, 2008; Domonkos et al., 2013; Guan et al., 2013; Sinharoy et al., 2013). A good example of this auxotrophic dependency is the halting of the branched-chain amino acids (Leu, Ile, Val) biosynthesis pathways, making the bacteria completely dependent on the host supply and requiring metabolite transporters at both, the symbiosome membrane as well as bacteroid membrane (Prell et al., 2009).

Symbiotic $\mathbf{N}_{2}$ fixation: Energetically, SNF is a highly demanding reaction. Therefore, the establishment of this symbiosis depends on the host plant providing photosynthates (a reduced $\mathrm{C}$ source, such as the dicarboxylates malate and succinate) and, in return, receiving reduced (fixed) $\mathrm{N}$ as ammonia $\left(\mathrm{NH}_{3}\right)$ from the bacteroid (White et al., 2007; Kaschuk et al., 2009). In order to reduce one molecule of $\mathrm{N}_{2}$ into two $\mathrm{NH}_{3}$, nitrogenase requires 16 ATPs (Patriarca et al., 2002). SNF can consume up to $14 \%$ of the photosynthesized $\mathrm{C}$ from the plant (Kaschuk et al., 2009). Once the endosymbiont fixes $\mathrm{N}, \mathrm{NH}_{3}$ moves out the bacteroid to the acidic peribacteroid space and is instantly protonated into $\mathrm{NH}_{4}{ }^{+}$(Udvardi and Day, 1997). The $\mathrm{NH}_{4}{ }^{+}$is sent to the plant cytosol via a channel and rapidly assimilated into glutamine via the GS/GOGAT cycle (Tyerman et al., 1995; Castillo et al., 2000; Hosie et al., 2002; Lodwig and Poole, 2003; Mulley et al., 2011). In plants, $\mathrm{NH}_{4}{ }^{+}$transporter families were identified and partially characterized based on their affinity to the substrate, high-affinity AMMONIUM TRANSPORTER (AMT1) and low-affinity AMT2 channels. Some $\mathrm{NH}_{4}{ }^{+}$transporters were characterized in legume nodules, such as MtAMT1;1 and MtAMT2;1, LjAMT2;1 and GmSAT1/GmbHLHm1 (Simon-Rosin et al., 2003; Chiasson et al., 2014; Straub et al., 2014). 
During SNF, the infected nodule cell must provide ideal conditions to the bacteroid, such as energy and other organic compounds (TCA metabolites, amino acids), and minerals. The conundrum of high energy demands (which require aerobic respiration) and the nitrogenase sensitivity to $\mathrm{O}_{2}$, which binds to the active site and permanently inhibits the enzyme, has been resolved in legume nodules with the use of leghemoglobins ( $\mathrm{Lb}$ ) to create a hypoxic environment (low $\mathrm{O}_{2}$ pressure) in the cytosol of the infected cell for a sustained but slow release of $\mathrm{O}_{2}$ for respiration (Witty et al., 1983; Ott et al., 2005). Leghemoglobins are not required for plant growth and development when external nitrogen source is available, however, are of paramount importance to support SNF into the nodule (Ott et al., 2005). By and large, Lb is the most prominent nodulin expressed in nodules and provides the characteristic pink color of functional nodules (Govers et al., 1985; Ott et al., 2005; Appleby, 1984; Ott et al., 2005).

Along with the complexity of legume-Rhizobium interaction, the $\mathrm{N}$ and $\mathrm{C}$ status of the plant exert autoregulation of nodulation (AON), which is activated by CLAVATA3 (CLV3)/ENDOSPERM SURROUNDING REGION (ESR) (CLE) peptides (Reid et al., 2011; Osipova et al., 2012) to control SNF (Murray et al., 2017). For example, $0.5 \mathrm{mM} \mathrm{KNO}_{3}$ supply in an inorganic medium did not inhibit nodulation in soybean, but a $7.5 \mathrm{mM} \mathrm{KNO}_{3}$ level inhibited $50 \%$ of nodulation (Day et al., 1989). In spite of the physiological control of nodulation and SNF, genetic mechanisms encompass another level of regulating nodule development and SNF. The CCaMK DMI3 protein contains an auto-inhibition domain that coordinates the expression of nodulins via its kinase activity through $\mathrm{Ca}^{2+}$ spiking (Gleason et al., 2006).

Plant hormones also play a fundamental role during nodulation and SNF. In general terms, auxin triggers nodule development (Bensmihen, 2015; Hiltenbrand et al., 2016); cytokinin is important for NF signaling and nodulation via cytokinin response regulators (RRs); gibberellic acid, brassinosteroid and strigolactones also seem to have a positive impact in nodulation at low concentrations. On the other hand, abscisic acid and jasmonic acid negatively regulate NF signaling and nodule development, along with high levels of strigolactones and gibberellic acid (Bensmihen, 2015).

Overall, the most basic mechanisms of legume-Rhizobium interaction have been resolved at the anatomic, cellular, physiological, biochemical, and genetic levels. However, a more refined picture is needed to reveal the molecular mechanisms that coordinate and link each step altogether to define the cell infection, nodule development and establishment as well as maintenance of SNF. In focusing in one or a few model species, and delving into modern techniques, involving -omics and functional genetics approaches, we will be able to dissect each element and eventually reveal the complete picture that makes legumes with such unique features of developing nodules de novo from root tissues and establish SNF.

M. truncatula as a model legume system: While mycorrhizal associations encompass broad groups of plants and fungi to establish symbiosis, the legume-Rhizobia associations are highly speciesspecific. As a case in point, M. truncatula associates specifically with Sinorhizobium meliloti (Sm) to 
develop nodules and fix $\mathrm{N}_{2}$. The Fabaceae family is the third largest plant family (after Orchidaceae and Asteraceae) and encompasses over 19,000 species with around 700 of them able to fix $\mathrm{N}_{2}$ through rhizobial symbiosis (Doyle, 2016). Legumes are also the second most important crop family, after the Poaceae (cereals) (Young and Bharti, 2012). Most legume crops are in the Faboideae (Papilionoideae) subfamily. Even though the foundation of genetics were established from pea studies carried out by Mendel, the genetics of many important crop legumes are complex often regarding polyploidy (e.g., tetraploids like alfalfa, soybean), allogamy (alfalfa), and large genomes (soybean: $1.1 \mathrm{~Gb}$; peanut: $2.7 \mathrm{~Gb}$; pea: $4.3 \mathrm{~Gb}$ ) (Soltis et al., 2015).

The three major models in the Papilionoideae subfamily are M. truncatula, Lotus japonicus and soybean (Oono et al., 2010). Additionally, molecular genetic resources, such as genome sequences, are available for common bean, chickpea, lupin, pigeon pea, and a few others (https://legumeinfo.org/genomes).

M. truncatula (barrel medic, henceforth called just Medicago) emerged as an ideal genetic model to study nodulation and SNF due to its small, sequenced genome ( $450 \mathrm{Mb})$, diploid genome distributed in a small number of chromosomes $(\mathrm{n}=8)$, autogamous pollination, natural diversity availability, short lifecycle $(<100$ days from seed to seed), not to mention being relatively easy to grow, having genetic transformation techniques well established (for both, transformation of whole plants with Agrobacterium tumefaciens as well as hairy root transformation with Agrobacterium rhizogenes to produce composite plants) (Young et al., 2011). Medicago nodules are indeterminate (Figure 2), and each symbiosome contains a single bacteroid (Oono et al., 2010). 


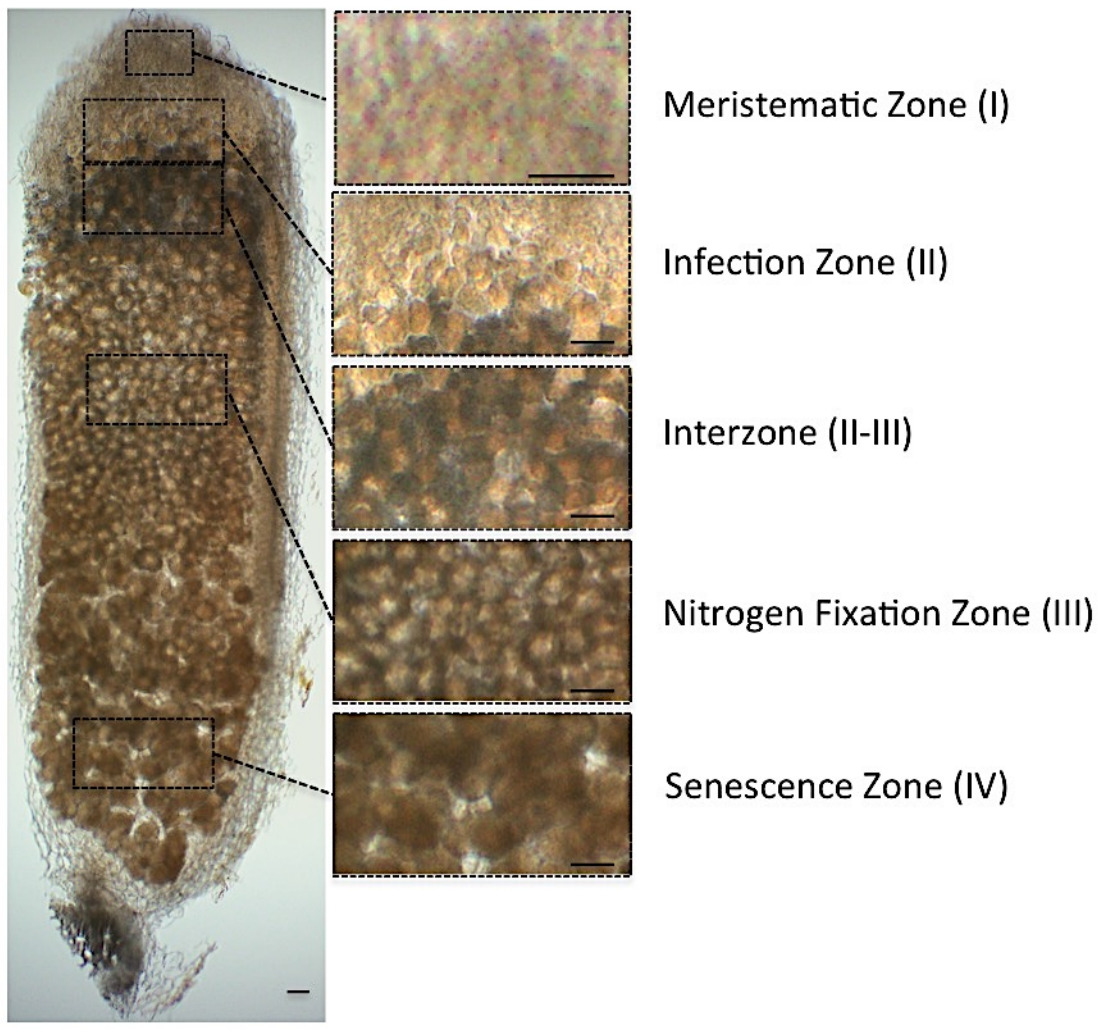

Figure 2. The indeterminate nodule of Medicago truncatula. Notice the five distinct zones of symbiosis development in the nodule internal tissues. A 28-dpi nodule was harvested and sectioned with vibratome with $70 \mu \mathrm{m}$ thickness. Scale bar represents $100 \mu \mathrm{m}$.

Systems biology of legume symbiosis: Understanding the evolution of root symbioses and how the nodule emerged as a new trait in legumes is fundamental to guide us tailor breeding efforts in legume crops and perhaps extend this trait to non-legumes. Genome sequences and annotation are available for many legume species, making genome-wide association studies (GWAS) feasible and allowing RNA-Seq analyses for construction of gene networks involving traits of particular relevance. Gene expression atlases are available for model legumes, such as Medicago (Benedito et al., 2008; He et al., 2009), Lotus japonicus (Verdier et al., 2013) and soybean (Severin et al., 2010). Furthermore, a detailed mapping of gene expression in Medicago nodule tissues through laser capture microdissection (LCM) samples can be publicly assessed (Roux et al., 2014). During nodule development, a massive transcriptional reprogramming takes place in both symbionts, in which transcription factors forge essential rules in the molecular orchestration of cell differentiation and de novo organogenesis (Moreau et al., 2011). The characterization of the DNA methylation landscape revealed 1,425 epigenetically regulated genes during the development and SNF in Medicago nodules (Satgé et al., 2016). A proteome atlas of all Medicago organs and three nodule developmental stages revealed more than 23,000 proteins, 20,000 phosphorylation and 700 lysine acetylation sites of potential post-translational modifications (Marx et al., 2016). A large collection of M. truncatula insertional mutants encompassing 190,000 stable Tnt1 retrotransposon 
insertions in 7,600 independent lines is available for functional characterization of individual genes (Tadege et al., 2008).

The development of the legume nodule is orchestrated molecularly by a precise genetic network program that is ultimately coordinated by transcription factors (Moreau et al., 2011; Oldroyd et al., 2011). Transcription factors (TFs) control the genetic expression of the cellular machinery, which fundamentally coordinate plant growth and development. In this regard, nodule organogenesis shows an intricate genetic regulatory network that still needs to be better characterized (Udvardi et al., 2007; Moreau et al., 2011; Oldroyd et al., 2011; Cerri et al., 2012a; Limpens et al., 2013; Oldroyd, 2013; Laloum et al., 2014; Soyano and Hayashi, 2014; Vernié et al., 2015; Geurts et al., 2016; Zipfel and Oldroyd, 2017). In the M. truncatula genome, 1,513 TF genes were previously identified (Young et al., 2011), with 1,111 pseudomolecule genes expressed in nodules, 92 TF of which showing a nodule-specific expression pattern (Young et al., 2011). A more detailed analysis of TFs in M. truncatula is provided in Chapter 2 of this dissertation.

\section{REFERENCES}

Adesemoyea, A., H. Torbertb and J. Kloeppera (2010) Increased plant uptake of nitrogen from ${ }^{15} \mathrm{~N}-$ depleted fertilizer using plant growth- promoting rhizobacteria. Applied Soil Ecology 56(1): 54-58.

A. D. L. Akkermans SA and MJT (1978) $\mathrm{N}_{2}$-fixing root nodules in Ulmaceae: Parasponia or (and) Trema spp.? Plant Soil 49: 7110715

Amor B Ben, Shaw SL, Oldroyd GED, Maillet F, Penmetsa RV, Cook D, Long SR, Dénarié J, Gough C (2003) The NFP locus of Medicago truncatula controls an early step of Nod factor signal transduction upstream of a rapid calcium flux and root hair deformation. Plant J 34: 495-506

Ané J-M, Kiss GB, Riely BK, Penmetsa RV, Oldroyd GED, Ayax C, Lévy J, Debellé F, Baek J-M, Kalo P, et al (2004) Medicago truncatula DMI1 required for bacterial and fungal symbioses in legumes. Science 303: 1364-7

Ariel F, Brault-Hernandez M, Laffont C, Huault E, Brault M, Plet J, Moison M, Blanchet S, Ichante JL, Chabaud M, et al (2012) Two direct targets of cytokinin signaling regulate symbiotic nodulation in Medicago truncatula. Plant Cell 24: 3838-3852

Benedito V a, Torres-Jerez I, Murray JD, Andriankaja A, Allen S, Kakar K, Wandrey M, Verdier J, Zuber H, Ott T, et al (2008) A gene expression atlas of the model legume Medicago truncatula. Plant J 55: 504-513

Bensmihen S (2015) Hormonal control of lateral root and nodule development in legumes. Plants 4: $523-$ 547

Bersoult A, Camut S, Perhald A, Kereszt A, Kiss GB, Cullimore J V (2005) Expression of the Medicago truncatula DMI2 gene suggests roles of the symbiotic nodulation receptor kinase in nodules and during early nodule development. Mol Plant Microbe Interact 18: 869-876

Boisson-dernier A, Andriankaja A, Chabaud M, Niebel A, Journet E, Barker DG, Carvalho-niebel F De (2005) MtENOD11 gene activation during rhizobial infection and mycorrhizal arbuscule development requires a common AT-rich-containing regulatory sequence. Mol Plant Microbe Interact 18: 1269-1276 
van Brussel AAN, Bakhuizen R, van Spronsen PC, Spaink HP, Tak T, Lugtenberg BJJ, Kijne JW (1992) Induction of preinfection thread structures in the leguminous host plant by mitogenic lipooligosaccharides of Rhizobium. Science 257: 70-72

Castillo A, Taboada H, Mendoza A, Mora J, Valderrama B, Encarnacio S (2000) Role of GOGAT in carbon and nitrogen partitioning in Rhizobium etli. Microbiology 146: 1627-1637

Cebolla A (1999) The mitotic inhibitor ccs52 is required for endoreduplication and ploidy-dependent cell enlargement in plants. EMBO J 18: 4476-4484

Cerri MR, Frances L, Laloum T, Auriac M-C, Niebel a., Oldroyd GED, Barker DG, Fournier J, de Carvalho-Niebel F (2012) Medicago truncatula ERN transcription factors: regulatory interplay with NSP1/NSP2 GRAS factors and expression dynamics throughout rhizobial infection. Plant Physiol 160: 2155-2172

Chiasson DM, Loughlin PC, Mazurkiewicz D, Mohammadidehcheshmeh M, Fedorova EE, Okamoto M, McLean E, Glass ADM, Smith SE, Bisseling T, et al (2014) Soybean SAT1 (Symbiotic Ammonium Transporter 1) encodes a bHLH transcription factor involved in nodule growth and $\mathrm{NH}_{4}{ }^{+}$transport. Proc Natl Acad Sci U S A 111: 4814-9

Czaja LF, Hogekamp C, Lamm P, Maillet F, Martinez E a., Samain E, Denarie J, Kuster H, Hohnjec N (2012) Transcriptional responses toward diffusible signals from symbiotic microbes reveal MtNFP- and MtDMI3-dependent reprogramming of host gene expression by arbuscular mycorrhizal fungal lipochitooligosaccharides. Plant Physiol 159: 1671-1685

Domonkos A, Horvath B, Marsh JF, Halasz G, Ayaydin F, Oldroyd GE, Kalo P (2013) The identification of novel loci required for appropriate nodule development in Medicago truncatula. BMC Plant Biol 13: 157

Doyle JJ (2016) Chasing unicorns: Nodulation origins and the paradox of novelty. Am J Bot 103: 18651868

Doyle JJ, Luckow MA (2003) The Rest of the Iceberg . Legume diversity and evolution in a phylogenetic context. Plant Physiol 131: 900-910

FAOSTAT F and AO of the U (2017) FAO. http://www.fao.org/faostat/en/\#data/QC/visualize

Franssen HJ, Vijn I, Yang WC, Bisseling T (1992) Developmental aspects of the Rhizobium-legume symbiosis. Plant Mol Biol 19: 89-107

Geurts R, Xiao TT, Reinhold-Hurek B (2016) What does it take to evolve a nitrogen-fixing endosymbiosis? Trends Plant Sci 21: 199-208

Gleason C, Chaudhuri S, Yang T, Mun A (2006) Nodulation independent of rhizobia induced by a calcium-activated kinase lacking autoinhibition. Nature 441: 1149-1152

Govers F, Gloudemans T, Moerman M, van Kammen A, Bisseling T (1985) Expression of plant genes during the development of pea root nodules. EMBO J 4: 861-7

Graham PH (2003) Legumes: Importance and constraints to greater use. Plant Physiol 131: 872-877

Guan D, Stacey N, Liu C, Wen J, Mysore KS, Torres-Jerez I, Vernie T, Tadege M, Zhou C, Wang $\mathbf{Z}$-y., et al (2013) Rhizobial infection is associated with the development of peripheral vasculature in nodules of Medicago truncatula. Plant Physiol 162: 107-115

Hartwig UA, Maxwell CA, Joseph CM, Phillips DA (1990) Effects of alfalfa nod gene-inducing flavonoids on nodABC transcription in Rhizobium meliloti strains containing different nodD genes. J Bacteriol 172: 2769-2773

He J, Benedito VA, Wang M, Murray JD, Zhao PX, Tang Y, Udvardi MK (2009) The Medicago 
truncatula gene expression atlas web server. BMC Bioinformatics 10: 441

Herridge DF, Peoples MB, Boddey RM (2008) Global inputs of biological nitrogen fixation in agricultural systems. Plant Soil 311: 1-18

Hiltenbrand R, Thomas J, McCarthy H, Dykema KJ, Spurr A, Newhart H, Winn ME, Mukherjee A (2016) A developmental and molecular view of formation of auxin-induced nodule-like structures in land plants. Front Plant Sci 7: 1-18

Hosie AHF, Allaway D, Galloway CS, Dunsby HA, Poole PS (2002) Rhizobium leguminosarum has a second general amino acid permease with unusually broad substrate specificity and high similarity to branched-chain amino acid transporters (Bra/LIV) of the ABC family. J Bacteriol 184: 4071-80

Kalo P (2005) Nodulation signaling in legumes requires NSP2, a member of the GRAS family of transcriptional regulators. Science 308: 1786-1789

Kaschuk G, Kuyper TW, Leffelaar PA, Hungria M, Giller KE (2009) Are the rates of photosynthesis stimulated by the carbon sink strength of rhizobial and arbuscular mycorrhizal symbioses? Soil Biol Biochem 41: 1233-1244

Kistner C, Winzer T, Pitzschke A, Mulder L, Sato S, Kaneko T, Tabata S, Sandal N, Stougaard J, Webb KJ, et al (2005) Seven Lotus japonicus genes required for transcriptional reprogramming of the root during fungal and bacterial symbiosis. Plant Cell 17: 2217-2229

Laffont C, Rey T, André O, Novero M, Kazmierczak T, Debellé F, Bonfante P, Jacquet C, Frugier F (2015) The CRE1 cytokinin pathway is differentially recruited depending on Medicago truncatula root environments and negatively Regulates resistance to a pathogen. PLoS One 10: 1-19

Laloum T, Baudin M, Frances L, Lepage A, Billault-Penneteau B, Cerri MR, Ariel F, Jardinaud M-F, Gamas P, de Carvalho-Niebel F, et al (2014) Two CCAAT-box-binding transcription factors redundantly regulate early steps of the legume-rhizobia endosymbiosis. Plant J 79: 757-768

Laporte P, Lepage A, Fournier J, Catrice O, Moreau S, Jardinaud M-F, Mun J-H, Larrainzar E, Cook DR, Gamas P, et al (2014) The CCAAT box-binding transcription factor NF-YA1 controls rhizobial infection. J Exp Bot 65: 481-494

Lavin M, Herendeen P, Wojciechowski M (2005) Evolutionary rates analysis of leguminosae implicates a rapid diversification of lineages during the tertiary. Syst Biol 54: 575-594

Lévy J, Bres C, Geurts R, Chalhoub B, Kulikova O, Duc G, Journet E-P, Ané J-M, Lauber E, Bisseling T, et al (2004) A putative $\mathrm{Ca}^{2+}$ and calmodulin- dependent protein kinase required. Science 303: 1361-4

Limpens E (2003) LysM domain receptor kinases regulating rhizobial Nod factor-induced infection. Science (80- ) 302: 630-633

Limpens E, Bisseling T (2003) Signaling in symbiosis. Curr Opin Plant Biol 6: 343-350

Limpens E, Mirabella R, Fedorova E, Franken C, Franssen H, Bisseling T, Geurts R (2005) Formation of organelle-like $\mathrm{N}_{2}$-fixing symbiosomes in legume root nodules is controlled by DMI2. Proc Natl Acad Sci USA 102: 10375-80

Limpens E, Moling S, Hooiveld G, Pereira P a, Bisseling T, Becker JD, Küster H (2013) Cell- and tissue-specific transcriptome analyses of Medicago truncatula root nodules. PLoS One 8: e64377

Lodwig E, Poole P (2003) Metabolism of Rhizobium Bacteroids. CRC Crit Rev Plant Sci 22: 37-78

Madsen EB, Madsen LH, Radutoiu S, Olbryt M, Rakwalska M, Szczyglowski K, Sato S, Kaneko T, Tabata S, Sandal N, et al (2003) A receptor kinase gene of the LysM type is involved in legumeperception of rhizobial signals. Nature 425: 637-640 
Madsen LH, Tirichine L, Jurkiewicz A, Sullivan JT, Heckmann AB, Bek AS, Ronson CW, James EK, Stougaard J (2010) The molecular network governing nodule organogenesis and infection in the model legume Lotus japonicus. Nat Commun. 12: 1-10 doi: 10.1038/ncomms 1009

Marsh JF, Rakocevic A, Mitra RM, Brocard L, Sun J, Eschstruth A, Long SR, Schultze M, Ratet P, Oldroyd GED (2007) Medicago truncatula NIN Is Essential for Rhizobial-Independent Nodule Organogenesis Induced by Autoactive Calcium/Calmodulin-Dependent Protein Kinase. Plant Physiol 144: 324-335

Marx H, Minogue CE, Jayaraman D, Richards AL, Kwiecien NW, Sihapirani AF, Rajasekar S, Maeda J, Garcia K, Del Valle-Echevarria AR, et al (2016) A proteomic atlas of the legume Medicago truncatula and its nitrogen-fixing endosymbiont Sinorhizobium meliloti. Nat Biotechnol advance on: $1198-1205$

Mergaert P, Uchiumi T, Alunni B, Evanno G, Cheron A, Catrice O, Mausset A-E, Barloy-Hubler F, Galibert F, Kondorosi A, et al (2006) Eukaryotic control on bacterial cell cycle and differentiation in the Rhizobium-legume symbiosis. Proc Natl Acad Sci 103: 5230-5235

Moreau S, Fromentin J, Vailleau F, Vernié T, Huguet S, Balzergue S, Frugier F, Gamas P, Jardinaud M-F (2014) The symbiotic transcription factor MtEFD and cytokinins are positively acting in the Medicago truncatula and Ralstonia solanacearum pathogenic interaction. New Phytol 201: $1343-1357$

Moreau S, Verdenaud M, Ott T, Letort S, de Billy F, Niebel A, Gouzy J, de Carvalho-Niebel F, Gamas P (2011) Transcription reprogramming during root nodule development in Medicago truncatula. PLoS One 6: e16463

Mulley G, White JP, Karunakaran R, Prell J, Bourdes A, Bunnewell S, Hill L, Poole PS (2011) Mutation of GOGAT prevents pea bacteroid formation and $\mathrm{N}_{2}$ fixation by globally downregulating transport of organic nitrogen sources. Mol Microbiol 80: 149-167

Murray JD, Liu C, Chen Y, Miller AJ (2017) Nitrogen sensing in legumes. 68: 1919-1926

Mus F, Crook MB, Garcia K, Garcia Costas A, Geddes BA, Kouri E-D, Paramasivan P, Ryu M-H, Oldroyd GED, Poole PS, et al (2016) Symbiotic nitrogen fixation and challenges to extending it to non-legumes. Appl Environ Microbiol 82: 1-39

Nagae M, Takeda N, Kawaguchi M (2014) Common symbiosis genes CERBERUS and NSP1 provide additional insight into the establishment of arbuscular mycorrhizal and root nodule symbioses in Lotus japonicus. Plant Signal Behav 9: 37-41

Oldroyd GED (2013) Speak, friend, and enter: signalling systems that promote beneficial symbiotic associations in plants. Nat Rev Microbiol 11: 252-263

Oldroyd GED, Downie JA (2008) Coordinating nodule morphogenesis with rhizobial infection in legumes. Annu Rev Plant Biol 59: 519-546

Oldroyd GED, Murray JD, Poole PS, Downie JA (2011) The rules of engagement in the legumerhizobial symbiosis. Annu Rev Genet 45: 119-144

Oono R, Schmitt I, Sprent JI, Denison RF (2010) Multiple evolutionary origins of legume traits leading to extreme rhizobial differentiation. New Phytol 187: 508-520

Osipova M a., Mortier V, Demchenko KN, Tsyganov VE, Tikhonovich I a., Lutova L a., Dolgikh E a., Goormachtig S (2012) WUSCHEL-RELATED HOMEOBOX5 gene expression and interaction of CLE peptides with components of the systemic control add two pieces to the puzzle of autoregulation of nodulation. Plant Physiol 158: 1329-1341

Ott T, van Dongen JT, Günther C, Krusell L, Desbrosses G, Vigeolas H, Bock V, Czechowski T, 
Geigenberger P, Udvardi MK (2005) Symbiotic leghemoglobins are crucial for nitrogen fixation in legume root nodules but not for general plant growth and development. Curr Biol 15: 531-535

Patriarca EJ, Tatè R, Iaccarino M (2002) Key Role of bacterial $\mathrm{NH}_{4}{ }^{+}$metabolism in Rhizobium-plant symbiosis. Microbiol Mol Biol Rev 66: 203-222

Peoples MB, Brockwell J, Herridge DF, Rochester IJ, Alves BJR, Urquiaga S, Boddey RM, Dakora FD, Bhattarai S, Maskey SL, et al (2009) The contributions of nitrogen-fixing crop legumes to the productivity of agricultural systems. Symbiosis 48: 1-17

Peters N, Frost J, Long S (1986) A plant flavone, luteolin, induces expression of Rhizobium meliloti nodulation genes. Science 233: 977-980

Pislariu CI, Dickstein R (2007) An IRE-Like AGC Kinase Gene, MtIRE, Has Unique Expression in the Invasion Zone of Developing Root Nodules in Medicago truncatula. Plant Physiol 144: 682-694

Popp C, Ott T (2011) Regulation of signal transduction and bacterial infection during root nodule symbiosis. Curr Opin Plant Biol 14: 458-467

Prell J, Poole P (2006) Metabolic changes of rhizobia in legume nodules. Trends Microbiol 14: 161-168

Prell J, White JP, Bourdes A, Bunnewell S, Bongaerts RJ, Poole PS (2009) Legumes regulate Rhizobium bacteroid development and persistence by the supply of branched-chain amino acids. Proc Natl Acad Sci 106: 12477-12482

Radutoiu S, Madsen LH, Madsen EB, Felle HH, Umehara Y, Grønlund M, Sato S, Nakamura Y, Tabata S, Sandal N, et al (2003) Plant recognition of symbiotic bacteria requires two LysM receptor-like kinases. Nature 425: 585-592

Reid DE, Ferguson BJ, Hayashi S, Lin YH, Gresshoff PM (2011) Molecular mechanisms controlling legume autoregulation of nodulation. Ann Bot 108: 789-795

Riely BK, Lougnon G, Ané JM, Cook DR (2007) The symbiotic ion channel homolog DMI1 is localized in the nuclear membrane of Medicago truncatula roots. Plant J 49: 208-216

Robson RL, Postgate JR (1980) Oxygen and hydrogen. 183-207

Roux B, Rodde N, Jardinaud M-F, Timmers T, Sauviac L, Cottret L, Carrère S, Sallet E, Courcelle E, Moreau S, et al (2014) An integrated analysis of plant and bacterial gene expression in symbiotic root nodules using laser-capture microdissection coupled to RNA sequencing. Plant J 77: $817-837$

Satgé C, Moreau S, Sallet E, Lefort G, Auriac M-C, Remblière C, Cottret L, Gallardo K, Noirot C, Jardinaud M-F, et al (2016) Reprogramming of DNA methylation is critical for nodule development in Medicago truncatula. Nat Plants 2: 16166

Severin AJ, Woody JL, Bolon Y-T, Joseph B, Diers BW, Farmer AD, Muehlbauer GJ, Nelson RT, Grant D, Specht JE, et al (2010) RNA-Seq Atlas of Glycine max: A guide to the soybean transcriptome. BMC Plant Biol 10: 160

Simon-Rosin U, Wood C, Udvardi MK (2003) Molecular and cellular characterisation of LjAMT2; 1, an ammonium transporter from the model legume Lotus japonicus. Plant Mol Biol 51: 99-108

Sinharoy S, Torres-Jerez I, Bandyopadhyay K, Kereszt A, Pislariu CI, Nakashima J, Benedito VA, Kondorosi E, Udvardi MK (2013) The $\mathrm{C}_{2} \mathrm{H}_{2}$ Transcription Factor REGULATOR OF SYMBIOSOME DIFFERENTIATION Represses transcription of the secretory pathway gene VAMP721a and promotes symbiosome development in Medicago truncatula. Plant Cell 25: 35843601

Smit P (2005) NSP1 of the GRAS protein family is essential for rhizobial Nod factor-induced 
transcription. Science 308: 1789-1791

Soltis DE, Soltis PS, Morgan DR, Swensen SM, Mullin BC, Dowd JM, Martin PG (1995) Chloroplast gene sequence data suggest a single origin of the predisposition for symbiotic nitrogen fixation in angiosperms. Proc Natl Acad Sci USA 92: 2647-2651

Soltis PS, Marchant DB, Van de Peer Y, Soltis DE (2015) Polyploidy and genome evolution in plants. Curr Opin Genet Dev. 35: 119-125 doi: 10.1016/j.gde.2015.11.003

Soyano T, Hayashi M (2014) Transcriptional networks leading to symbiotic nodule organogenesis. Curr Opin Plant Biol 20: 146-154

Soyano T, Kouchi H, Hirota A, Hayashi M (2013) NODULE INCEPTION directly targets NF-Y subunit genes to regulate essential processes of root nodule development in Lotus japonicus. PLoS Genet 9: e1003352

Sprent JI (2008) 60Ma of legume nodulation. What's new? What's changing? J Exp Bot 59: 1081-1084

Sprent JI (2007) Evolving ideas of legume evolution and diversity: a taxonomic perspective on the occurrence of nodulation. New Phytol 174: 11-25

Sprent JI, James EK (2007) Legume evolution: Where do nodules and mycorrhizas fit in? Plant Physiol 144: $575-581$

Stougaard J, Schauser L, Roussis A, Stiller J (1999) A plant regulator controlling development of symbiotic root nodules. Nature 402: 191-195

Straub D, Ludewig U, Neuhäuser B (2014) A nitrogen-dependent switch in the high affinity ammonium transport in Medicago truncatula. Plant Mol Biol 86: 485-494

Sugiyama A, Shitan N, Yazaki K (2008) Signaling from soybean roots to rhizobium: An ATP-binding cassette-type transporter mediates genistein secretion. Plant Signal Behav 3: $38-40$

Suzaki T, Yano K, Ito M, Umehara Y, Suganuma N, Kawaguchi M (2012) Positive and negative regulation of cortical cell division during root nodule development in Lotus japonicus is accompanied by auxin response. Development 139: 3997-4006

Tadege M, Wen J, He J, Tu H, Kwak Y, Eschstruth A, Cayrel A, Endre G, Zhao PX, Chabaud M, et al (2008) Large-scale insertional mutagenesis using the Tnt1 retrotransposon in the model legume Medicago truncatula. Plant J 54: 335-347

Thompson EP, Davies JM, Glover BJ (2010) Identifying the transporters of different flavonoids in plants. Plant Signal Behav 5: 860-3

Timmers AC, Auriac MC, Truchet G (1999) Refined analysis of early symbiotic steps of the Rhizobium-Medicago interaction in relationship with microtubular cytoskeleton rearrangements. Development 126: $3617-3628$

Timmers ACJ, Holsters M, Goormachtig S (2006) Endocytosis and endosymbiosis. Plant endocytosis $245-266$

Tyerman SD, Whitehead LF, Day DA (1995) A channel-like transporter for $\mathrm{NH}_{4}{ }^{+}$on the symbiotic interface of $\mathrm{N}_{2}$ fixing plants. Nature 378: 629-632

Udvardi M, Poole PS (2013) Transport and metabolism in legume-rhizobia symbioses. Annu Rev Plant Biol 64: 781-805

Udvardi MK, Day D a. (1997) metabolite transport across symbiotic membranes of legume nodules. Annu Rev Plant Physiol Plant Mol Biol 48: 493-523

Udvardi MK, Kakar K, Wandrey M, Montanari O, Murray J, Andriankaja A, Zhang J-Y, 
Benedito V, Hofer JMI, Chueng F, et al (2007) Legume transcription factors: global regulators of plant development and response to the environment. Plant Physiol 144: 538-549

Unkovich MJ, Baldock J, Peoples MB (2010) Prospects and problems of simple linear models for estimating symbiotic $\mathrm{N}_{2}$ fixation by crop and pasture legumes. Plant Soil 329: 75-89

Vasse J, De Billy F, Camut S, Truchet G (1990) Correlation between ultrastructural differentiation of bacteriods and nitrogen fixation in alfalfa nodules. J Bacteriol 172: 4295-4306

Veereshlingam H (2004) nip, a symbiotic Medicago truncatula mutant that forms root nodules with aberrant infection threads and plant defense-like response. Plant Physiol 136: 3692-3702

Verdier J, Torres-Jerez I, Wang M, Andriankaja A, Allen SN, He J, Tang Y, Murray JD, Udvardi MK (2013) Establishment of the Lotus japonicus Gene Expression Atlas (LjGEA) and its use to explore legume seed maturation. Plant J 74: 351-362

Vernié T, Kim J, Frances L, Ding Y, Sun J, Guan D, Niebel A, Gifford ML, de Carvalho-Niebel F, Oldroyd GED (2015) The NIN transcription factor coordinates diverse nodulation programs in different tissues of the Medicago truncatula root. Plant Cell 27: 3410-3424

Vernie T, Moreau S, de Billy F, Plet J, Combier J-P, Rogers C, Oldroyd G, Frugier F, Niebel A, Gamas P (2008) EFD Is an ERF transcription factor involved in the control of nodule number and differentiation in Medicago truncatula. Plant cell online 20: 2696-2713

Wasson AP, Pellerone FI, Mathesius U (2006) Silencing the flavonoid pathway in Medicago truncatula inhibits root nodule formation and prevents auxin transport regulation by rhizobia. Plant Cell 18: $1617-29$

White J, Prell J, James EK, Poole P (2007) Nutrient Sharing between Symbionts. Plant Physiol 144: 604-614

Wienkoop S, Saalbach G (2003) Proteome analysis. Novel proteins identified at the peribacteroid membrane from Lotus japonicus root nodules. Plant Physiol 131: 1080-1090

Witty JF, Minchin FR, Sheehy JE (1983) Carbon costs of nitrogenase activity in legume root nodules determined using Acetylene and Oxygen. J Exp Bot 34: 951-963

Yano K, Yoshida S, Muller J, Singh S, Banba M, Vickers K, Markmann K, White C, Schuller B, Sato S, et al (2008) CYCLOPS, a mediator of symbiotic intracellular accommodation. Proc Natl Acad Sci 105: 20540-20545

Yokota K, Hayashi M (2011) Function and evolution of nodulation genes in legumes. Cell Mol Life Sci 68: $1341-1351$

Young ND, Bharti AK (2012) Genome-Enabled Insights into Legume Biology. Annu Rev Plant Biol 63: 283-305

Young ND, Debellé F, Oldroyd GED, Geurts R, Cannon SB, Udvardi MK, Benedito V a, Mayer KFX, Gouzy J, Schoof H, et al (2011) The Medicago genome provides insight into the evolution of rhizobial symbioses. Nature 480: 520-4

Zhao H, Li M, Fang K, Chen W, Wang J (2012) In silico insights into the symbiotic nitrogen fixation in Sinorhizobium meliloti via metabolic reconstruction. PLoS One 7: e31287

Zipfel C, Oldroyd GED (2017) Plant signalling in symbiosis and immunity. Nature 543: 328-336 
CHAPTER 2 


\title{
THE MAKING OF THE LEGUME NODULE: TRANSCRIPTION FACTORS, REGULATORY GENE NETWORKS AND THE NOVEL GRF-TYPE ZINC FINGER FAMILY
}

\begin{abstract}
The genome sequencing of the nitrogen-fixing model legume Medicago truncatula provided tools to better understand the nodulation and nitrogen-fixation processes by genetic characterization and molecular approaches. Transcription factors (TFs) have fundamental functions throughout bacterial recognition, symbiosis establishment, nodule development, maintainance of nitrogen-fixation, to nodule senescence. Some of them have been characterized in diverse legume species, although most potential TFs still await functional studies. Understanding the orchestration dynamics of TFs during nodule symbiosis will open new avenues to explore nodulation in non-legumes. In this chapter, we delineate the current knowledge about the roles TFs play in legume nodule symbiosis. We also introduce and analyse a novel family of GRF-type zinc finger family, of which some members present genes that are highly expressed in the indeterminate nodule of Medicago truncatula.
\end{abstract}




\section{THE MAKING OF THE LEGUME NODULE: TRANSCRIPTION FACTORS, REGULATORY GENE NETWORKS AND THE NOVEL GRF-TYPE ZINC FINGER FAMILY}

\section{INTRODUCTION}

Transcription factors (TFs) control the genetic expression of the cellular machinery, fundamentally coordinating every aspect of metabolism, growth and development of an organism. Essentially, the entire phenome and the phenotypical plasticity of an organism (i.e., the entire set of phenotypes expressed by an individual) are dictated by the controlled its genome genes expression. The environment can only influence the phenotype inasmuch as the appropriate genes are present, and if so while they are induced (or repressed), whereas it cannot modulate traits without the coordination of a gene network that makes the phenotype. TFs are proteins with functional domains that interact with the DNA at promoter regions and directly regulate gene expression. Many TFs are hubs of regulatory gene networks that orchestrate, directly or indirectly, often a large number of genes. In plants, around 5-10\% of the genes in the genome encode for TFs (Udvardi et al., 2007; Libault et al., 2009; Jin et al., 2017). As hubs on which important gene networks are centered, TFs usually possess highly conserved domains that impart them with biochemistry properties to recognize distinct cis-elements of a gene promoter and either repress or call the basic transcriptional machinery. Therefore, understanding the essential roles that transcription factors play on biological systems allows us to delve more purposefully into the molecular genetics of particular attributes of an organism.

This chapter reviews what is known about TFs during nodulation and symbiotic nitrogen fixation (SNF) in legumes, and provides genomic and transcriptomic perspectives of nodule TFs, with a particular focus on the genetic model M. truncatula. Furthermore, I provide the first insights on nodule-specific putative TFs belonging to a largely uncharacterized family, the GRF-type zinc-finger.

\section{The making of the nodule at the molecular level}

The nodule is a new organ that develops de novo from the cortical tissues of the root. Determinate nodules rise from the outer cortex while indeterminate nodules grow from the inner cortex (Crespi and Gálvez, 2000). The developmental program of the nodule starts in response to the symbiotic colonization of diazotrophs bacteria. In legumes, this interaction is highly species-specific for both symbionts (Liu and Murray, 2016; Wang et al., 2017; Yang et al., 2017). The morphological and physiological changes observed during nodule development are orchestrated by a precise genetic network program triggered by signaling molecules and signal transduction pathways but that is ultimately coordinated by TFs (Moreau et al., 2011; Oldroyd et al., 2011). In this regard, nodule organogenesis shows an intricate genetic regulatory 
network that still needs to be better understood (Udvardi et al., 2007; Moreau et al., 2011; Oldroyd et al., 2011; Cerri et al., 2012; Limpens et al., 2013; Oldroyd, 2013; Laloum et al., 2014; Soyano and Hayashi, 2014; Vernié et al., 2015; Geurts et al., 2016; Zipfel and Oldroyd, 2017).

Initially, legume roots under low nitrogen status exudate flavonoids, such as luteolin, to the rhizosphere (Liu and Murray, 2016), which are perceived by soil-borne Rhizobium. In response, Rhizobium synthesizes membrane lipo-chitooligosaccharides (LCOs) called Nod factors (NF) and release them to the soil (Peters et al., 1986; Oldroyd, 2001; Limpens and Bisseling, 2003). These molecules are then recognized on the plasma membrane of root hair cells via sugar-binding receptor-like kinases containing lysin motifs (LysM) and a leucine-rich repeat (LRR) encoded by NFP and LYK3 in M. truncatula and NFR1 and NFR5 in L. japonicus (Madsen et al., 2003; Ané et al., 2004; Oldroyd and Downie, 2008). Early symbiotic events are dependent of LysM receptor, which elicit $\mathrm{Ca}^{2+}$ spiking signal-transduction cascade at the perimembrane of root hairs via the leucine-rich-repeat-containing receptor kinase M. truncatula DOES NOT MAKE INFECTIONS (MtDMI2), or SYMBIOSIS RECEPTOR LIKE KINASES (LjSYMRK) and (MtLYK) (Endre et al., 2002; Stracke et al., 2002; Limpens et al., 2005). Another gene, DMI1, is localized in the nuclear membrane of M. truncatula root hairs, while CASTOR and POLLUX are DMI1 homologs in Lotus japonicus (Ané et al., 2004; Imaizumi-Anraku et al., 2005; Hogg et al., 2006; Riely et al., 2007). DMI1 was localized in Endoplasmatic Reticulum (ER) of yeast presenting function of releasing $\mathrm{Ca}^{2+}$ of ER storage (Peiter et al., 2007). DMI1 is involved in $\mathrm{Ca}^{2+}$ spiking, of the common symbiotic pathway, (DMII) modulate the perinuclear cytosolic $\mathrm{Ca}^{2+}$ spiking signaling (Ané et al., 2004; Peiter et al., 2007). The $\mathrm{Ca}^{2+}$ spiking signal transduction cascade continues until it achieves the interior of the nucleus where, modulated by MtDMI3 or LjCYCLOPS, the signal induces nodule primordia formation in the root cortical cells (Lévy et al., 2004; Mitra et al., 2004). Another NF receptor, MtLYK3, acts as Rhizobium ssp. entry receptor controlling infection. MtLYK3 is not required for M. trunctula NODULE INCEPTION (MtNIN) induction, but it seems to play a function in the polar growth of ITs and regulation of a subset of NF-induced genes (Limpens, 2003; Smit et al., 2007; Arrighi et al., 2008). In summary, NFP functions as a signaling reception that elicits $\mathrm{Ca}^{2+}$ spiking, which induces MtNIN for nodule primordial initiation, while LYK3 coordinates the bacterial entry by developing ITs.

NF stimulation elicits the early responses required for root hair deformation (“curling"), like $\mathrm{Ca}^{2+}$ oscillations, cytoskeletal changes, root hair deformation, while also inducing the expression of early nodulins, like NIN and EARLY NODULINS (ENODs) during the early development of the nodule (Timmers et al., 1999). By means of the NF signaling cascade, cortical cells are elicited to start dividing in order to trigger nodule organogenesis. Figure 1 illustrates the most relevant legume TFs described during the process of nodulation and symbiotic nitrogen fixation. 


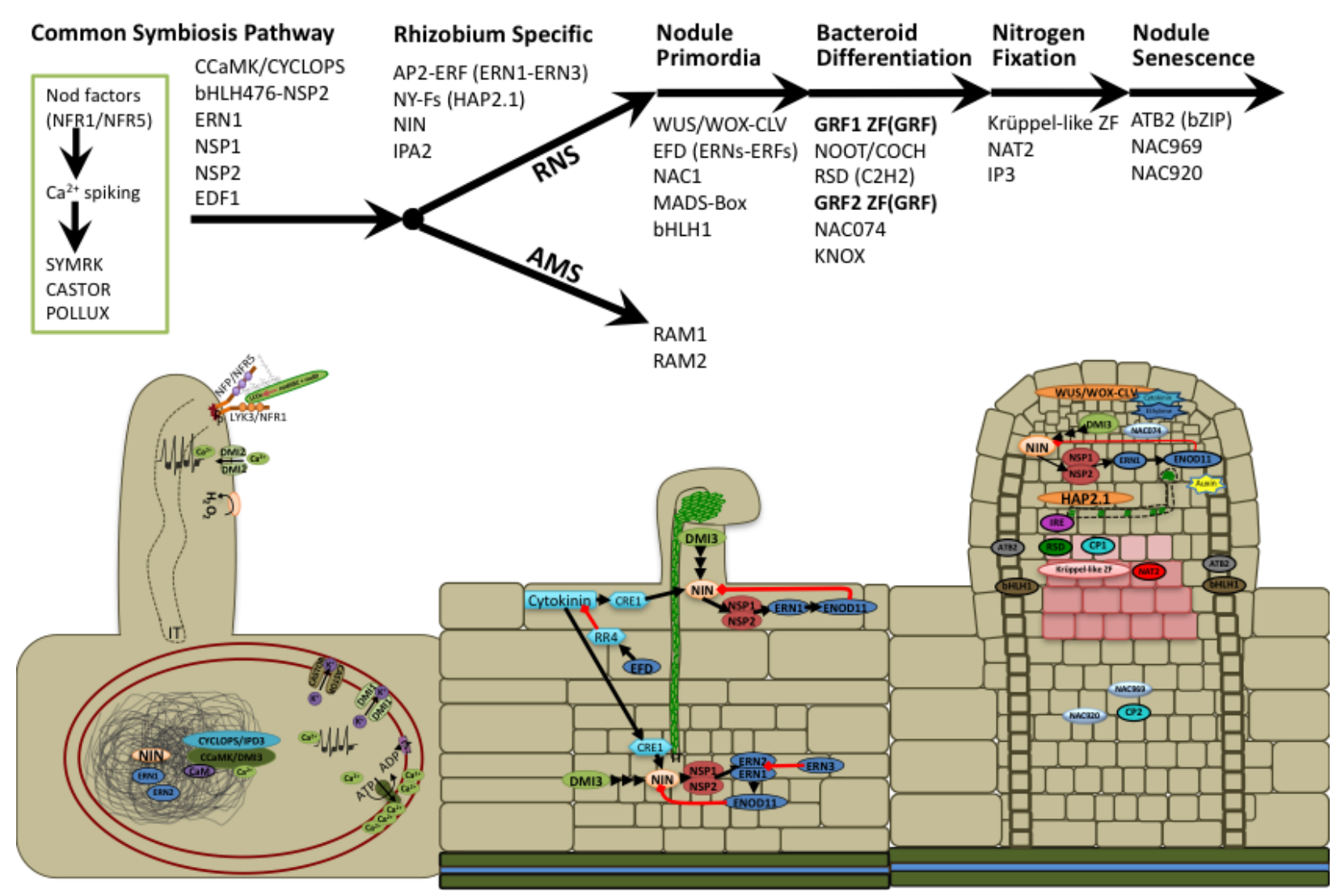

Figure 1. Characterized transcription factors involved in the common symbiotic pathway as well as the Rhizobiumspecific nitrogen fixation symbiosis in legumes.

During early NF signaling event, NOD-FACTOR PROTEIN (NFP) and DMI3 are responsible for rhizobial perception and ENOD11 induction present in the epidermis and root cortex, followed by infection thread formation and nodule organogenesis. A plant-specific $\mathrm{Ca}^{2+} /$ calmodulin-dependent protein kinase (CCaMK) encodes by DMI3 in Medicago and SYM15 in Lotus is fundamental for symbiotic gene expression, localized in the nucleus of epidermis and cortex cell of the root, which recognize and triggers the signal transduction cascade of the $\mathrm{Ca}^{2+}$ spiking (Lévy et al., 2004; Mitra et al., 2004; Tirichine et al., 2006; Rival et al., 2012). The first recognized TFs that play a role during this stage are the GRAS-domain regulators NODULATION SIGNALING PATHWAY 1 and 2 (NSP1 and NSP2) (Kalo, 2005; Smit, 2005; Zipfel and Oldroyd, 2017). This family has important roles in diverse biological processes, such as root development, phytohormone signal transduction, as well as meristem development and maintenance. In legumes, NSP1 and NSP2 are essential for nodule development and involved at early stages of organogenesis, but not for mycorrhizal associations. The nsp1 and nsp 2 mutants in M. truncatula and Lotus japonicus show a nod $/ \mathrm{myc}^{+}$phenotype (Kaló et al. 2005, Smith et al. 2005, Heckmann et al. 2006, Murakami et al 2006). Moreover, NSP1 plays an additional role beyond early signaling, as it is required for maintenance of infection or nodule development (Heckmann et al., 2006; Zipfel and Oldroyd, 2017). This 
protein binds to the ENOD11 promoter as well as ETHYLENE RESPONSIVE FACTOR (ERF) REQUIRED FOR NODULATION 1 (ERN1) and NIN, two other TFs acting downstream of CCaMK/DMI3 (Hirsch et al. 2009). Both, MtNSP1 and MtSNP2 form homo- as well as heterodimers at the MtENOD11 promoter and their expression levels are enhanced by NF treatment (Hirsch et al., 2009; Cerri et al., 2012). Both genes are induced by CCaMK/DMI3, possibly via phosphorylation, in which the kinase site of CCaMK phosphorylates DMI3 (Kalo, 2005; Smit, 2005; Heckmann et al., 2006; Messinese et al., 2007; Yano et al., 2008).

Downstream, DMI3 activates the gene expression of ERN1, a necessary for NF-induced TF involved at the early signaling pathway (Andriankaja et al., 2007). Via DMI3 activation, ERN1 is required for Nod-factor gene expression signaling, and necessary to induce spontaneous nodulation via DMI3 activation (Middleton et al., 2007). ERN1 encodes an APETALA2 (AP2)-domain protein that binds specifically to the NF box, which is a conserved NF-responsive element present in the promoters of MtENOD11, MtENOD12 and MtENOD9 (Andriankaja et al., 2007). The highly conserved AP2 DNAbinding domain of ERN is necessary to initiate NF signaling in presymbiotic cells. Therefore, loss of this function blocks the initiation and development of rhizobial invasion structures, termed infection threads, and thus block nodule invasion by the bacteria (Middleton et al., 2007). Indeed, ern knockout mutants have defective in infection and those that develop, form small primordia. (Middleton et al., 2007).

Subsequently, NIN is an early signaling component of the NF signaling pathway (Marsh et al., 2007). Although NIN is not required for NF signaling per se, it regulates negatively the spatial expression pattern of ENOD11 and bacteria entry. NIN expression occurs in nodule primordium cells, in the nodule parenchyma and vascular bundles, as well as infected and non-infected cells of mature determinate nodules (Borisov et al. 2003). Data also suggest that NIN may be a positive regulator of both, bacterial entry as well as nodule primordium development, because it abolishes nodulation when ectopically expressed. In conclusion, the TF NIN may be a key integrator that controls NF perception, nodule organogenesis, bacterial invasion and nodule number (Marsh et al., 2007).

Beyond TF regulation, the hyper-nodulating mutants sickle (skl) and supernumerary nodules (sunn) exhibit 10-fold number of nodules at the primary nodulation zone. Penmetsa et al. (2003) described that MtSUNN and MtSKL define distinct genetic pathways, in which SKL encodes for an ethylene sensitive that regulates nodule number and distribution while $M t S U N N$ for a leucine-rich repeat receptor-like kinase that regulates the nodule number via autoregulation of nodulation (AON) (Schnabel et al., 2005).

The WUSCHEL (WUS)-RELATED HOMEOBOX (WOX) family transcription factors, WOX5 transcription factor upon nodulation in M. truncatula and pea (Pisum sativum) form indeterminate nodules. Mature nodules can be of the indeterminate or determinate type depending on whether an apical meristem is sustained through development or not. Which type grows relies on the host: typical models for 
indeterminate nodule development are M. truncatula and pea. The expression of WOX5 in nodules is suppressed by the CLAVATA (CLV) signaling complex that controls the AON. AON is activated early after the perception of the Nod factors, at the onset of cell division for primordium formation, and its strength increases as nodule development proceeds (Pierce and Bauer, 1983; Caetano-Anolle's and Gresshoff, 1991; Li et al., 2009). So WOX5 is another component of the AON mechanism in addition to the CLV signaling mechanism in the shoot and the CLAVATA3/EMBRYO-SURROUNDING REGION (CLE) peptides in the root. Hence, a conserved WUS/WOX-CLV regulatory system might regulate cell proliferation and differentiation not only in regular plant apical meristems (RAM) and shoot apical meristem (SAM) but also in nodule meristems. The identified AON component, NOD3, might act downstream or alongside the CLE peptides during AON. Thus, although the exact interaction between the different AON components remains unsolved, the AON puzzle that can be used in the future to gain an integrated insight into how AON works. In summary, a conserved WUS/WOX-CLV regulatory system might control cell proliferation and differentiation not only in the root and shoot apical meristems but also in nodule meristems. And the component AON, NODULATION3 of pea, might act downstream from or beside the CLE peptides during AON (Osipova, et al., 2012)

The development stage is characterized by the nodule growth and zones differentiation, a stage between the early stages and the nodule operation, in nitrogen fixation. During the development of root nodules a basic helix-look-helix (bHLH) transcription factor gene family from M. truncatula has its expression regulated produced upon infection by rhizobia bacteria in M. truncatula. The MtbHLH1 is expressed in nodule primordia cells derived from pericycle divisions, in nodule vascular bundles and in uninfected cells of the nitrogen fixation zone. MtbHLH1 is also expressed in root tip, lateral root primordia cells and root vascular bundles and induced upon auxin treatment. The MtbHLH1 gene is involved in the control of nodule vasculature pattering and nutrient exchanges between nodules and roots, Godiard et al., 2011).

Plant microRNAs (miRNAs) have an impact on the regulation of several biological processes such as development, growth and metabolism by negatively controlling gene expression at the posttranscriptional level. Branscheid et al. (2011) identified 243 novel Medicago microRNAs and 118 mRNA cleavage targets of miRNA mature and star sequences. Several AM symbiosis-relevant genes were identified as miRNA targets. The transcript of MtNSP2 encodes for a GRAS transcription factor involved in the nodule and mycorrhizal signaling pathway. MtNSP2 mRNA can be downregulated via miR171h microRNA inducing cleavage (Lauressergues et al., 2012). This is an example of own primary transcript showing the ability it miRNA to self regulate.

A transcription factor of CCAAT-binding family identified by Combier et al. 2006, MtHAP2-1, for which RNA interference (RNAi) and in situ hybridization experiments indicate a key role during nodule 
development, possibly by controlling nodule meristem function. This TF is regulated by a microRNA169, whose overexpression leads to the same nodule developmental block as MtHAP2-1 RNAi. In addition, the restriction of MtHAP2-1 expression to the nodule meristematic zone is essential for the differentiation of nodule cells, by the miR169 (Combier et al., 2006). An small peptide from an alternative splicing of MtHAP2-1 first exton Open Reading Frame, uORF1p, binds to MtHAP2-1 5'leader sequence mRNA and downregulates MtHAP2.1 during nodule development (Combier et al., 2008).

In Arabidopsis, the (NAC1) transcription factor is involved in lateral root formation, and is regulated post-transcriptionally by miRNA164 and by SEVEN IN ABSENTIA HOMOLOG OF A. thaliana (SINAT)5-dependent ubiquitination. MtNAC1 shows a different expression pattern in response to auxin than its Arabidopsis homolog and no changes in lateral root number or nodulation were observed in plants affected in MtNAC1 expression. In addition, no interaction was found with SINA E3 ligases, suggesting that post-translational regulation of MtNAC1 does not occur in M. truncatula. The miR164 and MtNAC1 show an overlapping expression pattern in symbiotic nodules, and overexpression of this miRNA led to a reduction in nodule number, D'haeseleer et al., 2011.

Several transcription factors including genes encoding NAC (NAM/ATAF/CUC) identify by Zélicourt et al. (2012) have been linked to the M. truncatula response to salt stress in roots. The expression of MtNAC969 in central symbiotic nodule tissues was induced by nitrate treatment, and antagonistically affected by salt in roots and nodules, similarly to senescence markers. Accordingly, expression of salt stress markers was decreased in MtNAC969 over-expressing and induced in RNAi roots, suggesting a repressive function for this transcription factor in the salt-stress response. The MtNAC969 RNAi nodules accumulated amyloplasts in the nitrogen-fixing zone, and were prematurely senescent. This way, the MtNAC969 transcription factor is differentially affected by environmental cues in root and nodules and participates in several pathways controlling adaptation of the M. truncatula root system to the environment.

The ethylene response factor required for nodule differentiation transcription factor (EFD) belongs to the Ethylene Response Factor (ERF) group V, which contains ERN1, 2, and 3. These three ERFs involved in Nod factor signaling. The EFD is a negative regulator of root nodulation and infection by Rhizobium and that EFD is required for the formation of functional nitrogen-fixing nodules. As expected this gene is upregulated during nodulation in M. truncatula. EFD appears to be involved in the plant and bacteroid differentiation processes taking place beneath the nodule meristem. Vernié et al. (2008) showed that the EFD activated $M t R R 4$, a cytokinin primary response gene that encodes a type-A response regulator. At this work, the EFD induction of MtRR4 leads to the inhibition of cytokinin signaling, with two consequences: the suppression of new nodule initiation and the activation of differentiation as cells leave the nodule meristem. Thus reveals a key regulator linking early and late stages of nodulation and suggests that the 
regulation of the cytokinin pathway is important both for nodule initiation and development (Vernie et al., 2008).

KNOTTED1-LIKE HOMEOBOX (KNOX) genes have been characterized active during morphogenetic processes delimitating undifferentiated cells and organ outgrowth, such as during the formation of leaf primordia, leaf serrations and compound leaves (Di Giacomo et al., 2013; Bar and Ori, 2015). KNAT3/4/5-like class 2 KNOX transcription factors decreased the expression of the $M t E F D$, an ethylene response factor required for nodule differentiation, $\mathrm{TF}$ and its direct target $M t R R 4$, a cytokinin response gene, therefore regulate legume nodule development, as its has been presented in leaf development (Di Giacomo et al., 2016).

A M. truncatula member of the Cysteine-2/Histidine-2 $\left(\mathrm{C}_{2} \mathrm{H}_{2}\right)$ family of plant TFs, REGULATOR OF SYMBIOSOME DIFFERENTIATION (RSD), is required for normal symbiosome differentiation during nodule development has maximal transcript levels in the bacterial invasion zone. Transcriptome analysis of an rsd mutant identified 11 genes as potential targets of RSD repression. RSD interacted physically with the promoter of one of these genes, VAMP721a, which encodes vesicle-associated membrane protein 721a. Thus, RSD may influence symbiosome development in part by repressing transcription of VAMP721a and modifying vesicle trafficking in nodule cells. This establishes RSD as a TF implicated directly in symbiosome and bacteroid differentiation and a transcriptional regulator of secretory pathway genes in plants. So the RSD represses the transcription of the secretory pathway gene VAMP721a and promotes the symbiosome development in M. truncatula (Sinharoy et al., 2013).

Plant phytohormones also have a fundamental role in nodulation and SNF. In summary, auxin allows indeterminate nodules to grow, cytokinin is important for NF signaling and nodulation linked with cytokinin response regulator (RRs), gibberellic acid, brassinosteroid and strigolactones also seem to have a positive impact in nodulation at low concentrations. In another hand, abscisic acid and jasmonic acid negative regulates NF signaling and nodule development and high doses of strigolactones and gibberellic acid (Bensmihen, 2015).

The nodule senescence in M. truncatula is a genetically programmed process that is accompanied by degradation of the bacteroids and then of the plant structures. And this process is associated with nutrient recycling and remobilization of resources (Van de Velde, 2006). Fixation zone cells have a limited functional lifespan, old cells senesce and are continuously replenished by meristem descendants. During the lifespan of the indeterminate nodules, the senescence zone keeps expanding, but remains surrounded by a functional peripheral zone.

Throughout the lifespan of the nodules, the exchange of $\mathrm{C}$ sources and $\mathrm{N}$ compounds is maintained balance between the host plant and the bacteria. Sucrose provides $\mathrm{C}$ skeletons and energy to the bacteroids in the form of $\mathrm{C} 4$ carboxylic acids such as malate, and ammonia is assimilated into GS/GOGAT pathway. 
Nodule senescence of nodule cells apoptosis are established when $\mathrm{C} / \mathrm{N}$ ratio is out of balance or free nitrogen source is available.

The transcription of M. truncatula A. thaliana bZIP (MtATB2), encoding a bZIP transcription factor, down-regulated by sucrose and it is enhanced during nodule senescence, expressed in the vascular tissue of nodules, nodule apex and roots. MtATB2 transcription is influenced by light and sucrose, regulation of downstream functions related to linking $\mathrm{C}$ metabolism and metabolite partitioning and seems to reduce nodule formation and affected root growth in ectopic expression (D’Haeseleer et al., 2010).

\section{Hubs of nodule development: identification of nodule-specific transcription factors}

Based on the Affymetrix gene expression data and a last genome $M$. truncatula annotation version, we identified 1,298 TFs, with 1,169 of which falling into 45 known families, and 129 considered "putative novel TF" (Benedito et al., 2008). Later, using RNA-seq dataset from six different mature organs of the $M$. truncatula plant (leaf, seed/pod, bud, flower, root and nodule), 3,692 potential TFs and transcriptional regulators (TRs) were identified (5.9\% of all predicted gene in the genome) allocated into 74 families, including 47 bona fide TF families, 11 chromatin remodeling components and 16 potentially novel families. M. truncatula present 1,513 nodule specific TFs, in which approximately 142 genes were derived from whole-genome duplication, that occured 58-Myr-ago, and 92 are high expressed in nodules (Young et al., 2011). Herein, we offer an update on the TF inventory in the Medicago genome and an overview of transcriptional activity regarding available RNA-Seq datasets. Furthermore, we explore nodule-specific TF genes, and in special those that are expressed in particular developmental stages or zones of the mature nodule.

\section{Transcriptional regulomics of the $M$. truncatula nodule and symbiotic nitrogen fixation}

As an important aspect of systems biology, the regulome refers to the study of the whole set of regulators present in an organism (Ramalingam et al., 2015). The term encompasses TFs as well as other regulators, including miRNA and signaling molecules and proteins.

Here, we are present a deep investigation of TF and Trancriponal Regulators (TRs) using the proteome of the important model plants for nodulation and symbiosis nitrogen fixation, M. truncatula, Lotus japonicus, Glycine max and Phaseolus vulgaris and the most genetically explored model plant Arabidopsis thaliana. Arabidopsis thaliana, on PlantTFcat website (http://plantgrn.noble.org/PlantTFcat/). The PlantTFcat a transcription factor and transcriptional regulator categorization analysis tool, that possess a list of 108 published TF/TR/CR families in a systematic analysis in the InterproScan domains by common conserved domains families (Dai et al., 2013). PlantTFBD is considered as a benchmark tool with 58 families, and PlantTFcat came to complement and develop a deeper prediction, providing a better output including "Family-type", InterPro protein signature databases, in spite of "Family" (Dai et al., 2013; Jin et 
al., 2017). The result of this analysis is presented in Table 1. Each species assessed owns a categorized number of TFs and TRs identified family, followed by the respective abundance of proteins and Proteome Version used.

Table 1. Transcription factors and transcriptional regulators identified in the proteome of species of interest.

\begin{tabular}{lcccl}
\hline Species & TFs+TRs & Families & Proteins & Proteome Version \\
\hline Arabidopsis thaliana & 5,004 & 99 & 35,386 & Athaliana_167_TAIR v.10.protein \\
Glycine max & 13,462 & 98 & 88,647 & Gmax_275_Wm82.a2.v1.protein \\
Lotus japonicus & 4,741 & 99 & 48,105 & Lj3.0_pep \\
Medicago truncatula & 5,486 & 98 & 57,585 & Mt4.0v2_GenesProteinSeq_20140818_1100-1 \\
Phaseolus vulgaris & 5,460 & 98 & 36,995 & Pvulgaris_442_v2.1.protein-7 MB-PDT 2017 \\
\hline TFs (Transcription Factors) TRs (Transcription Regulators) &
\end{tabular}

In which the GRF-type zinc finger is one of the recognized TFs or TRs families recognized by PlantTFcat tool. With that we generate the Table 2, which show the representation of members on the five species analyzed. The abundance of proteins that each species owns the domain IPR010666, GRF-type zinc finger family, is shown in column IPR010666, followed by the Family that they were categorized and Associate domains, also present in some members, Table 2. And some of the proteins present other recognized domains, such as CCHC-ZF, LIM and topoisomerase beyond GRF-type zinc finger, as can be seen on Figure 3A.

Table 2. Abundance of and GRF type-ZF proteins in the proteome of species of interest, holds or not additional domains.

\begin{tabular}{lcl}
\hline Species & IPR010666 & Associated domains \\
\hline Arabidopsis thaliana & 7 & 4-CCHC(ZF); 3-only GRF-ZF \\
Glycine max & 5 & 2-CCHC(ZF); 3-only GRF-ZF \\
Lotus japonicus & 26 & 26-only GRF-ZF \\
Medicago truncatula & 52 & 1-LIM; 51-C2H2 \\
Phaseolus vulgaris & 2 & 1-CCHC(ZF); 1-only GRF-ZF \\
\hline
\end{tabular}

The IPR010666 domain is spread in the Zinc Finger proteins, and in which of Zinc Finger protein subfamily such as CCHC(Zn), Growth Regulate Factor, LIM and C2H2 (Figure 3A). CCHC(Zn)-type zinc finger protein recognizes and interacts with the specific sequence single-stranded DNA or RNA oligonucleotides (Espinosa et al., 2003; Brown, 2005). Growth Regulator Factors transcription regulators are involved in young tissue and present high expression in rice (Oriza sativa) when gibberellic acid $\left(\mathrm{GA}_{3}\right)$ is applied (Choi et al., 2004). Those genes for two highly conserved regions indicative of transcription factors domains, the QLQ (Gln, Leu, Gln) and WRC (Trp, Arg, Cys) (Kim et al., 2003; Choi et al., 2004). 
We identify one nodulin, MtN20 (Medtr7g086040.1) that presents high and specific expression in nodules, with a peak of expression at 4 days post inoculation (dpi) and persisting in the mature indeterminate nodule with Sinorhizobium meliloti (Sm1021). The M. truncatula gene atlas, which is based on Affymetrix Medicago GeneChip dataset from 274 experiments and 739 microarrays, underscores the nodule-specific expression profile of $M t N 20 / M t G R F 1$ (probeset Mtr.14503.1.S1_at; Figure 2).

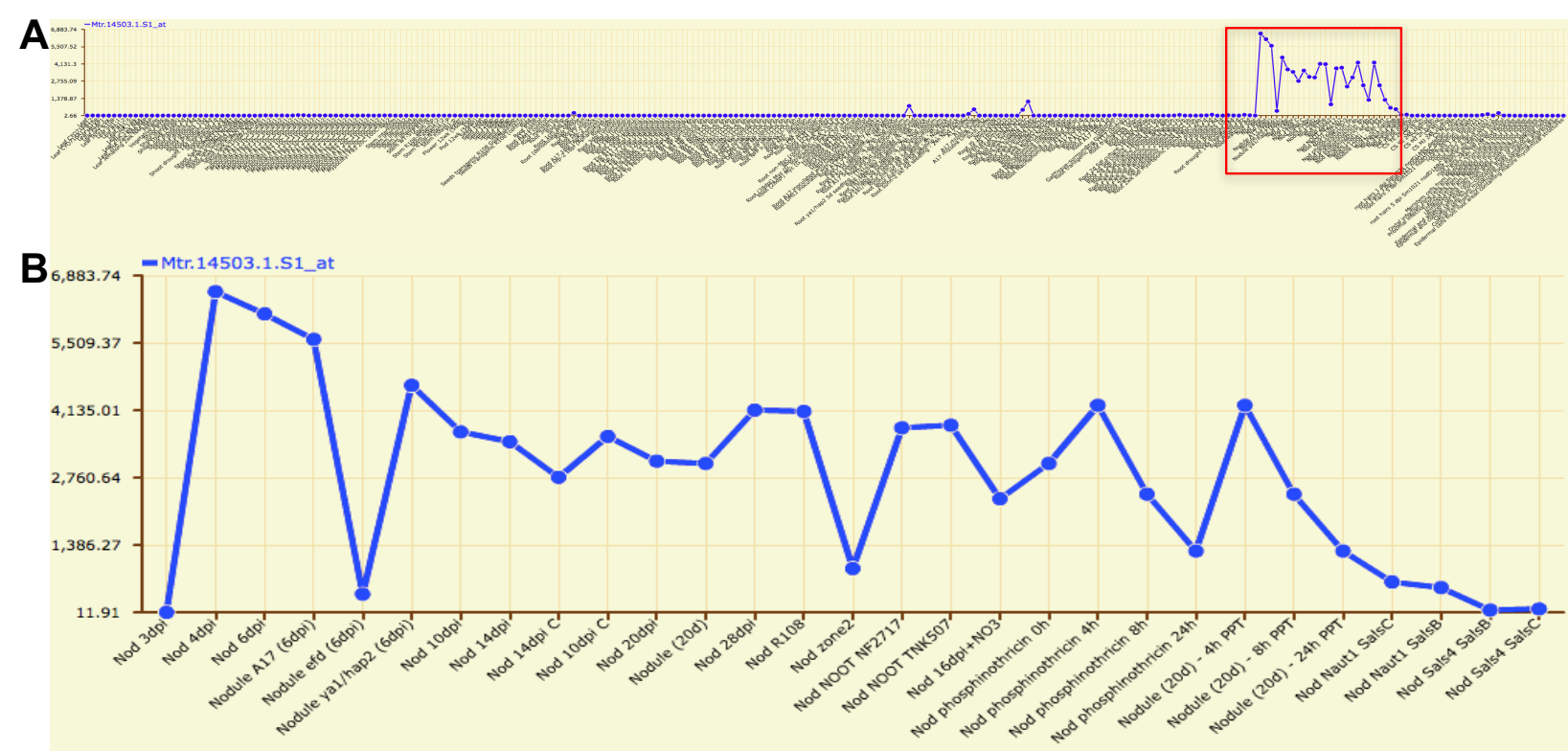

Figure 2. Affymetrix expression profile of MtN20 (gene locus Medtr7g086040; probset Mtr.14503.1.S1_at) in Medicago truncatula Gene Expression Atlas (http://mtgea.noble.org/v3). (A) Expression across all Affymetrix samples. (B) Expression in nodule specific samples highlighted in A.

A Tnt1 insertional mutant line presented white and round nodules. This nodulin was predicted as GRF-type Zinc Finger and some papers gave the idea that this protein was a GRF Zinc Finger, which is improper. MtN20 or (MtN20) have been classified as GRF-Zinc Finger (GRF-ZF), which the first member was characterized in A. thaliana Growth Regulator Factor1 (AtGRF1). This family was characterized presenting essential rules in stem elongation with the domains Glutamine-Leucine-Glutamine, QLQ:IPR014978 and WRC:IPR014977, which is not the GRF-type Zinc Finger (IPR010666) (Kim et al., 2003; Choi et al., 2004). In table 1 of (Udvardi et al., 2007), 8 GRF-type Zn-finger putative TFs, with domains descripted as IPR010666, were untimely allocated in the "GRF" TF family.. This gene of interest presents only the GRF-type Zinc Finger domain (IPR010666), which is different from GRF in Arabidopsis thaliana, and no protein has been characterized. 
A

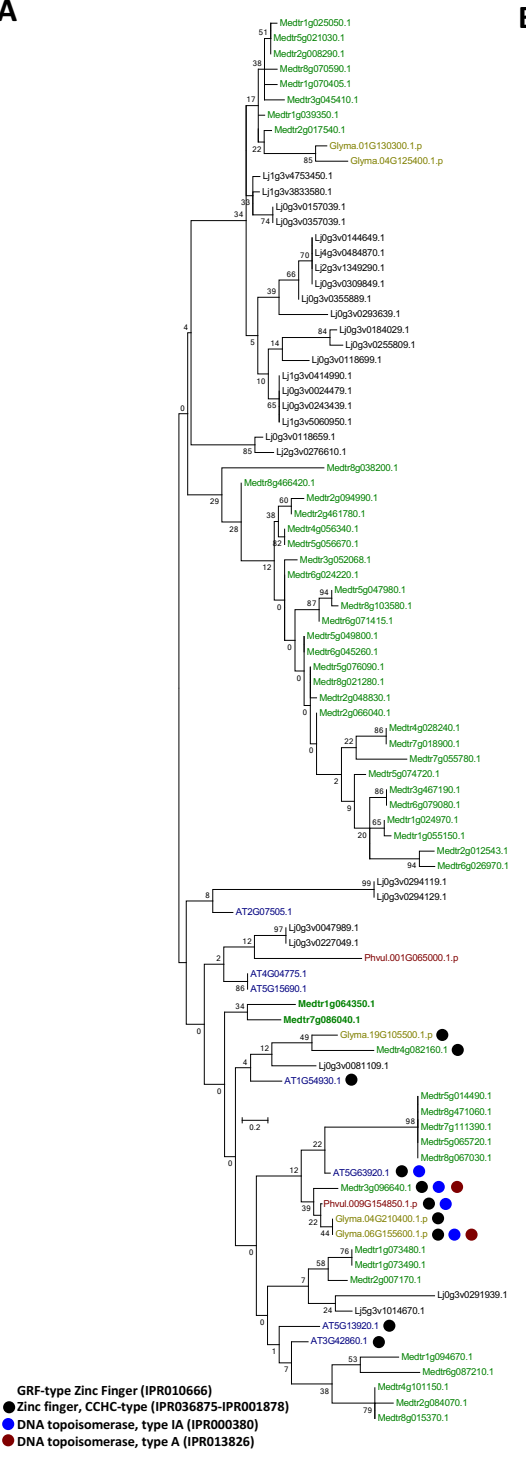

B

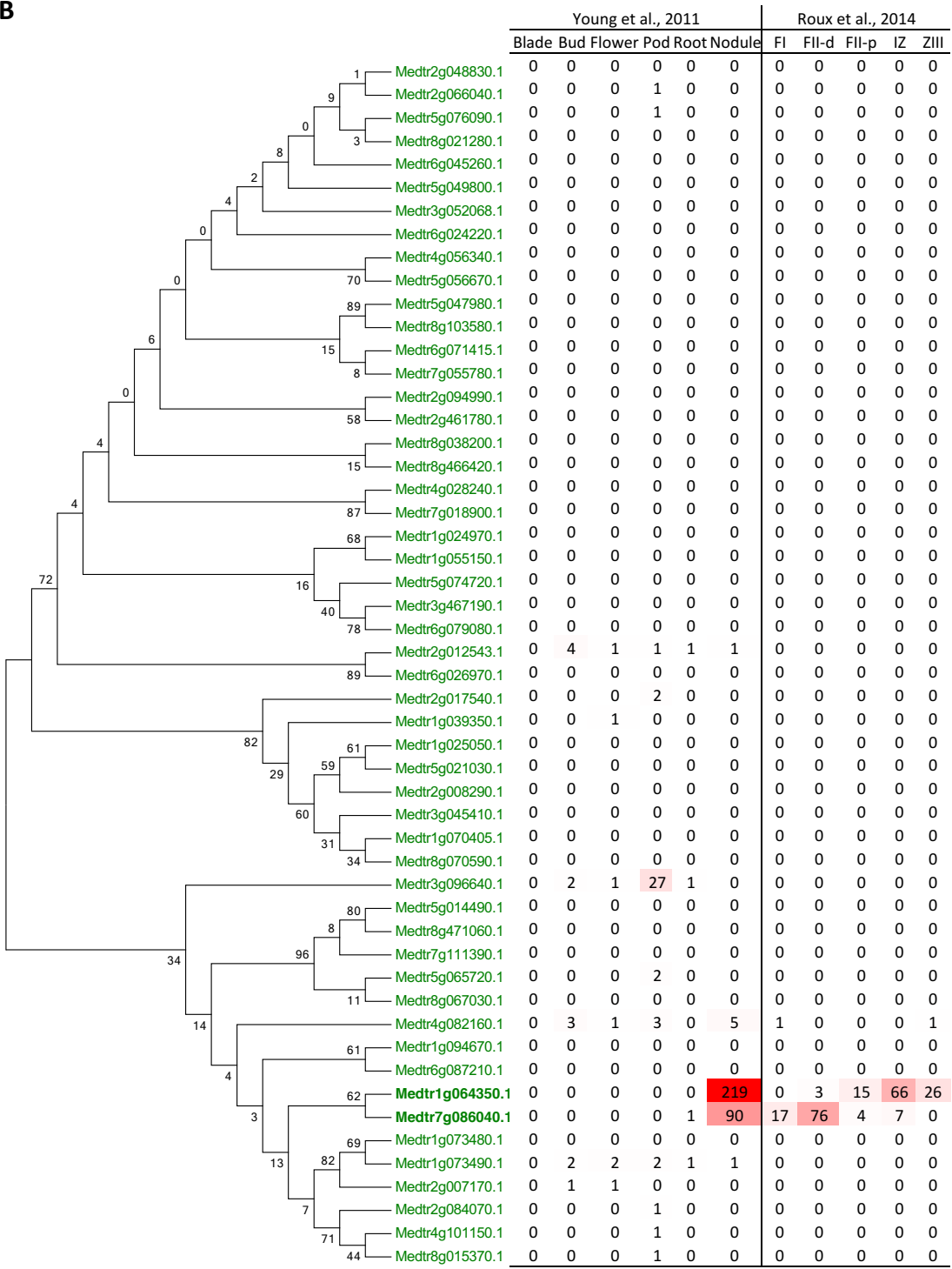

Figure 3. Phylogenetic reconstruction of GRF-type zinc finger proteins in select legume species and Arabidopsis and expression profile of the M. truncatula genes, in which the bold names are the proteins of interest in this research. (A) The original phylogenetic tree based on the Maximum Likelihood method was build with 10,000 bootstraps for all GRF-type Zinc Finger proteins found in the genomes of Arabidopsis thaliana, Phaseolus vulgaris, Lotus japonicus, Glycine max and Medicago truncatula generated on MEGA7 software (Kumar et al., 2016). (B) Maximum likelihood phylogenetic tree with 10,000 bootstraps the M. truncatula GRF-type zinc finger proteins was generated on MEGA7 (Kumar et al., 2016) and displayed along with their renormalized RNA-Seq data for gene expression profiles on six major tissues (Young et al., 2011) and nodule laser capture microdissection (Roux et al., 2014).

Zinc finger (ZF) proteins present a vast diversity of structures and functions. Generally, a ZF protein is defined as a functional protein with an independently folded domain stabilized by the coordination of one or more zinc ions (Laity et al., 2001). ZF proteins can interact with diverse types of molecules, such as peptides and other proteins, as well as RNAs, DNAs and lipids. In addition, they play several functions, including DNA recognition and signaling, RNA packaging, protein ubiquitination, assembly of transcriptional machinery, and lipid binding (Klug, 1999; Matthews and Sunde, 2002a; Matthews and 
Sunde, 2002; Brown, 2005; Gamsjaeger et al., 2007). In the InterPro database (https://www.ebi.ac.uk/interpro/entry/IPR010666), ZF proteins are allocated to 95 different families with 182 different domains, with the GRF-type domain being a well-defined group (Mitchell et al., 2015). GRFtype ZF proteins show a signature conserved GRF (Glycine, Arginine and Phenylalanine) residue interspaced domain encompassed within the larger ZF domain (Whitehead et al., 1997). Notwithstanding, very little is known about the functional roles GRF-type TFs play in the cell (Chen et al., 2015).

A special notice is required here in that this domain are different from GRF-type Zinc Finger IPR010666, which owns a GRF conserved residues into Zinc Finger domain presented by spaced Cysteines as seen in the protein alignment (Figure 4).

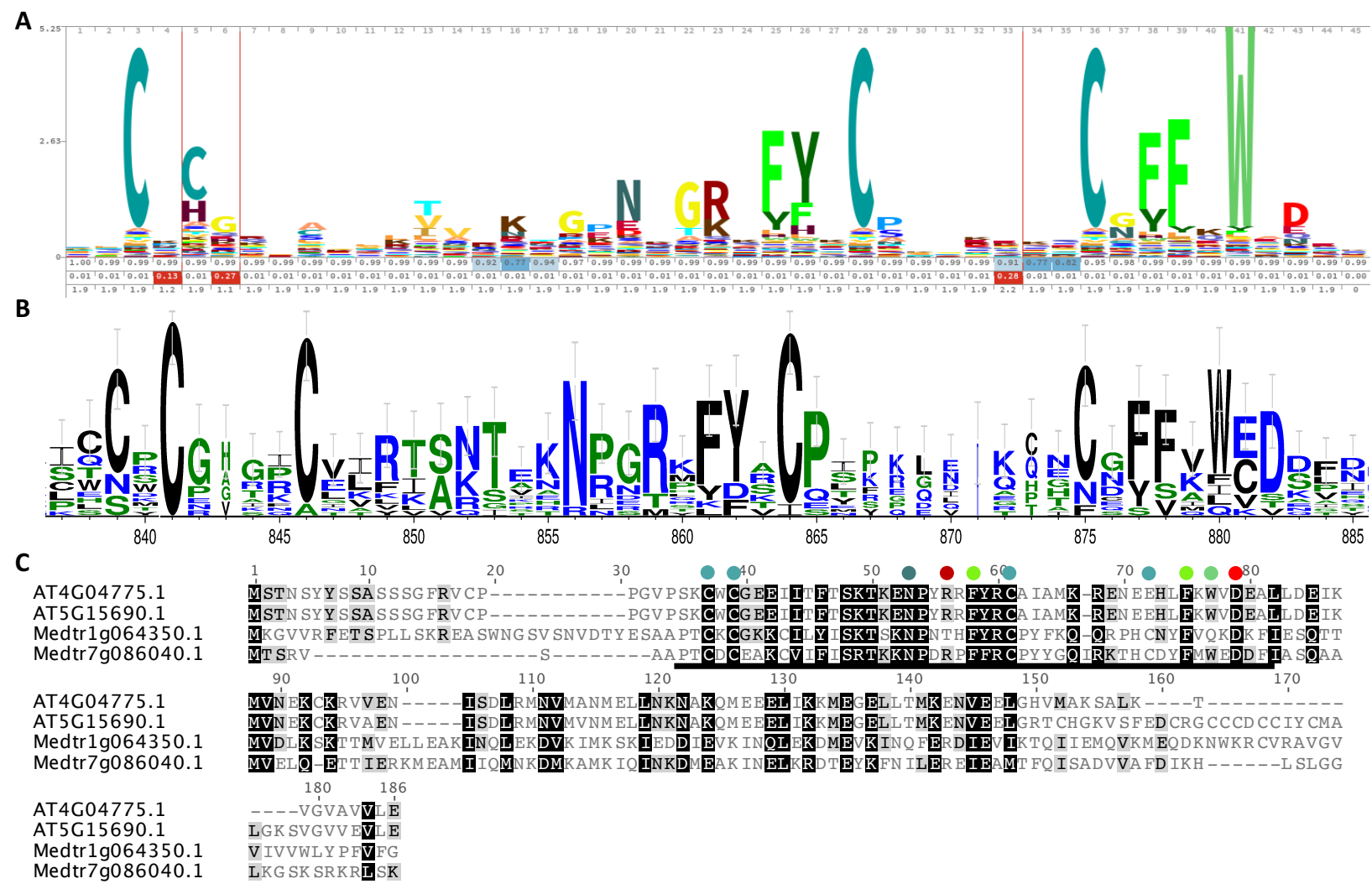

Figure 4. Protein GRF-type zinc finger alignments. (A) Pfam GRF-type zinc finger (PF06839) HMM logo from (http://pfam.xfam.org/). (B) Consensus domain for all 52 Medicago truncatula GRF-type zinc finger proteins using the "Sequence Logo" generator using fasta Clustal alignment (http://weblogo.berkeley.edu/) on (Galaxy.org). (C) Multiple alignment with BLOSUM62 matrix MtN20, GRF2 (Medtr1g063450.1) and two closest Arabidopsis homologous proteins. Alignment was generated on Geneious software version R11 (https://www.geneious.com/).

These results show that GRF-type Zinc finger family is still not very well defined by the family category, which will be better described after the posterior characterization of the gene and protein of interest (MtN20). 
The present research highlights our knowledge towards to the molecular role of GRF-type TFs legume nodulation. In Figure 3A, we present a phylogenetic tree of the proteins holding the IPR010666 domain from the proteomes shown in Table 1. Figure 3B shows only the M. truncatula proteins phylogenetic analysis linked with the RNA-Seq expression data.

The LIM sequence motif is contained twice on Cysteine-rich proteins coordinating zinc binding protein (Michelsen et al., 1993). A $\mathrm{C}_{2} \mathrm{H}_{2}$-type zinc finger is a widespread DNA binding motif in TF, coding for two or three $\beta$-layers and one $\alpha$-helix on a zinc finger formed by two cysteine and two histidine residues. In general, $\mathrm{C}_{2} \mathrm{H}_{2}$-type zinc finger proteins are present as transcriptional regulators involved in important cellular processes, such as development, differentiation, and suppression of malicious cell transformation (Razin et al., 2012). In M. truncatula, a $\mathrm{C}_{2} \mathrm{H}_{2}$ were characterized as transcription factor regulator of symbiosis differentiation, previously described (Sinharoy et al., 2013).

The $\mathrm{C} 2 \mathrm{H} 2$-type zinc finger domain alone is shown in some highly expressed proteins of $M$. truncatula root nodules, therefore apparently adding unknown but potentially important function in nodulation and nitrogen fixation.

Extensive transcriptome datasets of M. truncatula using the Affymetrix Medicago GeneChip platform and RNA-Seq data were previously published by Benedito et al. (2008), Young et al., (2011), and Roux et al. (2014). Benedito et al. (2008) presented a transcriptome compendium for all major organs and time-course analysis of nodules and seeds. Roux et al. (2014) studied the whole genome expression in nodule tissues through laser capture microdissection (LCM). Analyzing both datasets, our curiosity caught two putatively novel zinc-finger transcription factors through their nodule specificity and intensity of expression (Figures 3B \& 5 and Table 2). In this study, both genes are emphasized as novel nodule specific genes potentially involved with transcriptional regulation. 


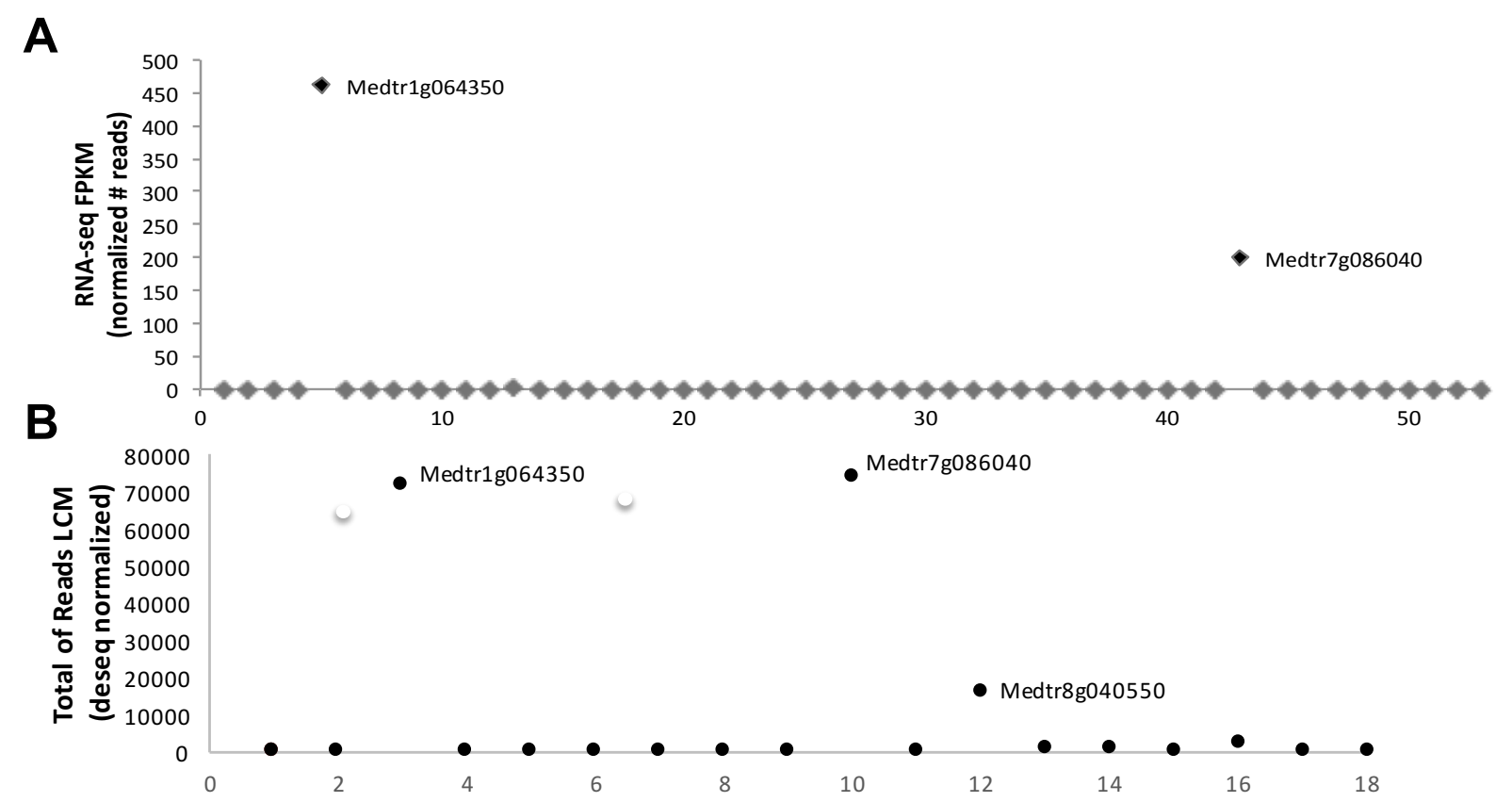

Figure 5. Expression profile of GRF-type zinc finger family members (IPR010666) in nodules of Medicago truncatula. (A) RNA-seq data was retrieved from Young et al. (2011). (B) Data retrieved from LCM-RNA-Seq root nodule (Roux et al., 2014).

Crossing the M. truncatula TFs and TRs, from Table 1, with LCM-RNA-Seq of nodule section from (Roux et al., 2014) we can identify all TFs and TRs that are expressed in nodules of M. truncatula. Roux et al., (2014) present 36495 genes, in which 2996 genes match with genes in the M. truncatula TFs and TRs list, from which 1955 and 2930 present expression more than 100 and 0 respectively. The majority of them, 2757 genes, are unknown and 239 genes present annotation name. Very interestingly the MtN20 was the fifth position of the most TFs and TRs expressed in nodules of $M$. truncatula, followed by Medtr1g064350.1 (another GRF-type Zinc Finger) (Supplemental material table 1S).

The phylogenetic tree with only M. truncatula members present a high similar protein with N20 that is also encoded by a nodule specific gene with high and distinct expression from MtN2O (Figure 3B). This same (Figure 3B) give us another very interesting idea, that those genes are the unique genes of the GRF-type zinc finger family that are been high expressed and they are seems to be nodules specific, with distinct expression pattern. This second gene (Medtr1g064350.1) of the GRF-type zinc finger is the second gene of interest on our research, called MtGRF2.

The Medicago Gene Expression Atlas (Benedito et al., 2008) shows MtGRF2/Medtr1g064350 (probeset Mtr.37013.1.S1_at) with an expression onset at around 6 days post-inoculation (dpi), and the strongest level in the adjacencies of zone 2 of nodule samples (Figure 6). 


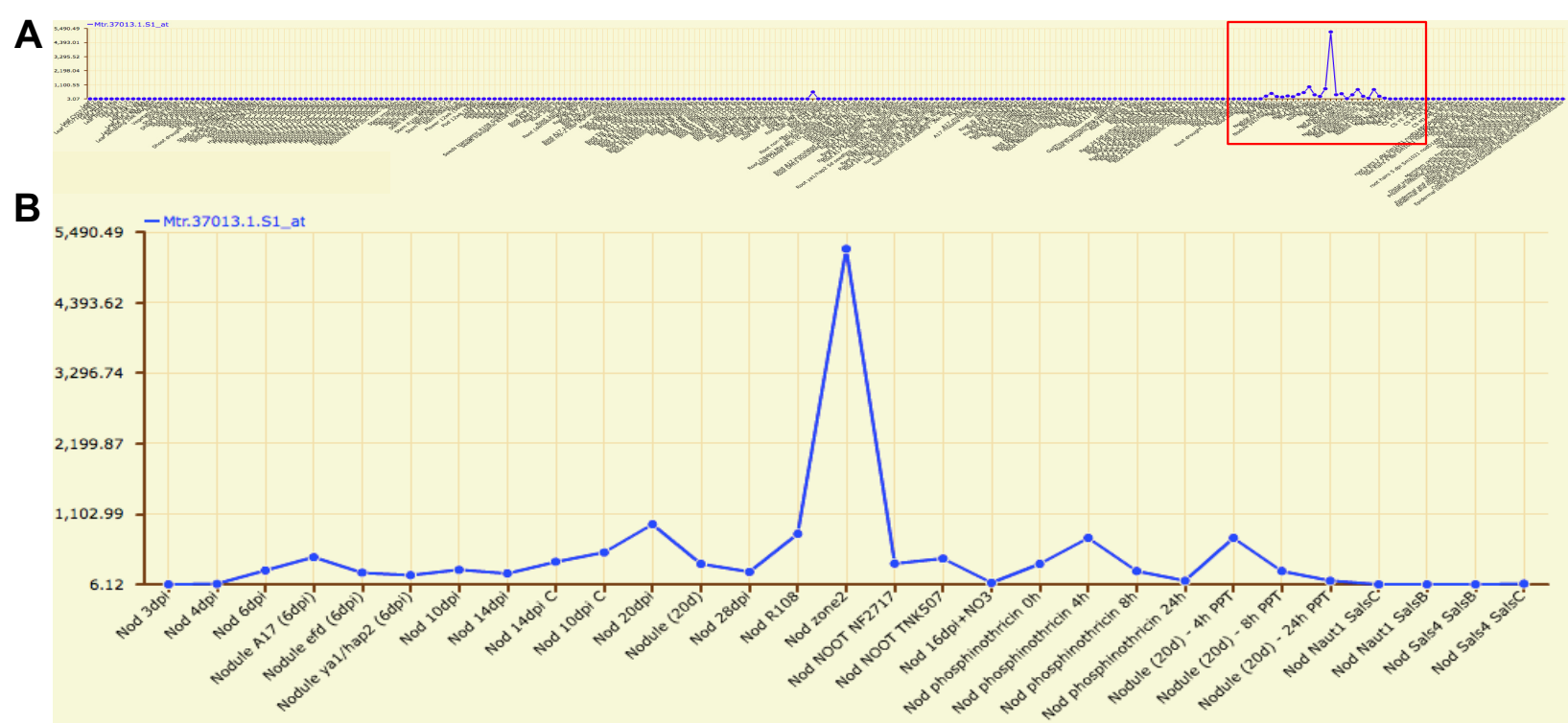

Figure 6. Affymetrix expression profile of $M t G R F 2$ (gene locus Medtr1g064350; probeset Mtr.37013.1.S1_at) in the Medicago truncatula Gene Expression Atlas (http://mtgea.noble.org/v3; Benedito et al., 2008). (A) Expression across all Affymetrix samples. (B) Expression in nodule samples as indicated in $\mathbf{A}$.

Since those genes of interest present differential expression we retrieve the data of Medicago root nodule LCM RNA-Seq to take it closed (Roux et al., 2014) (Table 3).

Table 3. Gene expression of the GRF-type zinc finger nodulins Medtr7g086040 and Medt1g064350 in nodule zones by RNA-Seq of laser capture microdissection (LCM) samples (Roux et al., 2014). Distribution of expression in percentage of total reads in all samples of the nodule are shown in parentheses.

\begin{tabular}{crr}
\hline SAMPLES & $\begin{array}{r}\text { Medtr7g086040 } \\
(M t N 20 / M t G R F 1)\end{array}$ & $\begin{array}{r}\text { Medtr1g064350 } \\
(M t G R F 2)\end{array}$ \\
\hline FI & $752690(10.2 \%)$ & $3988(00.1 \%)$ \\
FIID & $4662776(63.0 \%)$ & $83201(01.2 \%)$ \\
FIIP & $1967835(26.6 \%)$ & $828990(11.6 \%)$ \\
IZ & $19999(00.3 \%)$ & $4618594(64.8 \%)$ \\
ZIII & $3506(00.0 \%)$ & $1594961(22.4 \%)$ \\
\hline
\end{tabular}

The concistency of both Affymetrix (Figure 2 and 6) and LCM RNA-Seq of Medicago data (Table 3), give the level of gene expression indicates that both genes seems to play important functions in different stages of root nodulation in M. truncatula.

Taken all transcriptome data, two putative novel zinc-finger transcription factors highlight our curiosity through their nodule specificity and intensity of expression (Figure 2, 3, 5 and 6, Table 3). In these studies, both genes are emphasized as novel genes specific to nodules, potentially involved with transcriptional regulation. Having this knowledge it is important now to elucidate the TFs related with each biological activity, such as metabolism, development and function. We hypothesize their importance as 
putative TFs for normal nodulation and symbiosis nitrogen fixation linked with the predicted biological process in which they should be involved.

\section{METHODS}

Identification of GRF-type Zinc Finger proteins: For each species of interest we download the update latest version of their proteomes and we run them in PlantTFDB to identify what domains each protein owns, then we selected all genes with identify protein domain IPR010666, which is cataloged as GRF-type Zinc Finger. In which Arabidopsis thaliana, (Athaliana_167_TAIR10.protein), Lotus japonicus (Lj3.0_pep), Medicago truncatula (Mt4.0v2_GenesProteinSeq_20140818_1100-1), Phaseolus vulgaris (Pvulgaris_442_v2.1.protein-7 MB-PDT 2017) and Glycine max (Gmax_275_Wm82.a2.v1.protein).

RNA-Seq data analysis: The SRAs data were analyzed in the Galaxy platform. The fastq-dump tool were used to upload the SRAs files into Galaxy (Leinonen et al., 2011). The quality of read reports were processed using the FastQC tool (Andrews, S.. FastQC A Quality Control tool for High Throughput Sequence Data.). And the expression data were denerated in Transcription per Million (TPM) using Salmon (Patro et al., 2015). In which the reference transcriptome used was the last version of M. truncatula (Mt4.0v2), kmerLen size $=31$, single- or paired-end depending of each SRA source, quasi type of index, also no sequence biase correction were applied.

Phylogenetic analyses: The evolutionary history was inferred by using the Maximum Likelihood method based on the JTT matrix-based model (Jones et al., 1992). The tree with the highest log likelihood () is shown. The percentage of trees in which the associated taxa clustered together is shown next to the branches. Initial tree(s) for the heuristic search were obtained automatically by applying the Maximum Parsimony method. A discrete Gamma distribution was used to model evolutionary rate differences among sites (categories $(+\mathrm{G}$, parameter $=)$ ). The rate variation model allowed for some sites to be evolutionarily invariable $([+\mathrm{I}], \%$ sites $)$. The tree is drawn to scale, with branch lengths measured in the number of substitutions per site. The analysis involved 92 amino acid sequences. All positions containing gaps and missing data were eliminated. There were a total of 23 positions in the final dataset. Evolutionary analyses were conducted in MEGA7 (Kumar et al., 2016).

\section{REFERENCES}

Andriankaja A, Boisson-Dernier A, Frances L, Sauviac L, Jauneau A, Barker DG, de CarvalhoNiebel F (2007) AP2-ERF transcription factors mediate nod factor dependent MtENOD11 activation in root hairs via a novel cis-regulatory motif. Plant Cell 19: 2866-2885

Ané J-M, Kiss GB, Riely BK, Penmetsa RV, Oldroyd GED, Ayax C, Lévy J, Debellé F, Baek J-M, Kalo P, et al (2004) Medicago truncatula DMII required for bacterial and fungal symbioses in 
legumes. Science 303: 1364-7

Arrighi J-F, Godfroy O, de Billy F, Saurat O, Jauneau A, Gough C (2008) The RPG gene of Medicago truncatula controls Rhizobium-directed polar growth during infection. Proc Natl Acad Sci 105: $9817-9822$

Bar M, Ori N (2015) Compound leaf development in model plant species. Curr Opin Plant Biol 23: 6169

Benedito V a, Torres-Jerez I, Murray JD, Andriankaja A, Allen S, Kakar K, Wandrey M, Verdier J, Zuber H, Ott T, et al (2008) A gene expression atlas of the model legume Medicago truncatula. Plant J 55: 504-513

Bensmihen S (2015) Hormonal control of lateral root and nodule development in legumes. Plants 4: 523547

Brown RS (2005) Zinc finger proteins: getting a grip on RNA. Curr Opin Struct Biol 15: 94-98

Cerri MR, Frances L, Laloum T, Auriac M-C, Niebel a., Oldroyd GED, Barker DG, Fournier J, de Carvalho-Niebel F (2012) Medicago truncatula ERN transcription factors: regulatory interplay with NSP1/NSP2 GRAS factors and expression dynamics throughout rhizobial infection. Plant Physiol 160: 2155-2172

Chen D-S, Liu C-W, Roy S, Cousins D, Stacey N, Murray JD (2015) Identification of a core set of rhizobial infection genes using data from single cell-types. Front Plant Sci 6: 575

Choi D, Jeong HK, Kende H (2004) Whole genome analysis of the $O s G R F$ gene family encoding plantspecific putative transcription activators in rice (Oryza sativa L.). Plant Cell Physiol 45: 897-904

Combier J-P, Frugier F, de Billy F, Boualem A, El-Yahyaoui F, Moreau S, Vernie T, Ott T, Gamas P, Crespi M, et al (2006) MtHAP2-1 is a key transcriptional regulator of symbiotic nodule development regulated by microRNA169 in Medicago truncatula. Genes Dev 20: 3084-3088

Combier JP, de Billy F, Gamas P, Niebel A, Rivas S (2008) Trans-regulation of the expression of the transcription factor MtHAP2-1 by a uORF controls root nodule development. Genes Dev 22: 15491559

Crespi M, Gálvez S (2000) Molecular mechanisms in root nodule development. J Plant Growth Regul 19: $155-166$

D'Haeseleer K, De Keyser A, Goormachtig S, Holsters M (2010) Transcription factor MtATB2: About nodulation, sucrose and senescence. Plant Cell Physiol 51: 1416-1424

Dai X, Sinharoy S, Udvardi M, Zhao PX (2013) PlantTFcat: an online plant transcription factor and transcriptional regulator categorization and analysis tool. BMC Bioinformatics 14: 321

Endre G, Kereszt A, Kevei Z, Mihacea S, Kaló P, Kiss GB (2002) A receptor kinase gene regulating symbiotic nodule development. Nature 417: 962-966

Espinosa JM, Portal D, Lobo GS, Pereira CA, Alonso GD, Gómez EB, Lan GH, Pomar RVR, Flawiá MM, Torres HN (2003) Trypanosoma cruzi poly-zinc finger protein: A novel DNA/RNAbinding CCHC-zinc finger protein. Mol Biochem Parasitol 131: 35-44

Gamsjaeger R, Liew CK, Loughlin FE, Crossley M, Mackay JP (2007) Sticky fingers: zinc-fingers as protein-recognition motifs. Trends Biochem Sci 32: 63-70

Geurts R, Xiao TT, Reinhold-Hurek B (2016) What does it take to evolve a nitrogen-fixing endosymbiosis? Trends Plant Sci 21: 199-208

Di Giacomo E, Iannelli M, Frugis G (2013) TALE and shape: how to make a leaf different. Plants 2: 
$317-342$

Di Giacomo E, Laffont C, Sciarra F, Iannelli MA, Frugier F, Frugis G (2016) KNAT3/4/5-like class 2 KNOX transcription factors are involved in Medicago truncatula symbiotic nodule organ development. New Phytol. doi: 10.1111/nph.14146

He J, Benedito VA, Wang M, Murray JD, Zhao PX, Tang Y, Udvardi MK (2009) The Medicago truncatula gene expression atlas web server. BMC Bioinformatics 10: 441

Heckmann AB, Lombardo F, Miwa H, Perry JA, Bunnewell S, Parniske M, Wang TL, Downie JA (2006) Lotus japonicus nodulation requires two GRAS domain regulators, one of which is functionally conserved in a non-legume. Plant Physiol 142: 1739-50

Hirsch S, Kim J, Munoz A, Heckmann AB, Downie JA, Oldroyd GED (2009) GRAS proteins form a DNA binding complex to induce gene expression during nodulation signaling in Medicago truncatula. Plant Cell 21: 545-557

Hogg B V, Cullimore J V, Ranjeva R, Bono J (2006) The DMI1 and DMI2 early symbiotic genes of Medicago truncatula are required for a high-affinity nodulation factor-binding site associated to a particulate fraction of roots 1. 140: 365-373

Imaizumi-Anraku H, Takeda N, Charpentier M, Perry J, Miwa H, Umehara Y, Kouchi H, Murakami Y, Mulder L, Vickers K, et al (2005) Plastid proteins crucial for symbiotic fungal and bacterial entry into plant roots. Nature 433: $527-531$

Jin J, Tian F, Yang D, Meng Y, Kong L, Luo J, Gao G (2017) PlantTFDB 4.0: toward a central hub for transcription factors and regulatory interactions in plants. 45: 1040-1045

Jones DT, Taylor WR, Thornton JM (1992) The rapid generation of mutation data matrices from protein sequences. Comput Appl Biosci 8: 275-82

Kalo P (2005) Nodulation signaling in legumes requires NSP2, a member of the GRAS family of transcriptional regulators. Science 308: 1786-1789

Kim JH, Choi D, Kende H (2003) The AtGRF family of putative transcription factors is involved in leaf and cotyledon growth in Arabidopsis. Plant J 36: 94-104

Klug A (1999) Zinc finger peptides for the regulation of gene expression. J Mol Biol 293: 215-218

Kumar S, Stecher G, Tamura K (2016) MEGA7: Molecular evolutionary genetics analysis version 7.0 for bigger datasets. Mol Biol Evol 33: 1870-1874

Laity JH, Lee BM, Wright PE (2001) Zinc finger proteins: new insights into structural and functional diversity. Curr Opin Struct Biol 11: 39-46

Laloum T, Baudin M, Frances L, Lepage A, Billault-Penneteau B, Cerri MR, Ariel F, Jardinaud M-F, Gamas P, de Carvalho-Niebel F, et al (2014) Two CCAAT-box-binding transcription factors redundantly regulate early steps of the legume-rhizobia endosymbiosis. Plant J 79: 757-768

Lauressergues D, Delaux PM, Formey D, Lelandais-Brière C, Fort S, Cottaz S, Bécard G, Niebel A, Roux C, Combier, J. P. (2012). The microRNA miR171h modulates arbuscular mycorrhizal colonization of Medicago truncatula by targeting NSP2. The Plant Journal, 72(3): 512-522.

Leinonen R, Sugawara H, Shumway M (2011) The sequence read archive. 39: 2010-2012

Lévy J, Bres C, Geurts R, Chalhoub B, Kulikova O, Duc G, Journet E-P, Ané J-M, Lauber E, Bisseling $\mathbf{T}$, et al (2004) A putative $\mathrm{Ca}_{2}{ }^{+}$and calmodulin- dependent protein kinase required. Science 303: $1361-4$

Libault M, Joshi T, Benedito V a, Xu D, Udvardi MK, Stacey G (2009) Legume transcription factor 
genes: what makes legumes so special? Plant Physiol 151: 991-1001

Limpens E (2003) LysM domain receptor kinases regulating rhizobial Nod factor-induced infection. Science 302: 630-633

Limpens E, Bisseling T (2003) Signaling in symbiosis. Curr Opin Plant Biol 6: 343-350

Limpens E, Mirabella R, Fedorova E, Franken C, Franssen H, Bisseling T, Geurts R (2005) Formation of organelle-like $\mathrm{N}_{2}$-fixing symbiosomes in legume root nodules is controlled by DMI2. Proc Natl Acad Sci U S A 102: 10375-80

Limpens E, Moling S, Hooiveld G, Pereira P a, Bisseling T, Becker JD, Küster H (2013) Cell- and tissue-specific transcriptome analyses of Medicago truncatula root nodules. PLoS One 8: e64377

Lipka V, Kwon C, Panstruga R (2007) SNARE-Ware: The role of SNARE-domain proteins in plant biology. Annu Rev Cell Dev Biol 23: 147-174

Liu C-W, Murray J (2016) The role of flavonoids in nodulation host-range specificity: an update. Plants 5: 33

Madsen EB, Madsen LH, Radutoiu S, Olbryt M, Rakwalska M, Szczyglowski K, Sato S, Kaneko T, Tabata S, Sandal N, et al (2003) A receptor kinase gene of the LysM type is involved in legumeperception of rhizobial signals. Nature 425: 637-640

Marsh JF, Rakocevic A, Mitra RM, Brocard L, Sun J, Eschstruth A, Long SR, Schultze M, Ratet P, Oldroyd GED (2007) Medicago truncatula NIN is essential for rhizobial-independent nodule organogenesis induced by autoactive calcium/calmodulin-dependent protein kinase. Plant Physiol 144: $324-335$

Matthews JM, Sunde M (2002) Zinc fingers-folds for many occasions. IUBMB Life (International Union Biochem Mol Biol Life) 54: 351-355

Messinese E, Mun JH, Yeun LH, Jayaraman D, Rouge P, Barre A, Lougnon G, Schornack S, Bono JJ, Cook DR, et al (2007) A novel nuclear protein interacts with the symbiotic DMI3 calcium- and calmodulin-dependent protein kinase of Medicago truncatula. Mol Plant-Microbe Interact 20: 912 921

Michelsen JW, Schmeichel KL, Beckerle MC, Winge DR (1993) The LIM motif defines a specific zinc-binding protein domain. Proc Natl Acad Sci U S A 90: 4404-4408

Middleton PH, Jakab J, Penmetsa RV, Starker CG, Doll J, Kalo P, Prabhu R, Marsh JF, Mitra RM, Kereszt A, et al (2007) An ERF transcription factor in Medicago truncatula that is essential for nod factor signal transduction. Plant Cell 19: 1221-1234

Mitchell A, Chang H-Y, Daugherty L, Fraser M, Hunter S, Lopez R, McAnulla C, McMenamin C, Nuka G, Pesseat S, et al (2015) The InterPro protein families database: the classification resource after 15 years. Nucleic Acids Res 43: D213-D221

Mitra RM, Gleason CA, Edwards A, Hadfield J, Downie JA, Oldroyd GED, Long SR (2004) From The Cover: $\mathrm{A} \mathrm{Ca}_{2}{ }^{+} /$calmodulin-dependent protein kinase required for symbiotic nodule development: Gene identification by transcript-based cloning. Proc Natl Acad Sci 101: 4701-4705

Moreau S, Verdenaud M, Ott T, Letort S, de Billy F, Niebel A, Gouzy J, de Carvalho-Niebel F, Gamas P (2011) Transcription reprogramming during root nodule development in Medicago truncatula. PLoS One 6: e16463

Oldroyd G (2001) Dissecting symbiosis: developments in Nod factor signal transduction. Ann Bot 87: $709-718$

Oldroyd GED (2013) Speak, friend, and enter: signalling systems that promote beneficial symbiotic 
associations in plants. Nat Rev Microbiol 11: 252-263

Oldroyd GED, Downie JA (2008) Coordinating nodule morphogenesis with rhizobial infection in legumes. Annu Rev Plant Biol 59: 519-546

Oldroyd GED, Murray JD, Poole PS, Downie JA (2011) The rules of engagement in the legumerhizobial symbiosis. Annu Rev Genet 45: 119-144

Patro R, Duggal G, Love MI, Irizarry RA, Kingsford C (2017) Salmon provides fast and bias-aware quantification of transcript expression. Nature Methods 14, 417-419

Peiter E, Sun J, Heckmann AB, Venkateshwaran M, Riely BK, Otegui MS, Edwards A, Freshour G, Hahn MG, Cook DR, et al (2007) The Medicago truncatula DMI1 protein modulates cytosolic calcium signaling. Plant Physiol 145: 192-203

Penmetsa R V, Frugoli JA, Smith LS, Long SR, Cook DR (2003) Dual genetic pathways controlling nodule number in Medicago truncatula. Plant Physiol 131: 998-1008

Peters N, Frost J, Long S (1986) A plant flavone, luteolin, induces expression of Rhizobium meliloti nodulation genes. Science 233: 977-980

Ramalingam A, Kudapa H, Pazhamala LT, Weckwerth W, Varshney RK (2015) Proteomics and metabolomics: two emerging areas for legume improvement. Front Plant Sci 6: 1-21

Razin S V., Borunova V V., Maksimenko OG, Kantidze OL (2012) Cys2His2 zinc finger protein family: Classification, functions, and major members. Biochem 77: 217-226

Riely BK, Lougnon G, Ané JM, Cook DR (2007) The symbiotic ion channel homolog DMI1 is localized in the nuclear membrane of Medicago truncatula roots. Plant J 49: 208-216

Rival P, de Billy F, Bono J-J, Gough C, Rosenberg C, Bensmihen S (2012) Epidermal and cortical roles of NFP and DMI3 in coordinating early steps of nodulation in Medicago truncatula. Development 139: 3383-3391

Roux B, Rodde N, Jardinaud M-F, Timmers T, Sauviac L, Cottret L, Carrère S, Sallet E, Courcelle E, Moreau S, et al (2014) An integrated analysis of plant and bacterial gene expression in symbiotic root nodules using laser-capture microdissection coupled to RNA sequencing. Plant J 77: $817-837$

Schnabel E, Journet E-P, de Carvalho-Niebel F, Duc G, Frugoli J (2005) The Medicago truncatula $S U N N$ gene encodes a $C L V 1$-like leucine-rich repeat receptor kinase that regulates nodule number and root length. Plant Mol Biol 58: 809-22

Sinharoy S, Torres-Jerez I, Bandyopadhyay K, Kereszt A, Pislariu CI, Nakashima J, Benedito VA, Kondorosi E, Udvardi MK (2013) The $\mathrm{C}_{2} \mathrm{H}_{2}$ transcription factor REGULATOR OF SYMBIOSOME DIFFERENTIATION represses transcription of the secretory pathway gene VAMP721a and promotes symbiosome development in Medicago truncatula. Plant Cell 25: 35843601

Smit P (2005) NSP1 of the GRAS protein family is essential for rhizobial Nod factor-induced transcription. Science 308: 1789-1791

Smit P, Limpens E, Geurts R, Fedorova E, Dolgikh E, Gough C, Bisseling T (2007) Medicago LYK3 , an entry receptor in rhizobial. 145: 183-191

Soyano T, Hayashi M (2014) Transcriptional networks leading to symbiotic nodule organogenesis. Curr Opin Plant Biol 20: 146-154

Stracke S, Kistner C, Yoshida S, Mulder L, Sato S, Kaneko T, Tabata S, Sandal N, Stougaard J, 
Szczyglowski K, et al (2002) A plant receptor-like kinase required for both bacterial and fungal symbiosis. Nature 417: 959-962

Timmers AC, Auriac MC, Truchet G (1999) Refined analysis of early symbiotic steps of the Rhizobium-Medicago interaction in relationship with microtubular cytoskeleton rearrangements. Development 126: $3617-3628$

Tirichine L, Imaizumi-Anraku H, Yoshida S, Murakami Y, Madsen LH, Miwa H, Nakagawa T, Sandal N, Albrektsen AS, Kawaguchi M, et al (2006) Deregulation of a $\mathrm{Ca}_{2}{ }^{+} /$calmodulindependent kinase leads to spontaneous nodule development. Nature 441: 1153-6

Udvardi MK, Kakar K, Wandrey M, Montanari O, Murray J, Andriankaja A, Zhang J-Y, Benedito V, Hofer JMI, Chueng F, et al (2007) Legume transcription factors: Global regulators of plant development and response to the environment. Plant Physiol 144: 538-549

Van de Velde W (2006) Aging in Legume Symbiosis. A molecular view on nodule senescence in Medicago truncatula. Plant Physiol 141: 711-720

Vernié T, Kim J, Frances L, Ding Y, Sun J, Guan D, Niebel A, Gifford ML, de Carvalho-Niebel F, Oldroyd GED (2015) The NIN transcription factor coordinates diverse nodulation programs in different tissues of the Medicago truncatula root. Plant Cell 27: 3410-3424

Vernie T, Moreau S, de Billy F, Plet J, Combier J-P, Rogers C, Oldroyd G, Frugier F, Niebel A, Gamas P (2008) EFD is an ERF transcription factor involved in the control of nodule number and differentiation in Medicago truncatula. Plant Cell 20: 2696-2713

Wang Q, Yang S, Liu J, Terecskei K, Ábrahám E, Gombár A, Domonkos Á, Szúcs A, Körmöczi P, Wang T, et al (2017) Host-secreted antimicrobial peptide enforces symbiotic selectivity in Medicago truncatula. Proc Natl Acad Sci 114: 201700715

Whitehead CM, Winkfein RJ, Fritzler MJ, Rattner JB (1997) ASE-1: a novel protein of the fibrillar centres of the nucleolus and nucleolus organizer region of mitotic chromosomes. Chromosoma 106: 493

Yang S, Wang Q, Fedorova E, Liu J, Qin Q, Zheng Q, Price PA, Pan H, Wang D, Griffitts JS, et al (2017) Microsymbiont discrimination mediated by a host-secreted peptide in Medicago truncatula. Proc Natl Acad Sci 114: 201700460

Yano K, Yoshida S, Muller J, Singh S, Banba M, Vickers K, Markmann K, White C, Schuller B, Sato S, et al (2008) CYCLOPS, a mediator of symbiotic intracellular accommodation. Proc Natl Acad Sci 105: 20540-20545

Young ND, Debellé F, Oldroyd GED, Geurts R, Cannon SB, Udvardi MK, Benedito V a, Mayer KFX, Gouzy J, Schoof H, et al (2011) The Medicago genome provides insight into the evolution of rhizobial symbioses. Nature 480: $520-4$

Zipfel C, Oldroyd GED (2017) Plant signalling in symbiosis and immunity. Nature 543: 328-336 
CHAPTER 3 


\title{
MTN20 IS AN ESSENTIAL GRF-TYPE ZINC FINGER NODULIN FROM MEDICAGO \\ TRUNCATULA INVOLVED IN THE FIRST STAGE OF BACTEROID DIFFERENTIATION
}

\begin{abstract}
Legume root nodule proteins, called nodulins, have been explored in different ways in other to understand root nodulation, symbiosis nitrogen fixation and evolution of this relationship. Some nodulins have been functionally characterized and allocated in which the mechanism is involved, but many of them remain intangible regarding their molecular function. In this study, we aimed at studying the role of nodulin 20 (MtN20) during nodule development and symbiotic nitrogen fixation (SNF) in Medicago truncatula. This protein, MtGRF1/MtN20, has been predicted as a putative transcription factor highly and specifically expressed in root nodules 4 days post inoculation with Rhizobium, which refer to the zone II of indeterminate Medicago truncatula nodules. Also, this protein belongs to a largely uncharacterized family of putative transcription factors. We hypothesize that $\mathrm{MtN} 20$ is a transcription factor playing an essential role during nodule development by controlling expression of key symbiotic genes in early stages of bacterial infection of root nodules cells. Our findings demonstrate that MtN20 requires bacterial infection, but not bacteroid differentiation to express. We can conclude that MtN20/MtGRF1 is a novel gene potentially involved during early events of rhizobial infection of nodule cells. MtN20 belongs to a regulatory gene network participating with bona fide symbiotic genes, such as EFD, the EFD target Nod19, NIN and several nodule-specific cysteine-rich (NCR) peptides. A gene expression analysis using mutant bacteria defective to specific symbiotic milestones can be used to help further elucidate which process must occur before a nodulin is triggered to express.
\end{abstract}




\section{MTN20 IS AN ESSENTIAL GRF-TYPE ZINC FINGER NODULIN FROM MEDICAGO \\ TRUNCATULA INVOLVED IN THE FIRST STAGE OF BACTEROID DIFFERENTIATION}

\section{INTRODUCTION}

Nodulins encompass a large and diverse class of legume proteins defined by their nodule-specific expression pattern. These are a significant group of legume proteins that evidently evolved to express in an organ that is characteristic of this botanical group, with potential roles in nodule development and symbiotic nitrogen fixation (SNF). Nodulins were first identified in soybean nodules by 2D-gel analysis and described as proteins potentially involved in the development of the Rhizobium-legume symbiosis (Legocki and Verma, 1980). They were named according to their approximate weight on gel proteins, in kiloDaltons $(17 \mathrm{kDa})$ and classified according to the onset of gene expression during nodule development (Gamas et al., 1996). Interestingly, non-legume nodulins are proteins that which families were first characterized with specific expression in legume nodules and then found to exist in non-legume species. A review on dicot and monocot non-legume nodulins was published previously (Denance et al., 2014).

In Medicago truncatula, nodulins were first described by Gamas et al. (1996), which 29 novel distinct families of nodulins were identified by Northern blot and classified into three groups based on their expression during nodule development, of root, 24 and 48 hours post inoculation and 4 and 14 days post inoculation (dpi). Later, among the 50,900 M. truncatula probesets represented on the Affymetrix microchip, Mtr.14503.1.S1_at was identified as nodule-specific transcripts ((http://mtgea.noble.org/v3/; Figure 1) (Benedito et al., 2008; He et al., 2009),). Using a transcriptomic approach based on RNA-Seq, MtN20/MtGRF1 (Medtr7g086040) gene was identified as specifically expressed in nodules (Young et al., 2011; Roux et al., 2014), therefore being nodulins by definition.

While some nodulins have been functionally characterized, such as leghemoglobins (Appleby, 1984; Andersson et al., 1996). The large majority remain elusive regarding their molecular roles. In this study, we aimed at studying the role of nodulin 20 (MtN20) during nodule development and SNF in $M$. truncatula. Given the high and specific gene expression profile of MtGRF1/MtN20 in the nodule and its conserved domain, we hypothesize that $\mathrm{MtN} 20$ is a transcription factor playing an essential role during nodule development by controlling gene expression of key symbiotic genes. 


\section{RESULTS AND DISCUSSION}

\section{Nodulin 20 (MtGRF1) is an elusive protein recurrently identified in early transcriptomic}

studies

In M. truncatula, nodulin 20 (MtN20) was classified Gamas et al. (1996) as a group 1 nodulin, with expression starting at 4 days post-inoculation based on hybridization signal. Györgyey et al. (2000) identified MtN20 using an expression sequence tag (EST) sequencing approach (clone 74), even though it presented a relatively low expression level. The genome sequencing and annotation of $M$. truncatula (Young et al, 2011) and transcriptomic studies allowed to identify MtN20 as encoded by the locus Medtr7g086040, which belongs to a largely unexplored family of putative transcription factors (GRF-type zinc finger, IPR010666). Therefore, we renamed MtN20 as the founder member of this protein family (MtN20). It is important to underscore that, given the nodulin name designation via protein mass on gel electrophoresis, other N20 potentially identified in other legume species may be completely unrelated to MtN20.

The Medicago gene expression atlas (Benedito et al., 2008) shows that MtN20 was down-regulated in 6-dpi ethylene response factor required for nodule differentiation (efd-1) mutant nodules (Figure 2 in Chapter 2) (Vernie et al., 2008). Furthermore, transcriptional analyses indicated MtN20 as a potential "Class A3" activator of nodule development (Moreau et al., 2011) due to its expression profile between the early steps of infection thread formation and EFD expression, which controls nodule numbers (Vernie et al., 2008). Both data highlight the notion that MtN20 is implicated in the mechanism of cell infection. The symbiotic ERF transcription factor MtEFD (ETHYLENE RESPONSE FACTOR REQUIRED FOR NODULE DIFFERENTIATION) was characterized as playing an important role controlling Sinorhizobium meliloti infection in nodule cells (Vernie et al., 2008).

$M t N 20$ has been recurrently identified as a nodulin in transcriptome studies. Notwithstanding, very little has been explored about its function in SNF. Using micro- and macroarrays, El Yahyaoui et al. (2004) identified 756 genes differentially expressed during nodule development. Among these, MtN20 appeared up-regulated at 4-dpi nodules against non-inoculated roots. Using a similar approach, Manthey et al. (2004) also identified MtN20 as differently expressed into nodules compared to non-inoculated root, but not in arbuscular mycorrhiza. Godiard et al. (2007) grouped MtN20 as an early nodulin from a study using suppression subtractive hybridization, along with other important early nodulins, such as MtENOD11, MtENOD12, MtENOD16, MtENOD20, MtENOD40, RIP1, MtANN1, and MtN1.

Fedorova et al. (2002) also identified MtN2O as a major nodulin significantly expressed in developing and mature nodules, but not in senescent nodules. The extensive Medicago transcriptome studies were published by Benedito et al. (2008), Young et al. (2011), and Roux et al. (2014) based on the 
Affymetrix Medicago GeneChip, and RNA-Seq of several whole, mature organs of the plant, and RNA-Seq of nodule laser capture microdissection (LCM) of mature nodule tissues, respectively. All three studies presented MtN2O expression data as highly and nodule-specifically expressed (Figure 2 in Chapter 2, Table 1).

\section{MtN20 is potentially a novel nuclear protein}

The GRF-type zinc finger proteins encompass a family (IPR010666) that although it is present in green algae, it has highly expanded in M. truncatula, compared even to other legumes, referred in the phylogenetic analysis Chapter 2. This protein family is defined by three, non-consecutive very conserved amino acids (Gly, Arg, Phe) in the center of the protein domain, along with additional zinc-finger domains. So far, no function has been attributed to any GRF protein in the scientific literature. Importantly, GRF proteins have been previously reported in plants, especially in Arabidopsis and rice (Kim et al., 2003). However, these proteins are named after the acronym Growth-Regulating Factor and encompass a nonrelated family (IPR031137). Therefore, we refer to the members of the MtGRF1/N20 family as GRF-type zinc finger proteins. Interestingly, among the 53 GRF-type zinc finger genes present in the M. truncatula genome, only two of them are expressed in nodules (Figure $\mathbf{2}$ in Chapter 2), and hardly anywhere else in the mature plant. The second member of this family (Medtr1g064350) is even more highly expressed in nodules. We named it MtGRF2 and explored its properties and potential function in Chapter 4. The phylogeny of this protein family is presented in Chapter $\mathbf{2}$ of this dissertation.

MtN20 codes for a 146-amino acid residue protein with a molecular weight of $17 \mathrm{kDa}$ and an isoelectric point of 7.59. Its small protein size $(<60 \mathrm{kDa}$ for diffusion through the nuclear pore) and isoelectric point (the pI value of the plant nucleoplasm is $\sim 7.2$ ) are compatible for nuclear import and activity (Wang and Brattain, 2007; Shen et al., 2013). Based on its deduced amino acid sequence, Fedorova et al. (2002) suggested that the nodulin 20 gene product is potentially a peroxisomal protein or localized in the mitochondrial matrix space. However, a nuclear localization signal (NLS) was predicted in the Cterminus of the protein. The M. truncatula proteome compendium (Marx et al., 2016) identified MtN20 as a protein highly and specifically expressed in nodules, and it also determined the existence of a phosphorylation site at S138, just before the estimated NLS in the C-terminus. Subcellular localization studies are still necessary to confirm GRF-type zinc fingers are directed to the nucleus of the cell (Figure 1).

\section{MTSRVSAAPTCDCEAKCVIFISRTKKNPDRPFFRCPYYGOIRKTHCDYFMWEDDFIASQAAMV ELQETTIERKMEAMIIQMNKDMKAMKIQINKDMEAKINELKRDTEYKFNILEREIEAMTFQISA DVVAFDIKHLSLGGLKGSK}

Figure 1. MtN20 protein sequence retrieved data from Medicago truncatula Proteome compendium on six major organs and three time-points of nodules development from (Marx et al., 2016). Showing one serine phosphorylated 
on position 138 (red tag), the protein domain red underline and nuclear localization signal (NLS) in green box (estimated via SBC-NucPred (Brameier et al., 2007))

In the M. truncatula Compendium proteome, MtN20/MtGRF1 was identified in 10, 14 and 28 dpi nodules of Medicago (Figure 2).

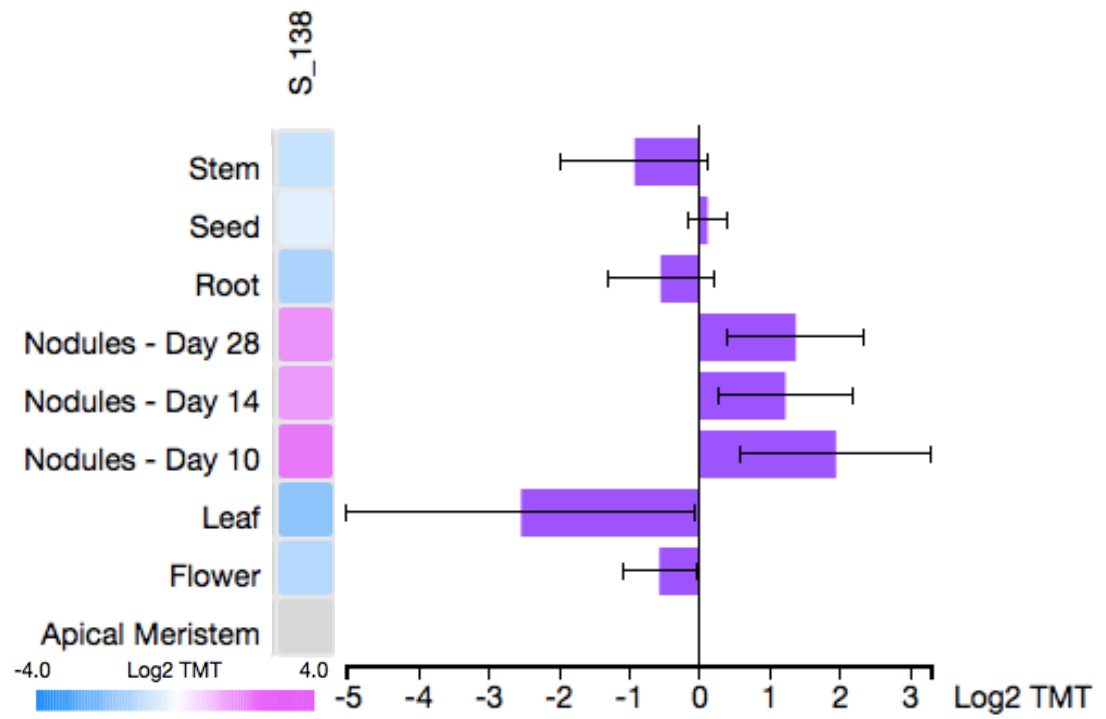

Figure 2. MtN20/MtGRF1 quantification retrieved from the Medicago truncatula Compendium proteome (Marx et al., 2016). MtN20 is present in nodules samples. The $\mathrm{x}$-axis is presented as $\log 2$ of TMT (relative protein abundance). In which positive values indicate more while negative values indicate less amount in of protein against the average of all samples. It is important to highlight that the quantification is based on protein fragments, peptides, which can be common between different proteins.

Tnt1 insertional mutant lines for MtN20/MtGRF1 were identified in the Noble Foundation collection and are illustrated in the gene structure presented below (Figure 3). A disadvantage of these mutants is that they can present more than one insertion in each line, which often generates confounding phenotypes. Therefore, a more reliable approach is to knock-out the gene using a gene editing method, such as the CRISPR-Cas9 system. We had tried to produce ex-vitro hairy root transformation knock-out via CRISPR-Cas9 using Agrobacterium rhizogenes, but we could not screen the transgenic roots, we had a problem with our selective fluorescence mark, DsRed. And then, we used antibiotic selective media with $25 \mathrm{mg} / \mathrm{L}$ of Kanamycin, and the plants did not produce healthy roots and plants to conduct the experiment.

A segregating population of MtN20 Tnt1 mutant lines, NF1858, NF2990, NF3070 and NF17000, had been used in this study, Tnt1-insertional position and direction are present in (Figure 3). In which we had identified homozygous plants for the insertion line NF1858 in the gene of interest.

Interestingly, although most commonly conserved domains are coded within the confines of an exon (Sibley et al., 2016), the GRF-type zinc finger domain of both genes of interest are split in different exons (Figures 3). 


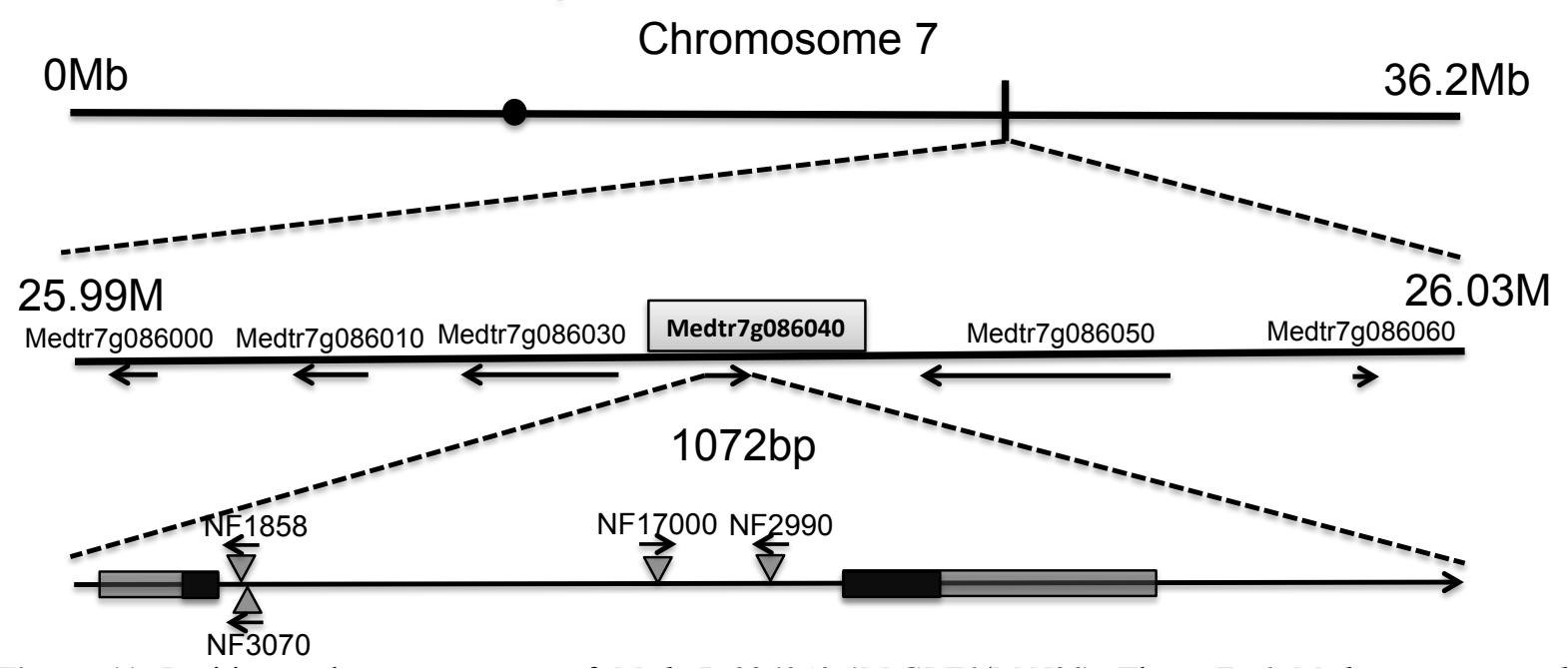

Figure 3. Position and gene structure of Medtr7g086040 (MtGRF1/MtN20) in Medicago truncatula chromosome 7. Four Tnt1 Medicago truncatula insertion lines (NF-1858, NF-2990, NF-3070 and NF17000) are represented with their respective positions and directions (arrows). The centromere is represented with a black circle on chromosome 7 . In the lower representation, exons are indicated by boxes, with the sequence coding for the GRF-type zinc finger domain (IPR010666) represented as black boxes. Introns and UTRs are represented as lines.

Five homozygous recessive plants from the NF1858 line were genotyped via PCR in which the dominant PCR generate an amplicon of 1508bp and recessive of 862bp (653bp-Tnt1+209bp-MtN20), the recessive PCR band was sequenced in order to verify the position and direction of the Tnt1 (Figure 4). 
A

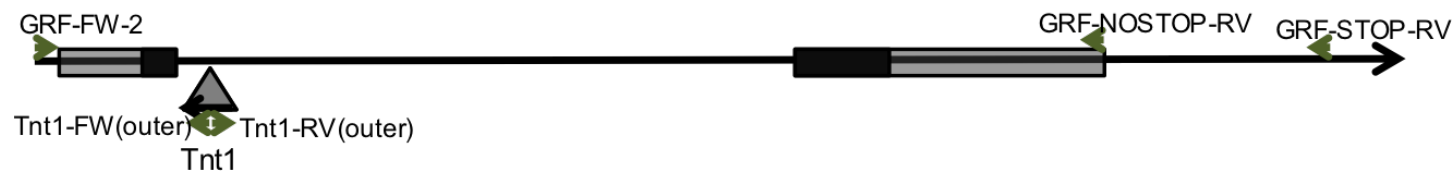

B Dominant PCR GRF-FW-2+GRFSTOP-RV $\left(59^{\circ} \mathrm{C}\right)$

Recessive PCR Tnt1-Fw-outer+GRF-FW-2 $\left(60^{\circ} \mathrm{C}\right)$

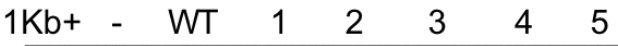
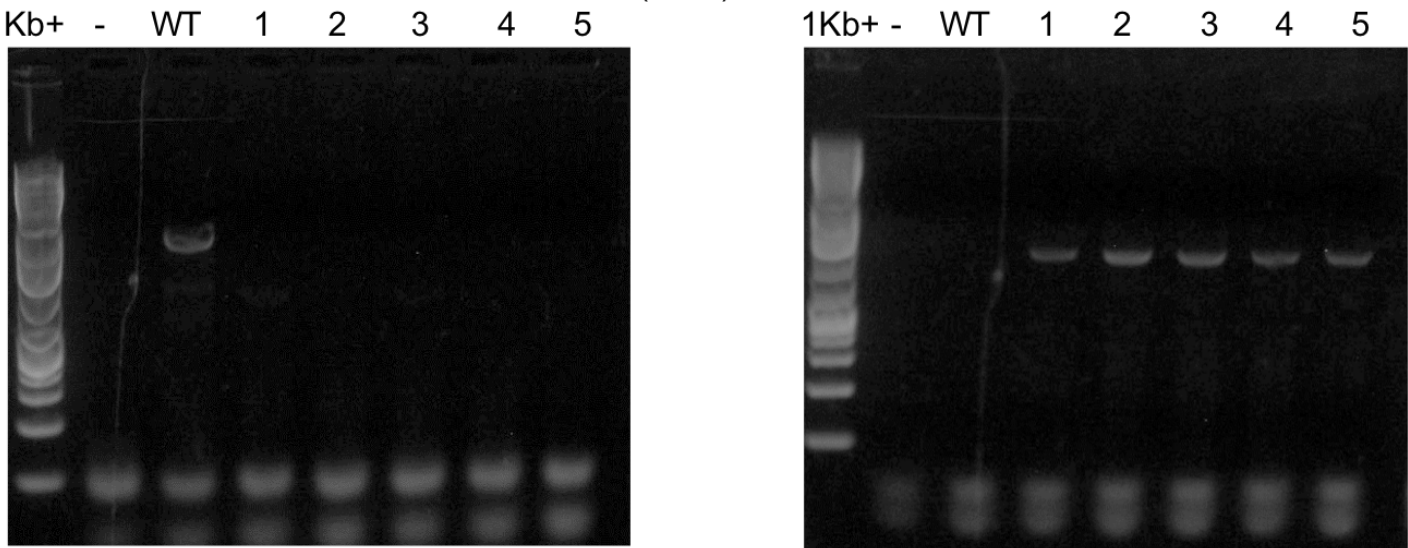

C

Tnt1- GCTTTATTACCGTGAATATTATTTTGGTAAGGGGTTTATTCCCAACA $-\cdots$ GCTTTATTACCGTGAATATTATTTTGGTAAGGGGTTTATTCCCAACAAG GGTAA GGTTCTTTGTATTAATTTACCTGACCAT

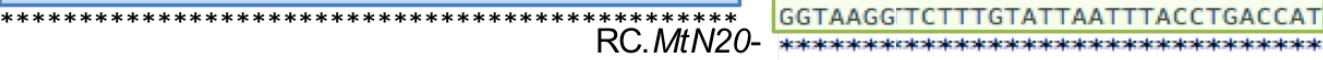

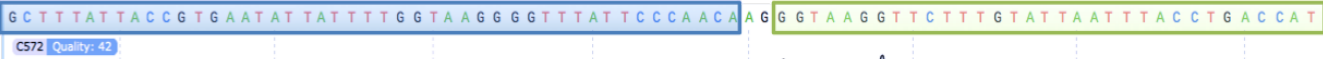

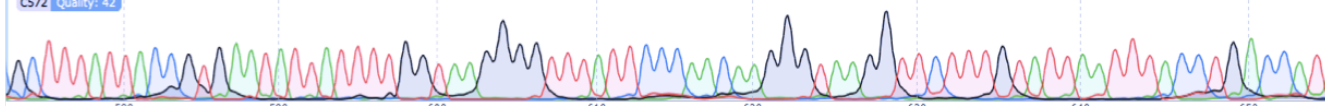

Figure 4. Genotyping of NF1858 Tnt1 line. A) MtGRF1/MtN20 gene architecture with primers in green arrows. B) Gel images of dominant and recessive PCR, in which the dominant and recessive PCR represent amplicons of 1953bp and $866 \mathrm{pb}$ respectively. C) PCR-direct sequence with alignment with Tnt1 (blue box) and MtGRF1/MtN20 (lightgreen box), in which $\mathrm{RC}$ is reverse complement, primers are represented in green.

MtN20 function may be essential for symbiotic nitrogen fixation but not for nodule development

Five Tnt1 insertional lines were identified in in the MtN20 (Tadege et al., 2008; Pislariu et al., 2012). However, all lines presented insertions in the intron between the only two exons (Figure 3). Notwithstanding, the line NF1858 developed normally shaped but smaller, white nodules (Figures 5 and 6A). Cell infection was defective, with a very narrow infection zone and numerous infection droplets unable to fully carry infection out (Figure 5). 

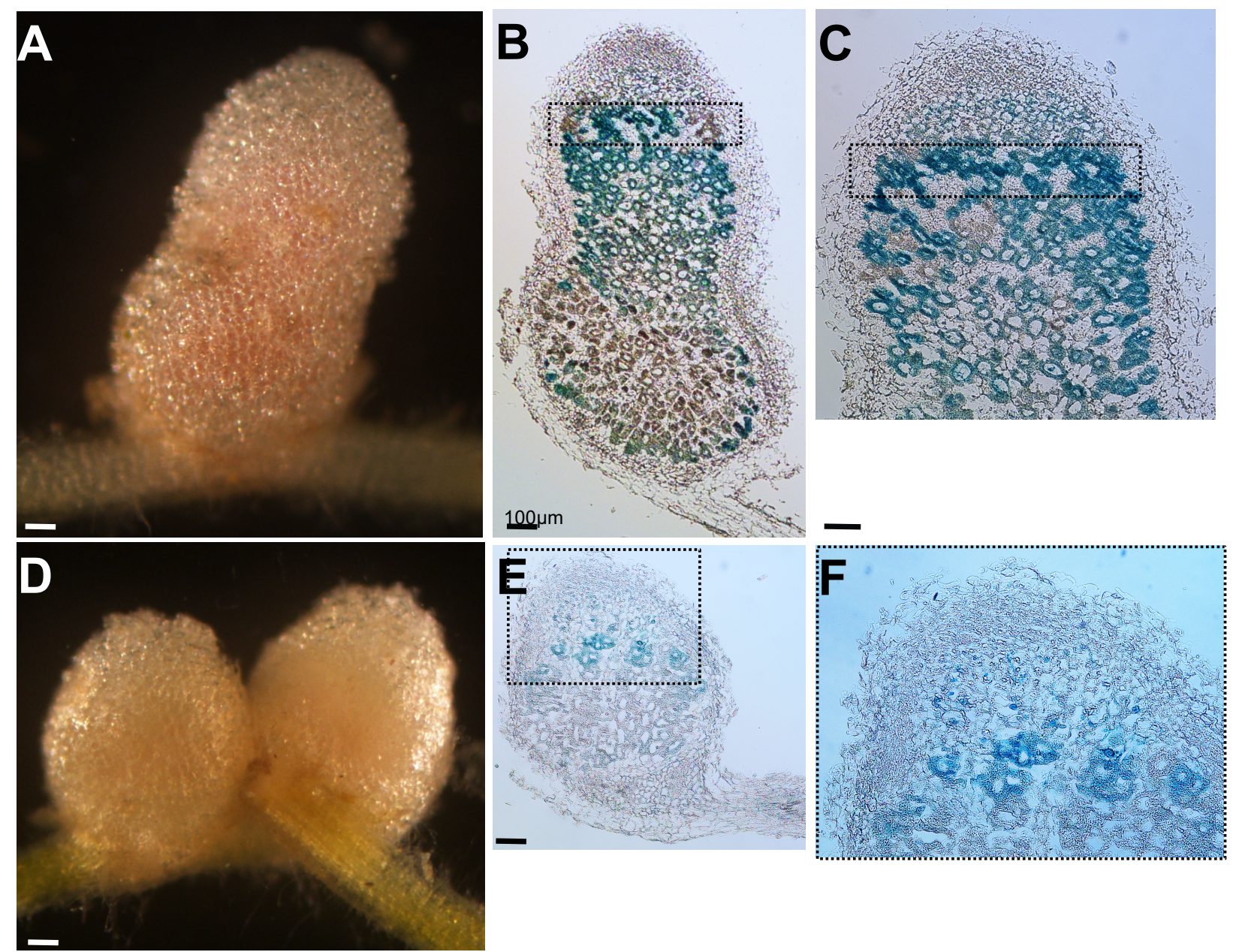

Figure 5. Phenotype of NF1858 Tnt1 insertion line of Medtr7g086040.1 (MtN20). A-C is R108 ecotype and E-G is the mutant line. In which $\mathbf{A}$ and $\mathbf{D}$ are fresh nodule picture in $5 \mathrm{X}$ amplification, $\mathbf{B}, \mathbf{C}, \mathbf{E}$ and $\mathbf{F}$ is $7 \mu \mathrm{m}$ sectioning of nodule after fixation and X-gal stained lac-Z Rhizobium, B and $\mathbf{E} 5 \mathrm{X}$ amplification, $\mathbf{C}$ and $\mathbf{F} 10 \mathrm{X}$ amplification.

Indeed, the symbiotic phenotype of line NF1858 was already noticed by Pislariu et al. (2012). The nodule phenotype of line NF1858 is indicative that MtN20 loss-of-function does not affect nodule development, but it is essential for symbiotic nitrogen fixation (SNF), possibly due to a defective cell infection. It is important to note, however, that at least 86 Tnt 1 insertions are scattered in the genome of this line, among which 27 were identified in gene spaces (defined herein as the DNA between the start and stop codons). Of those genes, with only two expressed exclusively in nodules, MtN20 and another nodulespecific gene is SUNN (Medtr4g070970.1) (Pislariu et al., 2012). However, SUNN is a negative regulator of nodulation and its loss-of-function leads to a striking supernumerary nodulation with functional nodules (Schnabel et al., 2005). Therefore, the symbiotic effect observed in NF1858 nodules is unlikely to be due to SUNN loss-of-function. Unfortunately, we were unable to identify homozygous recessive plants in the segregant $\left(\mathrm{T}_{2}\right)$ population for insertions in the MtN20 in the Tnt1 lines NF2990, NF3070 and NF17000. A 
clear approach to establish the essentiality of MtN20 for rhizobial symbiosis is still needed. The use of CRISPR/Cas9 system for loss-of-function is a viable approach to fully tackle this question.

\section{MtN20 expression occurs specifically in the very early stages of bacterial infection}

The early onset of MtN20 gene expression (3 dpi - Figure 6I) indicates a role during the initial phases of nodule development. Transcriptomic data presented by Roux et al. (2014) showed that most of the MtN20 expression occurs in the distal portion of zone II, where the early stages of infection occur. In the same study, similar expression patterns were noted for the pre-infection marker MtN6 (Mathis et al., 1999), the early nodulin MtENOD12 (Limpens et al., 2013), and EFD (Vernie et al., 2008). Interestingly, the expression of MtENOD11, which is an early marker for pre-infection of Rhizobium as well as mycorrhizae, is significantly high also in the meristem. This may indicate that MtN20 acts downstream of MtENOD11. Our 2-kb promoter activity (pMtN20::GUS) analysis on hairy roots (Figure 6C) confirmed the very restrict realm of MtN20 gene expression in mature nodules, congruent to data published by Roux et al. (2014) (Figure 6J).

A gene expression analysis using mutant bacteria defective to specific symbiotic milestones can be used to help further elucidate which process must occur before a nodulin is triggered to express. Our analysis demonstrates that $M t N 20$ requires bacterial infection, but not bacteroid differentiation to express (Figure 6H). This further indicates that MtN20 is involved in the very early stages of bacterial infection. 

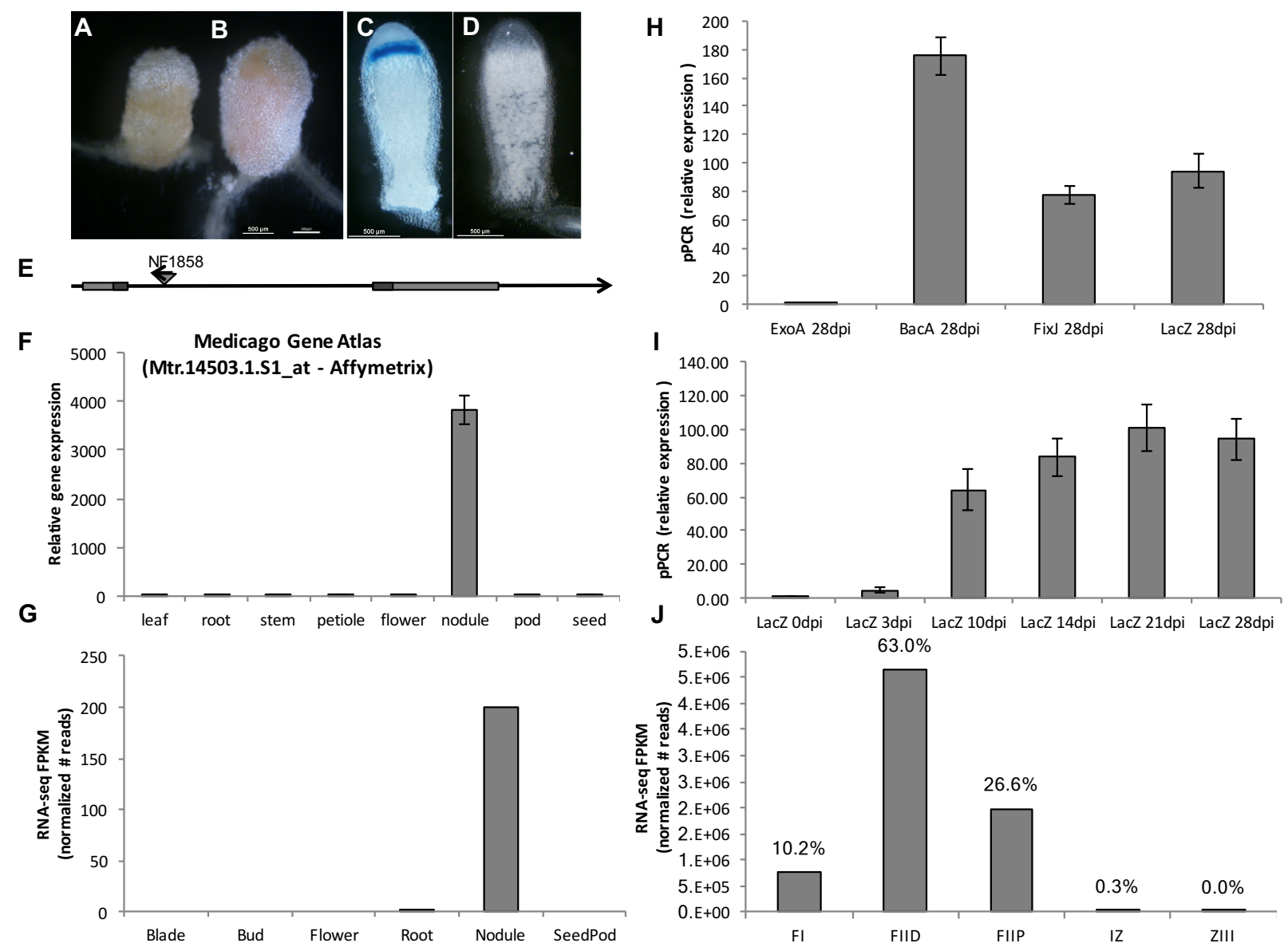

Figure 6. MtN20 (Medtr7g086040) function and gene expression of roots inoculated with Sinorhizobium meliloti strain ABS7. (A-B) Tnt1 insertion in MtN20 leads to impaired nodule development: (A) 21-day old nodule of Tnt1 mutant line NF1858 of Medicago truncatula. (B) 21-day old nodule of cv. R108, as a control (wild-type). (C-D) Expression profile of the $M t N 20$ is specifically expressed in zone II of the mature nodule sectioned in $70 \mu \mathrm{m}$. Nodules were stained with X-Gluc: (C) 28-day old nodule expressing the $p M t N 20:: G U S$ cassette. (D) 28-day old nodule section (non-transgenic control). (E) Location of Tnt1 insertions in the MtN20 gene available at the Noble Foundation mutant population. (F-G) MtN20 expression is specific to nodules: (F) Affymetrix data from Medicago Gene Atlas (Benedito et al., 2008); (G) RNA-Seq data from Young et al., 2011. (H-I) MtN20 qRT-PCR expression analysis: (H) symbiotic mutants of Sinorhizobium meliloti in mature nodules, MtN20 expression requires infection, but not bacteroid differentiation or symbiotic nitrogen fixation. (I) Time course of $M t N 20$ gene expression in roots inoculated with lacZ Sinorhizobium meliloti strain ABS7 (qRT-PCR, own data). (J) MtN20 is expressed in higher in distal side of zone II (RNA-Seq data from Roux et al., 2014).

\section{The MtN20 transcriptional network correlates with the development of the early infection}

\section{zone of the nodule}

If MtN20 functions as a transcription factor during early infection, it is relevant to understand the transcriptional module to which it is related in order to better understand the mechanisms it may be involved with. A transcriptional network centered on MtN20 was developed using 72 sequence reads archive (SRA) files from $M$. truncatula available at the NCBI database. The last annotation version of the M. truncatula genome was used to map the public RNA-Seq data and generate a normalized (transcript per million, TPM) expression matrix for all identified 57,585 gene models. Following, we gathered the first-degree correlation 
with MtN20 produced by Pearson Coefficient Correlation (PCC, $\rho \geq 0.85$ ) and then built a second-degree correlation matrix $(\rho \geq 0.90)$ to produce a genetic network (Figure 7).

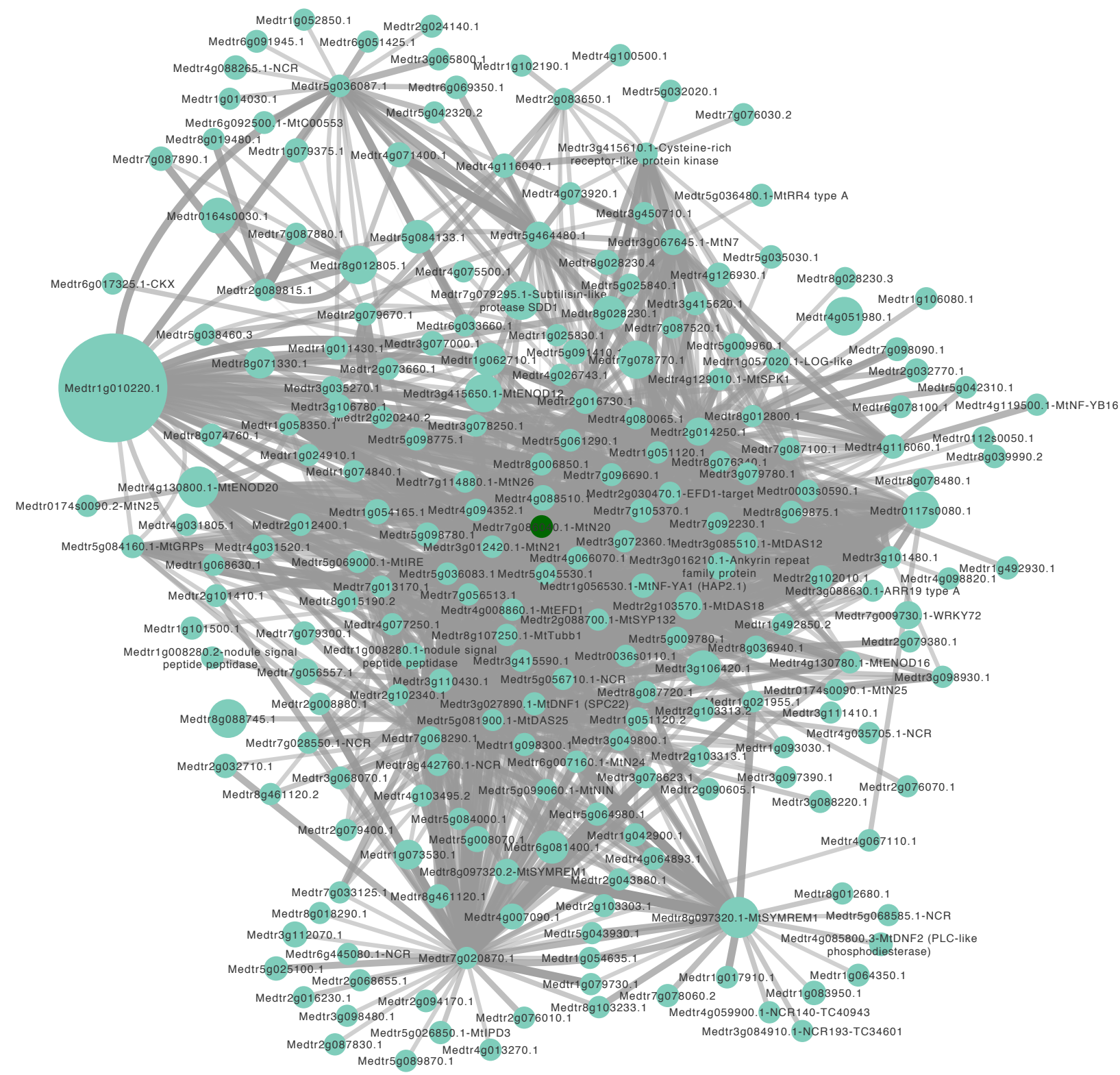

Figure 7. Co-expression genetic network of $M t N 20$. In this network, we had our gene of interest $M t N 20$ in green node in the center and other genes in blue node, the node size corresponds to the level of each gene expression in Medicago truncatula root nodule. The correlation of each node is represented by the line between them, edge, in which the thickness is correspondent to the level of Pearson correlation between the genes.

In this network, genes directly connected to MtN20 include: MtDAS25 (Medtr5g081900.1), MtN7 (Medtr3g067645.1), MtSYMREM (Medtr8g097320.1), the syntaxin MtSYP132 (Medtr2g088700.1), MtENOD20 (Medtr4g130800), Cysteine-rich receptor-like protein kinase (Medtr3g415610.1), MtN21 
(Medtr3g012420.1), Ankyrin repeat family protein (Medtr3g016210.1), MtGRPs (Medtr5g084160.1), MtEFD-1 (Medtr4g008860.1), MtEFD-target (Medtr2g030470.1).

MtSYMREMI characterized as a protein of the Remorin presents interaction with at least three essentials root nodule symbiosis (RNS) receptor-like kinases (RLKs). MtSYMREM1 has a lotus homologs (LjSYMREM1), that increases the nodulation when overexpressed. It is important to highlight that this gene presents changes in mapping annotation, such as Medtr8g097320 for Mt4.0v2.1, Medtr8g098650 for Mt3.5v1 and Mtr.13003.1.S1_at for Affymetrix probeset. MtSYMREM1 was found related to infection process and with symbiosomes [56], In the microarray analysis of transcription reprogramming of root nodule development, (Moreau et al., 2011).

The syntaxin MtSYP132 (Medtr2g088700.1), which is localized to the symbiosome membrane contributing to the specialization involved in infection thread development and endocytosis (Catalano et al., 2004).

The early nodulin ENOD20 (Medtr4g130800), was induced in inoculated lumpy infections (lin) roots and present similar expression pattern (Kuppusamy et al., 2004). ENOD20 was predicted to participate in the reorganization of the cell wall during infection thread growth and/or in the differentiation of the infected cells of the root nodules (Greene et al., 1998).

ERF transcription factor ETHYLENE RESPONSE FACTOR REQUIRED FOR NODULE DIFFERENTIATION (MtEFD-1, Medtr4g008860.1), which is a bona fide marker for infection zone at early steps of nodulation, been expressed between zones I and II border (Vernie et al., 2008; Limpens et al., 2013). Which seems to be involved with the MtEFD-target (Medtr2g030470.1).

Second-order correlations with the MtN20 hub revealed additional genes involved in cell infection processes: MtRR19 type A, LOG-like, MtC00553, MtDAS12, MtDAS18, MtDNF1 (SPC22), ENOD12, ENOD16, MtIPD3, MtIRE, MtN24, MtN24, MtN25, MtN26, MtNF-YA1(HAP2.1), MtN-FYB16, MtNIN, MtRR4 type A, MtSPK1, MtTubb1, nodule signal peptide peptidase, Subtilisin-like protease SDD1 and the putative transcriptional factor WRKY72, NCR140-TC40943 (Medtr4g059900.1), NCR193-TC34601 (Medtr3g084910.1) and 5 the nodule-specific cysteine-rich peptides Medtr4g035705.1-NCR, Medtr4g088265.1-NCR， Medtr5g056710.1-NCR， Medtr5g068585.1-NCR， Medtr6g445080.1-NCR, Medtr7g028550.1-NCR, Medtr8g442760.1-NCR.

Nodule-specific cysteine-rich (NCR) peptide are large family of bacteroid-targeted plant-driven antimicrobial peptides that place essential rules on terminal bacteroid differentiation process, such as hostbacteria discrimination (Van de Velde et al., 2010; Wang et al., 2017b; Yang et al., 2017). NCR seems to be the most abundant type of symbiosis target molecules that coordinates symbiosis nitrogen fixation via plan secretory pathway. In which many other proteins are important for bacteroid differentiation such as VAMPs, DNF1, DNF2, Trx s1 and many others (Alunni and Gourion, 2016). 
Overall, this transcriptional module reflects a potential function during the very early stages of rhizobial infection of the nodule cell. Interestingly, novel genes are revealed in this network, which should be functionally characterized for a full understanding of the rhizobial infection process in the developing nodule. From those we can highlight some that are highly expressed $(>200 \mathrm{TPM})$ in root nodules, such as Medtr1g051120.1, Medtr3g415590.1, Medtr0117s0080.1, Medtr8g012800.1, Medtr1g025830.1 and Medtr7g096690.1 within the first degree of correlation, and Medtr2g016730.1, Medtr2g014250.1, Medtr8g012800.1， Medtr2g014250.1， Medtr1g051120.1， Medtr5g036083.1， Medtr7g068290.1， Medtr5g036083.1， Medtr4g116060.1， Medtr3g101480.1， Medtr2g014250.1， Medtr7g068290.1， Medtr5g009780.1 and Medtr2g014250.1 for the second degree of correlation (Table 1).
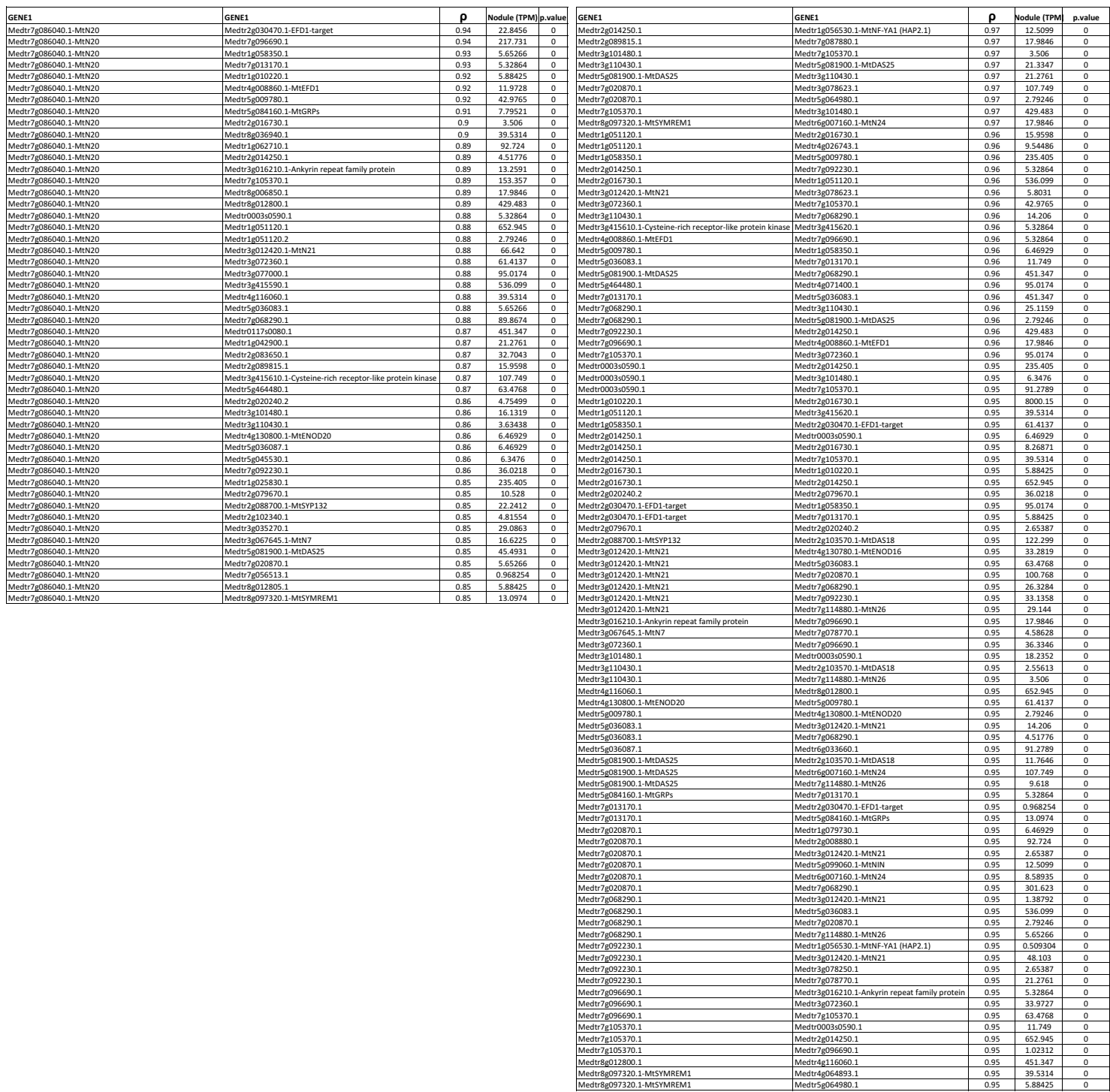

Table 1. First and second degree of correlated expression genes with $M t N 20 / M t G R F 1$. The first degree of correlated genes with $\varrho>0.95$ and the second degree of correlation the $\varrho>0.95$ correlated genes, follows by their expression level in root nodule (TPM), in which we ordered the table by MtN20/MtGRF1 in the analysis. In which the gene annotation are separated with "-“" following the gene mapping. 


\section{Identifying cis-elements in the MtN20 promoter}

A reasonable question raised by the very specific transcriptional domain of $M t N 20$ in the nodule is which cis-elements in the promoter (and which transcription factors) are responsible for this transcriptional activity during rhizobial infection. In order to start looking into this question, we identified common plant cis-elements using the PLACE tool (http://www.dna.affrc.go.jp/htdocs/PLACE; Higo et al., 1999) in the 2011 bp regions upstream the $M t N 20$ start codon (Figure 8).

For the MtN20, several cis-elements are present in multiple copies (Higo et al., 1999): DOFCOREZM (18 times), GATABOX (17), CACTFTPPCA1 (15), ROOTMOTIFTAPOX1 (12), CAATBOX (12), IBOXCORE (10), GT1CONSENSUS (8), ARRIAT (8), OSE2ROOTNODULE (6), NODCON2GM (6), MYCCONSENSUSAT (6), EBOXNNAPA (6), and several others with lower representation (Figure 7). DOFCOREZM was identified as a binding site of Dof transcription factors in maize (Wang et al., 2017a). GATABOX is highly conserved cis-element for GATA transcription factors. The conserved sequence CACTFTPPCA1 was found in the promoter of PEP carboxylase gene of the C4 plant, Flaveria trinervia (Gowik et al., 2004), that also had been characterized in Arabidopsis male meiocytes ( $\mathrm{Li}$ et al., 2014). Interestingly, ROOTMOTIFTAPOX1 is found in rolD promoters of Agrobacterium rhizogenes. CAATBOX relates to the CAAT box, which is a heat shock element (HSE) characterized as a synergistic element to induce expression during stresses (Rieping and Schöffl, 1992). Unexpectedly, IBOXCORE refers to the highly conserved domain (I-box) previously described as induced by light (Terzaghi and Cashmore, 1995). The potential contribution of each of these elements to the tissue specificity of MtN20 should be assessed to better characterize the molecular mechanisms involved with the transcriptional activity of this gene during nodule development.

\section{CONCLUSIONS AND PERSPECTIVES}

MtN2O is a novel gene potentially involved in rhizobial infection of nodule cells. It belongs to a largely uncharacterized family of putative transcription factors. MtN20 belongs to a regulatory gene network encompassing bona fide symbiotic genes, such as EFD, the EFD target Nod19, NIN and several nodule-specific cysteine-rich (NCR) peptides. Several overrepresented cis-elements were identified in the MtN20 gene promoter, with potential implications to understand its tissue specificity. 


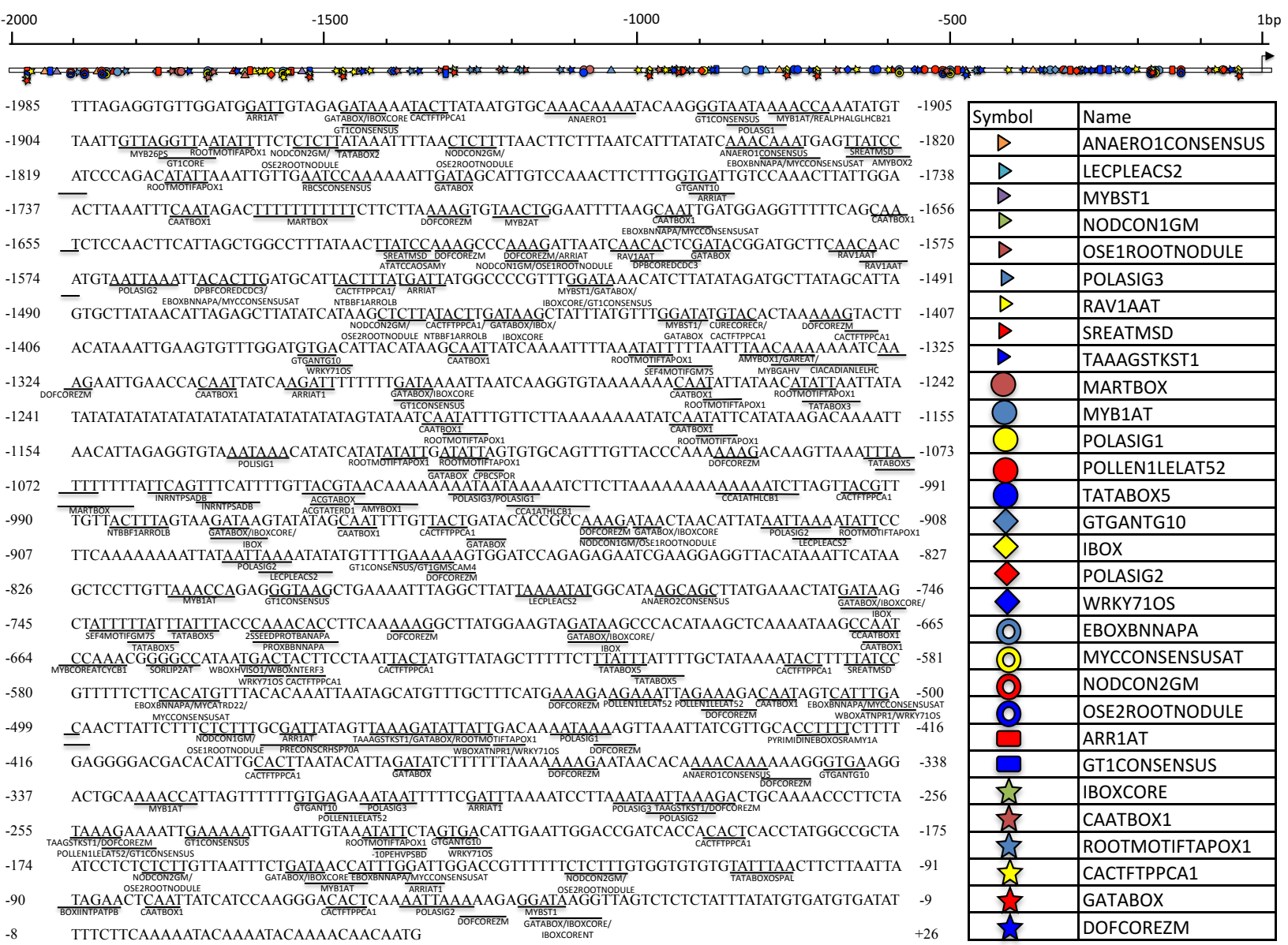

Figure 9. Cis-regulatory elements identified in promoter region of MtN20 (Medtr7g086040.1). A 2008bp region upstream the transcriptional start site (TSS) was analyzed in PLACE (Higo et al., 1999). Cis-elements are highlighted and names are provided underneath. For a complete list of elements found in this promoter region.

The second gene of interest, MtGRF2, described in the chapter 4 of this dissertation, and detailed explored in the next chapter 4, MtN20 and MtGRF2 present distinguished expression pattern conferred by each promoter element. A comparative table was generated, in which we pointed out the number of copies of differential promoter element between both genes of interest in a 2008bp upstream region (Chapter 4 Table 2).

\section{MATERIAL AND METHODS}

Plant growth conditions: The plants were grown in 2:1 turface:vermiculite medium in 4" Azalea pots under 16:8-h (light:dark) photoperiod and $24^{\circ} \mathrm{C}: 22^{\circ} \mathrm{C}$ (day:night) temperature conditions in a Percival growth chamber. Plants received $50 \mathrm{~mL}$ 1X B\&D (Broughton and Dilworth, 1971) fertilizer solution with low nitrogen $(0.5 \mathrm{mM}$ ammonium nitrate) every other day except at day of inoculation with rhizobium. 
Cloning of MtN20 promoter: A $1968 \mathrm{bp}$ genomic region upstream the MtGRF1/MtN20 (Medtr7g086040.1) start codon (coordinates chr7:33359964..33361035 of the M. truncatula genome assembly v.4.0) was cloned into a binary vector to express the GUS reporter gene. Medicago genomic DNA (ecotype 'A17') was extracted from young leafs using the IDT Plant DNA Extraction Protocol (www.idtdna.com/pages/docs/educational-resources/plant-dna-extraction-protocol.pdf?sfvrsn=5). $\quad$ PCR was carried out with the high-fidelity KOD Extreme Hot-Start DNA polymerase (Toyobo, catalog \#71086) in an Mastercycler ep Gradient S Thermal Cycler (Eppendorf). The amplicon was run on 1\% agarose gel, purified and further cloned into the directional pENTR-D/ TOPO vector (ThermoFisher), followed by Gateway LR reaction, using Gateway LR Clonase II Enzyme Mix (ThermoFisher) to recombine it into the the destination vector (pKGWFS7). and finally incorporate into the All final cassettes were confirmed by Sanger sequencing at the WVU Genomics Core Facility. Plasmids were used to transform Agrobacterium rhizogenes strain 'ARqua1' for ex-vitro hairy-root transformation. All primer sequences used in this dissertation are provided in Annex I.

Ex-vitro hairy-root transformation: A slightly modified version of the freeze-thaw method for Agrobacterium transformation protocol (openwetware.org/wiki/Maloof_Lab:Agro_Transformation) was used for Agrobacterium rhizogenes strain 'ARqual'. Ex-vitro hairy root transformation of M. truncatula ecotype "A17" was performed as described by Boisson-Dernier et al. (2006). In brief, roots of four-day old seedlings were diagonally cut out and the wound was inoculated with a three day-old plate cultivated with ARqua1 transformed with the final destination on solid LB medium containing the respective selective antibiotic $(100 \mathrm{mg} / \mathrm{L}$ spectinomycin plus $100 \mathrm{mg} / \mathrm{L}$ streptomycin). The seedlings were then grown on modified Fahraeus medium (pH 7.5) with 15g/L agar in tissue culture tubes for 2 weeks under 16:8-h light:dark photoperiod regimen at $24^{\circ} \mathrm{C}: 22^{\circ} \mathrm{C}$ day:night temperature before transplanting to a turface:vermiculite $(2: 1$ ratio) under the same growth conditions. $0.5 \mathrm{mM}$ were provided $1 / 2$-strengh $\mathrm{B} \& \mathrm{D}$ fertilizer solution $(50 \mathrm{~mL})$ every other day 7 days before rhizobial inoculation. When applicable, transgenic roots and nodules were visualized under fluorescence stereoscope via expression of the fluorescent marker DsRed (excitation/emission $\sim 580 / 605 \mathrm{~nm}$ ).

Rhizobial inoculation: Unless specified otherwise, roots of one week-old plants were inoculated with 50 $\mathrm{mL}$ suspension $\left(\mathrm{OD}_{600}=0.05\right)$ of Sinorhizobium meliloti rhizobial strain Sm1021 (Sm1021-lacZ) harboring the hem A::LacZ cassette in $1 \mathrm{X}$ B\&D solution without nitrogen to induce nodulation. One inoculation loop of Sinorhizobium meliloti rhizobial strain Sm1021 from glycerol stock was grown for three days in $3 \mathrm{~mL}$ YM medium supplemented with $6 \mathrm{mM} \mathrm{CaCl}_{2}$ and proper antibiotic, according to the destination vector (e.g., $10 \mathrm{mg} / \mathrm{L}$ Tetracycline or $100 \mathrm{mg} / \mathrm{L}$ Streptomycin). Sixteen hours before rhizobial inoculation, the 1-mL 
inoculum was regrown in $200 \mathrm{~mL}$ flask until $\mathrm{OD}_{600} \sim 1.0$. The suspension was centrifuged at $10,000 \mathrm{~g}$ for 10 minutes, the pellet washed by resuspension and centrifugation, and the clean pellet was then resuspended and diluted with $1 \mathrm{X}$ no-N $\mathrm{B} \& \mathrm{D}$ solution without nitrogen to an $\mathrm{OD}_{600}$ of 0.05 . Fifty milliliters of the rhizobial suspension were used to inoculate each plant.

Histochemical assay (tissue fixation and GUS staining): Sections were cut by hand from unfixed stems of plants grown in vitro, essentially as described (Jefferson et al., 1987) and fixed in $0.3 \%$ formaldehyde in $10 \mathrm{mM}$ MES, pH 5.6, 0.3 M D-mannitol for $45 \mathrm{~min}$ at room temperature, followed by several washes in 50 $\mathrm{mM} \mathrm{NaH}_{2} \mathrm{PO}_{4}, \mathrm{pH}$ 7.0. All fixatives and substrate solution were introduced into sections with a brief (1 $\mathrm{min}$ ) vacuum infiltration. Histochemical reactions with X-Gluc were be performed with $1 \mathrm{mM}$ substrate in $50 \mathrm{mM} \mathrm{NaH}_{2} \mathrm{PO}_{4}, \mathrm{pH} 7.0$ at $37^{\circ} \mathrm{C}$ from 3 hours and 16 hours. After staining, sections were be rinsed in $70 \%$ ethanol for $5 \mathrm{~min}$, and then mounted for microscopy (Jefferson et al., 1987). For anatomical analyses, transformed nodules at $28 \mathrm{dpi}$ were embedded in 5\% low-melting agarose and sectioned on a vibratome at $70 \mu \mathrm{m}$ thickness. Those sections were extracted from agarose and kept $1.5 \mathrm{~mL}$ tube with $\mathrm{NaH}_{2} \mathrm{PO}_{4}, \mathrm{pH} 7.0$, to be observed under light microscopy (Nikon Eclipse E600 microscope coupled with a Nikon DS-Ri1 camera).

Gene expression profile: Gene expression profile analyses of $M t N 20 / M t G R F 1$ in nodulating roots inoculated with rhizobial mutants were performed in ecotype "A17" plants inoculated with fixJ, bacA, exoA, or hemA::LacZ strains of Sinorhizorium meliloti in the Sm1021 background. For gene expression analyses via qRT-PCR, root samples not inoculated with rhizobia provided full nitrogen fertilization (6 $\mathrm{mM} \mathrm{N}$ provided as $\mathrm{KNO}_{3}$ and $\mathrm{NH}_{4} \mathrm{NO}_{3}$ ) were used as control. Whole root systems were harvested at $0,3,14,21$, and 28 dpi. RNA were extracted with mirVana mRNA Isolation kit (Life Technologies) followed by DNA removal with Turbo DNA-free kit (Applied Biosystems). First strand cDNA was synthesized with oligodT priming using the SuperScript III First-Strand Synthesis Super mix (ThermoFisher), following the manual instructions. Primers are described in cf. Suppl. Table 1.

Three biological and three technical replicates were run for qRT-PCR analyses. SYBR green master mix (Applied Biosystems) we used for $5-\mu \mathrm{L}$ reactions on ABI7500 Real Time qPCR System (Applied Biosystems). In which was made two MasterMix one with SyBR green $(2.5 \mu \mathrm{L})$ and cDNA $(1 \mu \mathrm{L} 1: 10)$ and another between with primers $(2 \mathrm{x} 0.5 \mu \mathrm{L} 20 \mathrm{mM})$ and water $(0.5 \mu \mathrm{L})$. All templates were amplified using the same cycling conditions: $50^{\circ} \mathrm{C}$ for 2 minutes; $95^{\circ} \mathrm{C}$ for 10 minute; 40 cycles of $95^{\circ} \mathrm{C}$ for 15 seconds and $60^{\circ} \mathrm{C}$ for 1 minute. Melt curves were produced following the same protocol in 10-fold serial dilutions of cDNA (1:10 to $1: 100,000)$. Ct (threshold cycle) values were exported to Excel to organize data and comparative analysis of gene expression. 
The symbiotic marker genes used: $N C R 2 A$ (Medtr2g042480, marker of bacteroid differentiation: Moreau et al., 2011), LEG (Medtr5g081000, marker of nitrogen fixation: Vinardell, 2003), Sennex2 (Medtr7g104360, an uncharacterized gene expressed specifically in the senescence zone: cf. Roux et al., 2014, LYK3 (Medtr5g086130, marker of root hair curling: Smit et al., 2007), the early nodulin ENOD11 (Medtr3g415670, marker of pre-infection and infection: Svistoonoff et al., 2010), and HAP2.1 (Medtr1g05653, which expresses exclusively in the nodule meristem: Combier et al., 2006; Combier et al., 2008). The housekeeping genes used for RT-qPCR were: EF1 (Medtr6g021800) and Tub1 (Medtr7g089120). LinRegPCR was used to extract PCR efficiencies for each primer pair (REF). The software NormFinder (Andersen, 2004) was used to identify stably-expressed housekeeping genes for the experiment. Relative expression was calculated according to the Pfaffl method (Pfaffl, 2001). All primers are described in Annex 1.

Light microscopy: At 28 days post-inoculation with $\mathrm{Sm} 1021-\mathrm{LacZ}$, nodules were harvested and fixed under vacuum with $2.5 \%$ glutaraldehyde in 0.1 M PIPES ( $\mathrm{pH} 7.2$ ) for one hour at room temperature, followed by two rinses with 0.1 M PIPES (pH 7.2). When applicable, samples were stained in fresh staining solution containing $50 \mathrm{mM}$ potassium ferricyanide, $50 \mathrm{mM}$ potassium ferrocyanide, $0.08 \% \mathrm{X}$-Gal $(0.08 \mathrm{mg} / \mathrm{mL})$ or $0.08 \%$ Red-Gal $(0.08 \mathrm{mg} / \mathrm{mL})$ and $0.1 \mathrm{M}$ PIPES $(\mathrm{pH} 7.2)$ for 16 hours at room temperature (Boivin et al., 2016), followed by two rinses with 0.1M PIPES (pH 7.2), and stored at 70\% ethanol until processing. After fixation (and staining), tissues were cleared with $2.4 \%$ sodium hypochlorite for 5 min and dehydrated with an ethanol series (50\%, 70\%, 90\%, 95\%, and 100\% twice for 45 minutes each). Samples were then transferred to $100 \%$ xylene for 15 minutes or until translucent. The completely dehydrated samples were embedded in fresh $60^{\circ} \mathrm{C}$ xylene:paraplast $(1: 1)$ mix for two hours at $60^{\circ} \mathrm{C}$ and transferred to melted $\left(60^{\circ} \mathrm{C}\right) 100 \%$ paraplast and incubated at $60^{\circ} \mathrm{C}$ for at least three hours. Each sample were blocked and cut in $7 \mu \mathrm{m}$ section with a conventional microtome. The slices were placed on glass slides and incubated overnight at $37^{\circ} \mathrm{C}$. On the next day, the slides were washed twice with $100 \%$ xylene for 3 minutes and twice with $100 \%$ ethanol, followed by the hydration process using submersion in $95 \%$ ethanol and then water for 5 minutes each. The samples were then ready to accept water-based dyes. The slides were observed under bright field microscope (Nikon Eclipse E600 microscope coupled with a Nikon DS-Ri1 camera). Often, Xgal staining was used to visualize lac $Z$ bacteria and the tissue was counterstained with chloramphenicol to visualize the lignin in the plant cell wall. 


\section{REFERENCES}

Adesemoyea, A., H. Torbertb and J. Kloeppera (2010) Increased plant uptake of nitrogen from ${ }^{15} \mathrm{~N}-$ depleted fertilizer using plant growth- promoting rhizobacteria. Applied Soil Ecology 56(1): 54-58.

Alunni B, Gourion B (2016) Terminal bacteroid differentiation in the legume-rhizobium symbiosis: nodule-specific cysteine-rich peptides and beyond. New Phytol 211: 411-417

Andersen CL (2004) Normalization of real-time quantitative reverse transcription-PCR data: A modelbased variance estimation approach to identify genes suited for normalization, applied to bladder and colon cancer data sets. Cancer Res 64: 5245-5250

Andersson CR, Jensen EO, Llewellyn DJ, Dennis ES, Peacock AWJ (1996) A new hemoglobin gene from soybean: A role for hemoglobin in all plants (nonsymbiotic/leghemoglobin/evolution). Plant Biol 93: 5682-5687

Appleby CA (1984) Leghemoglobin and Rhizobium Respiration Ann. Rev. Plant Physiol 35:443-78

Benedito V a, Torres-Jerez I, Murray JD, Andriankaja A, Allen S, Kakar K, Wandrey M, Verdier J, Zuber H, Ott T, et al (2008) A gene expression atlas of the model legume Medicago truncatula. Plant J 55: 504-513

Boivin S, Fonouni-Farde C, Frugier F (2016) How auxin and cytokinin phytohormones modulate root microbe interactions. Front Plant Sci 7: 1-12

Brameier M, Krings A, MacCallum RM (2007) NucPred - Predicting nuclear localization of proteins. Bioinformatics 23: 1159-1160

Broughton WJ, Dilworth MJ (1971) Control of leghaemoglobin synthesis in snake beans. Biochem J 125: $1075-1080$

Catalano CM, Lane WS, Sherrier DJ (2004) Biochemical characterization of symbiosome membrane proteins from Medicago truncatula root nodules. Electrophoresis 25: 519-531

Combier J-P, Frugier F, de Billy F, Boualem A, El-Yahyaoui F, Moreau S, Vernie T, Ott T, Gamas P, Crespi M, et al (2006) MtHAP2-1 is a key transcriptional regulator of symbiotic nodule development regulated by microRNA169 in Medicago truncatula. Genes Dev 20: 3084-3088

Combier JP, de Billy F, Gamas P, Niebel A, Rivas S (2008) Trans-regulation of the expression of the transcription factor MtHAP2-1 by a uORF controls root nodule development. Genes Dev 22: 15491559

Denance N, Szurek B, Noel LD (2014) Emerging functions of nodulin-like proteins in non-nodulating plant species. Plant Cell Physiol 55: 469-474

Fedorova M (2002) Genome-wide identification of nodule-specific transcripts in the model legume Medicago truncatula. Plant Physiol 130: 519-537

Gamas P, Niebel F de C, Lescure N, Cullimore J (1996) Use of a subtractive hybridization approach to identify new Medicago truncatula genes induced during root nodule development. Mol Plant Microbe Interact 9: 233-42

Godiard L, Niebel A, Micheli F, Gouzy J, Ott T, Gamas P (2007) Identification of new potential regulators of the Medicago truncatula-Sinorhizobium meliloti symbiosis using a large-scale suppression subtractive hybridization approach. Mol Plant-Microbe Interact 20: 321-332

Gowik U, Burscheidt J, Akyildiz M, Schlue U, Koczor M, Streubel M, Westhoff P (2004) cisregulatory elements for mesophyll-specific gene expression in the $\mathrm{C}_{4}$ plant Flaveria trinervia, the 
promoter of the $\mathrm{C}_{4}$ phosphoenolpyruvate carboxylase gene. Plant Cell 16: 1077-1090

Greene EA, Erard M, Dedieu A, Barker DG (1998) MtENOD16 and 20 are members of a family of phytocyanin-related early nodulins. Plant Mol Biol 36: 775-783

Györgyey J, Vaubert D, Jiménez-Zurdo JI, Charon C, Troussard L, Kondorosi Á, Kondorosi É (2000) Analysis of Medicago truncatula nodule expressed sequence tags. Mol Plant-Microbe Interact 13: 62-71

He J, Benedito VA, Wang M, Murray JD, Zhao PX, Tang Y, Udvardi MK (2009) The Medicago truncatula gene expression atlas web server. BMC Bioinformatics 10: 441

Higo K, Ugawa Y, Iwamoto M, Korenaga T (1999) Plant cis-acting regulatory DNA elements (PLACE) database: 1999. Nucleic Acids Res 27: 297-300

Kim JH, Choi D, Kende H (2003) The AtGRF family of putative transcription factors is involved in leaf and cotyledon growth in Arabidopsis. Plant J 36: 94-104

Kuppusamy KT, Endre G, Prabhu R, Penmetsa RV, Veereshlingam H, Cook DR, Dickstein R, Vandenbosch K a (2004) LIN, a Medicago truncatula gene required for nodule differentiation and persistence of rhizobial infections. Plant Physiol 136: 3682-3691

Legocki RP, Verma DPS (1980) Identification of "nodule-specific" host proteins (nodulins) involved in the development of Rhizobium-Legume symbiosis. Cell 20: 153-163

Li J, Yuan J, Li M (2014) Characterization of putative cis-regulatory elements in genes preferentially expressed in Arabidopsis male meiocytes. Biomed Res Int. doi: 10.1155/2014/708364

Limpens E, Moling S, Hooiveld G, Pereira P a, Bisseling T, Becker JD, Küster H (2013) Cell- and tissue-specific transcriptome analyses of Medicago truncatula root nodules. PLoS One 8: e64377

Manthey K, Krajinski F, Hohnjec N, Firnhaber C, Pühler A, Perlick AM, Küster H (2004) Transcriptome profiling in root nodules and arbuscular mycorrhiza identifies a collection of novel genes induced during Medicago truncatula root endosymbioses. Mol Plant Microbe Interact 17: 1063-77

Marx H, Minogue CE, Jayaraman D, Richards AL, Kwiecien NW, Sihapirani AF, Rajasekar S, Maeda J, Garcia K, Del Valle-Echevarria AR, et al (2016) A proteomic atlas of the legume Medicago truncatula and its nitrogen-fixing endosymbiont Sinorhizobium meliloti. Nat Biotechnol advance on: $1198-1205$

Mathis R, Grosjean C, de Billy F, Huguet T, Gamas P (1999) The early nodulin gene MtN6 is a novel marker for events preceding infection of Medicago truncatula roots by Sinorhizobium meliloti. Mol Plant-Microbe Interact 12: 544-555

Moreau S, Verdenaud M, Ott T, Letort S, de Billy F, Niebel A, Gouzy J, de Carvalho-Niebel F, Gamas P (2011) Transcription reprogramming during root nodule development in Medicago truncatula. PLoS One 6: e16463

Pfaffl MW (2001) A new mathematical model for relative quantification in real-time RT-PCR. Nucleic Acids Res 29: e45

Pislariu CI, D. Murray J, Wen J, Cosson V, Muni RRD, Wang M, A. Benedito V, Andriankaja A, Cheng X, Jerez IT, et al (2012) A Medicago truncatula tobacco retrotransposon insertion mutant collection with defects in nodule development and symbiotic nitrogen fixation. Plant Physiol 159: 1686-1699

Rieping M, Schöffl F (1992) Synergistic effect of upstream sequences, CCAAT box elements, and HSE sequences for enhanced expression of chimaeric heat shock genes in transgenic tobacco. Mol Gen 
Genet 231: 226-232

Roux B, Rodde N, Jardinaud M-F, Timmers T, Sauviac L, Cottret L, Carrère S, Sallet E, Courcelle E, Moreau S, et al (2014) An integrated analysis of plant and bacterial gene expression in symbiotic root nodules using laser-capture microdissection coupled to RNA sequencing. Plant $\mathbf{J}$ 77: $817-837$

Schnabel E, Journet E-P, de Carvalho-Niebel F, Duc G, Frugoli J (2005) The Medicago truncatula $S U N N$ gene encodes a $C L V 1$-like leucine-rich repeat receptor kinase that regulates nodule number and root length. Plant Mol Biol 58: 809-22

Shen J, Zeng Y, Zhuang X, Sun L, Yao X, Pimpl P, Jiang L (2013) Organelle pH in the Arabidopsis endomembrane system. Mol Plant 6: 1419-1437

Sibley CR, Blazquez L, Ule J (2016) Lessons from non-canonical splicing. Nat Rev Genet 17: 407-421

Smit P, Limpens E, Geurts R, Fedorova E, Dolgikh E, Gough C, Bisseling T (2007) Medicago LYK3, an entry receptor in rhizobial nodulation factor signaling. PLANT Physiol 145: 183-191

Svistoonoff S, Sy M-O, Diagne N, Barker DG, Bogusz D, Franche C (2010) Infection-specific activation of the Medicago truncatula enod11 early nodulin gene promoter during actinorhizal root nodulation. Mol Plant-Microbe Interact 23: 740-747

Tadege M, Wen J, He J, Tu H, Kwak Y, Eschstruth A, Cayrel A, Endre G, Zhao PX, Chabaud M, et al (2008) Large-scale insertional mutagenesis using the Tnt1 retrotransposon in the model legume Medicago truncatula. Plant J 54: 335-347

Terzaghi WB, Cashmore AR (1995) Light-regulated transcription. Annu Rev Plant Physiol Plant Mol Biol 46: 445-474

Van de Velde W, Zehirov G, Szatmari A, Debreczeny M, Ishihara H, Kevei Z, Farkas A, Mikulass K, Nagy A, Tiricz H, et al (2010) Plant peptides govern terminal differentiation of bacteria in symbiosis. Science 327: 1122-1126

Vernie T, Moreau S, de Billy F, Plet J, Combier J-P, Rogers C, Oldroyd G, Frugier F, Niebel A, Gamas P (2008) EFD is an ERF transcription factor involved in the control of nodule number and differentiation in Medicago truncatula. Plant Cell 20: 2696-2713

Vinardell JM (2003) Endoreduplication mediated by the anaphase-promoting complex activator CCS52A is required for symbiotic cell differentiation in Medicago truncatula nodules. Plant Cell 15: 2093-2105

Wang H, Zhao S, Gao Y, Yang J (2017a) Characterization of dof transcription factors and their responses to osmotic stress in poplar (Populus trichocarpa). PLoS One 12: 1-19

Wang Q, Yang S, Liu J, Terecskei K, Ábrahám E, Gombár A, Domonkos Á, Szúcs A, Körmöczi P, Wang T, et al (2017b) Host-secreted antimicrobial peptide enforces symbiotic selectivity in Medicago truncatula. Proc Natl Acad Sci 114: 201700715

Wang R, Brattain MG (2007) The maximal size of protein to diffuse through the nuclear pore is larger than $60 \mathrm{kDa}$. FEBS Lett 581: 3164-3170

El Yahyaoui F (2004) Expression profiling in Medicago truncatula identifies more than 750 genes differentially expressed during nodulation, including many potential regulators of the symbiotic program. Plant Physiol 136: 3159-3176

Yang S, Wang Q, Fedorova E, Liu J, Qin Q, Zheng Q, Price PA, Pan H, Wang D, Griffitts JS, et al (2017) Microsymbiont discrimination mediated by a host-secreted peptide in Medicago truncatula. Proc Natl Acad Sci 114: 201700460 
Young ND, Debellé F, Oldroyd GED, Geurts R, Cannon SB, Udvardi MK, Benedito V a, Mayer KFX, Gouzy J, Schoof H, et al (2011) The Medicago genome provides insight into the evolution of rhizobial symbioses. Nature 480: $520-4$ 
CHAPTER 4 


\title{
MTGRF2 IS A GRF-TYPE ZINC FINGER NODULIN FROM MEDICAGO TRUNCATULA POTENTIALLY INVOLVED IN BACTEROID DIFFERENTIATION
}

\begin{abstract}
Nodule specific proteins, called nodulins, are involved in the coordination of nodule formation and symbiotic nitrogen fixation in legumes. In addition to MtN20/MtGRF1, a second GRF-type zinc finger nodulin (MtGRF2, Medtr1g064350.1) is highly and specifically expressed in interzone of Medicago truncatula nodules. During nodule development, nodule cells are colonized by Rhizobium bacteria, which differentiate into a symbiotic form specialized to fix nitrogen: the bacteroid. Bacteroids go through five distinct steps of differentiation (types 1-5) and each stage is present sequentially in the interzone of Medicago truncatula indeterminate nodules. Based on its very discrete gene expression pattern in the interzone and regulatory gene network, MtGRF2 is potentially involved in late bacteroid differentiation. Three Ser residues were experimentally verified as phosphorylated in the amino terminus of the protein, for which the biological relevance and interacting kinase need to be determined. We also identified a putative nuclear localization signal at the carboxyl terminus of the protein, suggesting a potential function as a transcription factor. A comparative analysis of cis-elements presents in MtN20/MtGRF1 and MtGRF2 gene promoters revealed overrepresented shared and unique sequences between that may account for the unique spatial-temporal patterns of expression of each GRF-type zinc finger nodulin.
\end{abstract}




\section{MTGRF2 IS A GRF-TYPE ZINC FINGER NODULIN FROM MEDICAGO TRUNCATULA POTENTIALLY INVOLVED IN BACTEROID DIFFERENTIATION}

\section{INTRODUCTION}

Distinctly from the processes of legume-Rhizobium recognition and cell infection, the plant mechanisms and genes involved in controlling bacteroid maturation largely remain a "black box". In legumes, many species belonging to the inverted repeat-lacking clade (IRLC), such as Medicago truncatula, impose terminal bacteroid differentiation (Czernic et al., 2015). Nodule-specific cysteine-rich (NCR) peptides have been implicated in this process (Mortier et al., 2010; Van de Velde et al., 2010; Farkas et al., 2014; Pan and Wang, 2017).

During the rhizobial infection in the nodule cell via endocytosis, they become enclosed within the confines of a semi-organelle called the symbiosome, which is derived from the plant plasma membrane during endocytosis of the infecting bacteria. Each infected nodule cell can hold several thousands of symbiosomes (Kereszt et al., 2011). The rhizobia undergo through an exceptional differentiation process from the free-living, non-nitrogen fixing organism to turn into an auxotrophic endocellular microsymbiont capable of mutualistically fixing nitrogen, called the bacteroid (Jones et al., 2007). Plant peptides coordinate and elicit transcriptional response controlling the bacteroid differentiation (Ferguson et al., 2002; Van de Velde et al., 2010; Bourcy et al., 2013; Berrabah et al., 2015; de Bang et al., 2017). In indeterminate nodules, bacteroid differentiation occurs in the interzone II-III (Emerich and Krishnan, 2014; Maróti and Kondorosi, 2014; Penterman et al., 2014). At first, the bacteria may or may not reproduce to generate a few cells in each symbiosome (Maróti and Kondorosi, 2014). In M. truncatula, however, bacteria do not reproduce and each symbiosome holds a single bacteroid. The bacteroid differentiation process starts with NCRs peptides, SymCRK and RSD preventing defense mechanisms, receiving differentiation inducement of plant genes, until the nitrogenase will be synthesized, culminating in a mature, fully functional bacteroid capable to fix nitrogen (Penterman et al., 2014; Berrabah et al., 2015). One important stage of symbiosome differentiation occurs at nodule Interzone (IZ or ZII-ZIII), which is characterized by infected cells showing starch accumulation in plastids, and type-3 bacteroid with cytoplasmic heterogeneity and DNA endoreduplication, as explored in Chapter 1 (Vasse et al., 1990).

Very few legume genes have been specifically characterized in the process of bacteroid differentiation. The phosphatidylinositol phospholipase C-like (PI-PLC-XD)-containing protein DOES NOT FIX NITROGEN 2 (DNF2) is required for bacteroid persistence (Bourcy et al., 2013; Wang et al., 2017). The $\mathrm{C} 2 \mathrm{H} 2$ zinc finger transcription factor REGULATOR OF SYMBIOSOME DIFFERENTIATION (RSD) regulates the early stages of symbiosome development (Sinharoy et al., 2013). 
Additionally, SymCRK and DNF2 are required in infected cells to prevent defense-like reactions in nodules after bacterial infection (Berrabah et al., 2015). Recently, the Lotus ASPARTIC PEPTIDASE NODULEINDUCED 1 (LjAPN1) was characterized as involved in bacteroid persistence (Yamaya-Ito et al., 2017). Bacteroid terminal differentiation requires the interaction between MtTRXS1 with NCR247 and NCR335. This interaction allows MtTRXS1 to activate those NCR247 and NCR335, in order the plant to regulates the bacteroid differentiation (Ribeiro et al., 2017). Given the complexity of the processes occurring in the interzone, it is reasonable to expect that a much larger number of genes are specifically involved and await functional characterization.

Herein, we present a novel putative GRF-type zinc finger transcription factor expressed specifically in the interzone of the indeterminate nodule of M. truncatula. Among the 52 genes coding for GRF-type zinc finger proteins in the M. truncatula genome, only two were expressed specifically in nodules (Chapter 2). The Medicago nodulin 20 (MtN20/MtGRF1) is introduced in Chapter 3. We anticipate MtGRF2 is a hub transcription factor controlling the expression of key genes involved in the process of bacteroid differentiation in nodule cells.

\section{RESULTS AND DISCUSSION}

Moreover, the Medicago proteome compendium (Marx et al., 2016) of the six major organs of the mature plant and three late time-points during nodules development confirms the presence of the MtGRF2 protein found specifically in nodules (Figure 1).

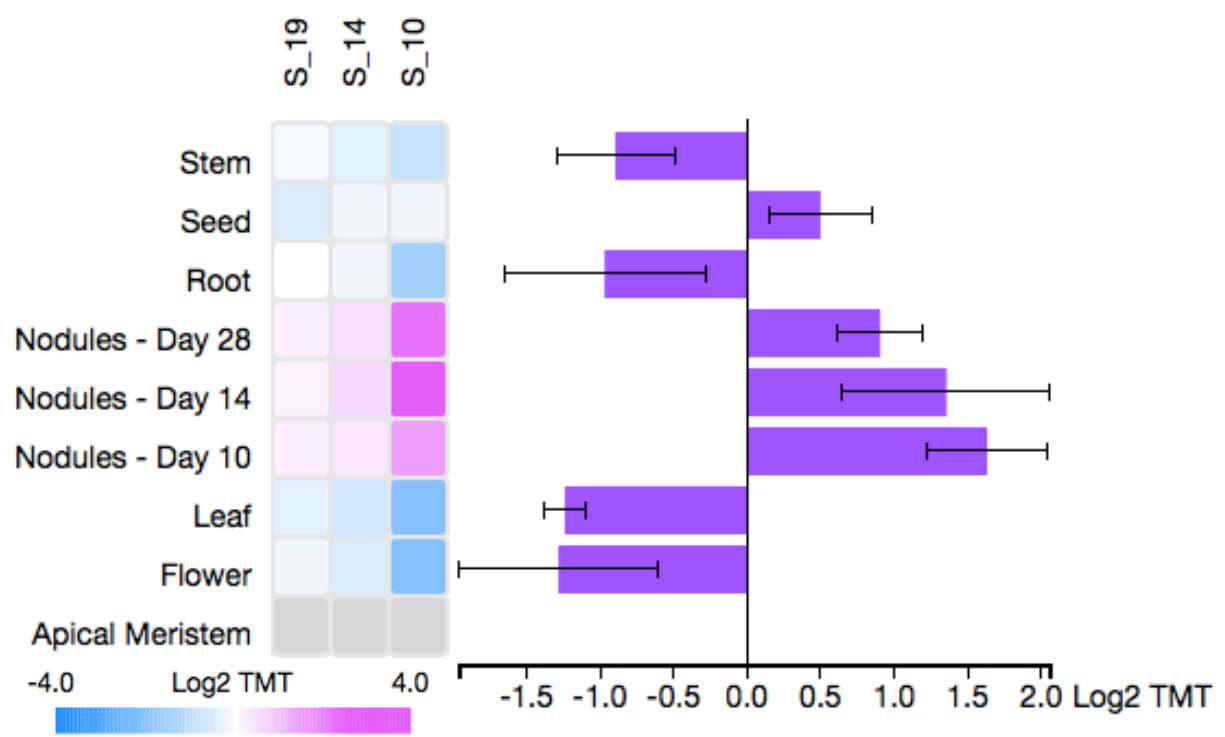

Figure 1. MtGRF2 quantification retrieved from the Medicago truncatula Compendium proteome (Marx et al., 2016). The MtGRF2 protein is present in nodules samples. The $\mathrm{x}$-axis is presented as $\log 2$ of the relative protein abundance (TMT), in which the values are normalized against the average of all samples. Note that the quantification is based on protein fragments (small peptides), which sequences may be shared between different proteins in some instances. 
Moreover, phosphorylation sites were detected in Ser residues in the positions 10, 14 and 19

(Figure 2). The significance of these phosphorylations and the kinase(s) involved in the process are still to be determined. Next, using the NucPred tool (Brameier et al., 2007) we identified a putative nuclear localization signal (NLS) in the very carboxy-terminus of the MtGRF2 protein (Figure 2).

\section{MKGVVRFETS̊PLLS์KREAS์WNGSVSNVDTYESAAPTCKCGKKCILYISKTSKNPNTHFYRCPYFK QQRPHCNYFVQKDKFIESQTTMVDLKSKTTMVELLEAKINQLEKDVKIMKSKIEDDIEVKINQLE KDMEVKINQFERDIEVIKTQIIEMQVKMEQDKNWKRCVRAVGVVIVVWLYPFVFGSRKRLSK}

Figure 2. The MtGRF2 protein sequence was retrieved from Medicago truncatula Proteome Compendium (Marx et al., 2016). Three serine phosphorylated were noticed on positions 10, 14 and 19 (shown with red tags atop). The GRFtype zinc finger protein domain is denoted with red underline. The putative nuclear localization signal (NLS) as estimated by the SBC-NucPred tool is denoted with a green box (Brameier et al., 2007). The actual amino acid residues covered in the proteome sequencing project are shown in bold.

The conserved domains of a protein are usually encoded within the confines of a single exon (Blaker, 1985; Doolittle, 1985; Sibley et al., 2016). Interestingly, the gene architecture of $M t G R F 2$ is quite unusual in the sense that it is split between its only two exons (Figure 3). The same observation was also noticed for MtGRF1 (Chapter 3).

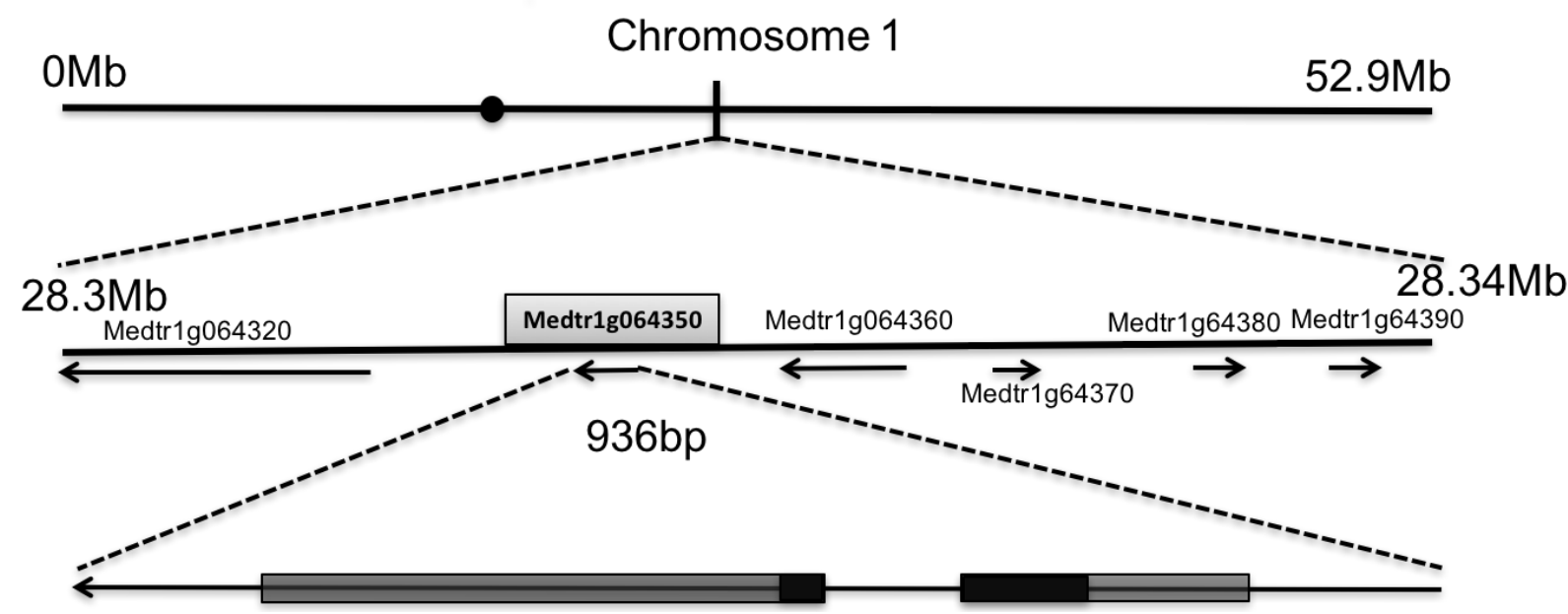

Figure 3. Gene structure of Medtr1g064350 (MtGRF2). The centromere position of chromosome 1 of Medicago truncatula is represented by a black circle. The transcription direction of genes in the vicinity of $M t G R F 2$ are indicated by arrows. The exons of MtGRF2 are represented by boxes, and the intron and extragenic regions, by lines. The sequence coding for the GRF-type zinc finger domain (IPR010666) is represented in black.

Nodules of hairy roots generated with a construct expressing GUS expression driven by a 2,062-bp promoter region of $M t G R F 2$ confirmed the expression domain clearly in the interzone of the mature nodule, although some expression was also noticed at the basis of the nodule, close to the root (Figure 4A-C). 
$M t G R F 2$ expression is negligible at 3-dpi roots but very high at 10-dpi nodulating root systems (Figure 4F). Mutant rhizobial strains impaired in specific milestones of symbiotic establishment showed that bacteroid differentiation, but not nitrogen fixation per se, is needed for $M t G R F 2$ expression, although a leaky expression level was observed in the bacA mutant (Figure 4G). The RNA-Seq laser capture microdissection dataset of five distinct zones of the mature nodule (Roux et al., 2014) shows MtGRF2 with maximum expression in the interzone (IZ, a.k.a. zone II-III). The RNA-Seq LCM dataset (Roux et al., 2014) shows MtGRF2 expressed most strongly in the interzone (Figure 4H). Altogether, the level and spatiotemporal transcriptional activity of $M t G R F 2$ indicates a role during bacteroid differentiation.
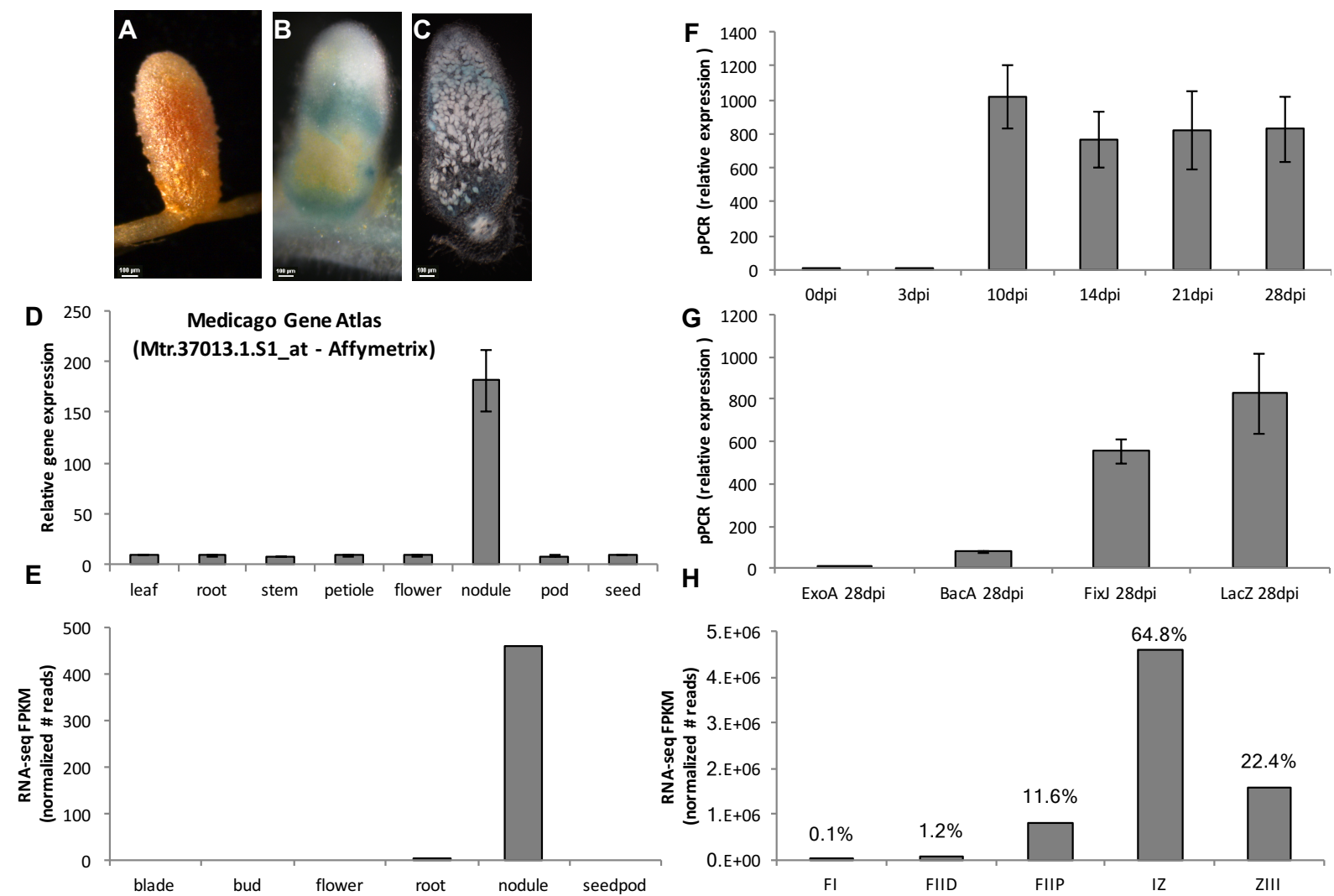

Figure 4. MtGRF2 (Medtr1g064350) gene expression in nodules and roots inoculated with Sinorhizobium meliloti. (A-C) pMtGRF2::GUS expression profile of root nodules stained with X-Gluc. (A) 28-day old whole, wild-type nodule (non-transgenic control). (B) 28-day old whole nodule expressing the $p G R F 2:: G U S$ cassette. C) A 70- $\mu \mathrm{m}$ section of the nodule shown in B. MtGRF2 expression is localized to the interzone (IZ) or zone II-III of the mature nodule, as well as the basis of the nodule close to the root. (D-E) MtGRF2 expression is specific to nodules. (D) Affymetrix data from the Medicago Gene Atlas (Benedito et al., 2008). (E) RNA-Seq dataset from Young et al. (2011). (F-G) $M t G R F 2$ qRT-PCR expression analysis of nodulating roots. (F) Time-course of MtGRF2 gene expression in roots inoculated with Sinorhizobium meliloti strain ABS7 expressing lacZ (ABS7-lacZ). (G) MtGRF2 gene expression in 28-dpi nodulating roots inoculated with symbiotic mutants of Sinorhizobium meliloti (Sm1021-lacZ). MtGRF2 expression requires bacterial differentiation, but not symbiotic nitrogen fixation per se. (H) $M t G R F 2$ is expressed highest in the interzone (IZ or zone II-II) of the mature nodule (data extracted from Roux et al., 2014). 
Therefore, $M t G R F 2$ is a nodule-specific gene expressed after Rhizobium infection and before the nitrogen fixation during bacteroid differentiation in the nodule interzone. This indicates that MtGRF2 may play an essential role during the bacteroid differentiation for normal symbiotic nitrogen fixation in root nodules of $M$. truncatula.

\section{Genetic Network Analysis}

In order to understand the relationship between MtGRF2 and other genes during nodule development, we developed a correlation genetic network using a selection of 72 SRAs from M. truncatula to generate an expression matrix for all 57,585 identified genes. We gathered the significant first- and second-degree Pearson correlations $(\rho \geq 0.90)$ to build the correlation genetic network (Figure 5). For better perusal of the data, Table 1 shows the first-degree correlations $(\rho \geq 0.90)$ between the expression of MtGRF2 and other genes, along with second-degree correlations $(\rho \geq 0.95)$. 


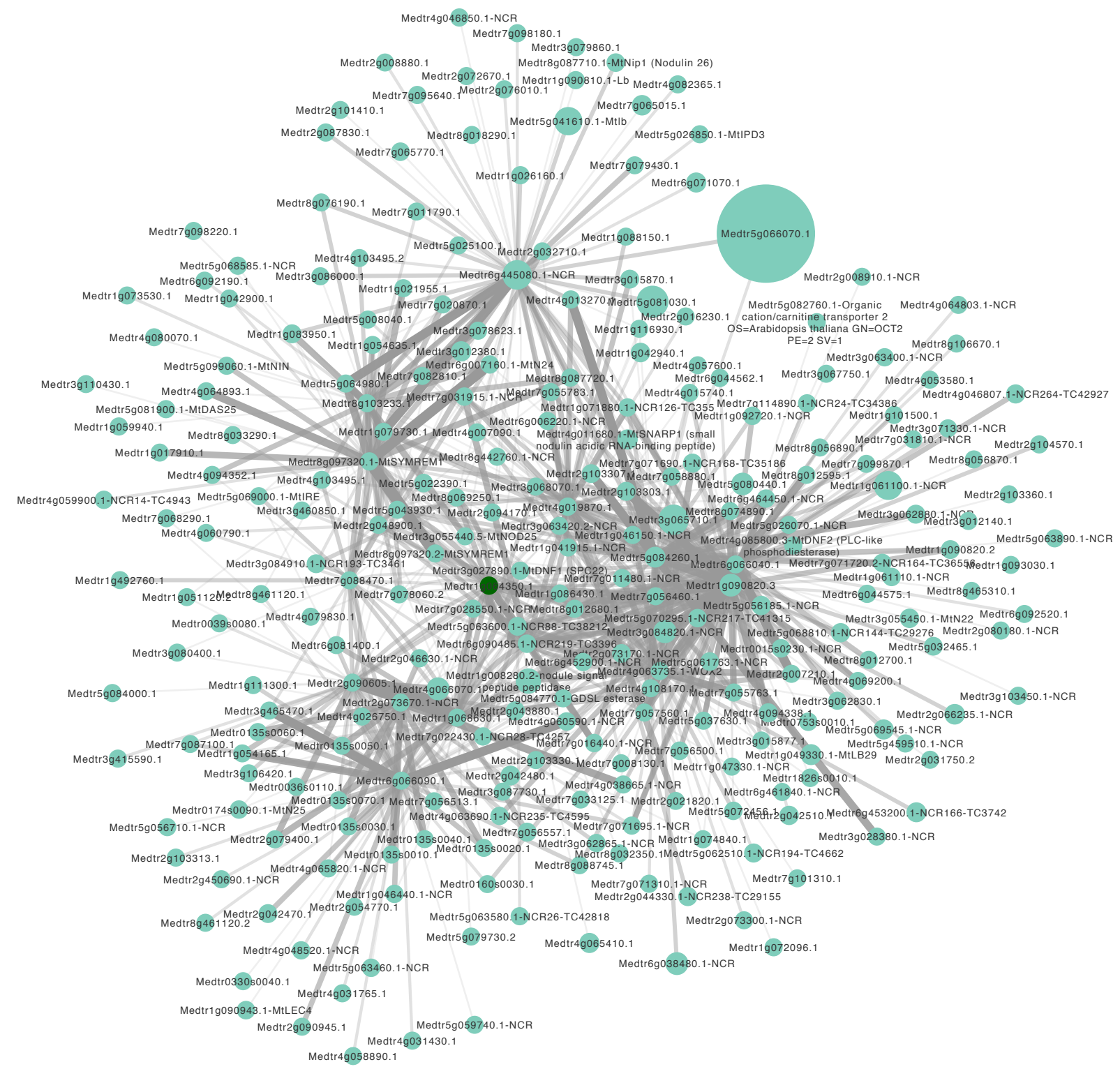

Figure 5. Co-expression genetic network of $M t G R F 2 . M t G R F 2$ is shown in dark green centralizing the network, while all other nodes are shown in turquoise. Node size corresponds to expression level in the Medicago truncatula root nodule. The edges of the network correspond to the correlations between each node, which thickness and transparency correspond to Pearson correlation between the genes. Only genes directly correlated with $M t G R F 2$ expression $(\rho \geq 0.90)$ and those correlated in second-order $(\rho \geq 0.95)$ are shown.

In this analysis centered on MtGRF2 expression, several NCR peptide genes are significantly correlated in the first degree, such as MtNCR88-TC38212 (Medtr5g063600.1), NCR219-TC3396 (Medtr6g090485.1), as well as the unnamed NCR peptides coded by the genes Medtr2g073170, Medtr2g073670, and Medtr2g073670. Additionally, the gene activities of MtWOX2 (Medtr4g063735.1) and MTSYMREM (Medtr8g097320.1) were found significantly and directly correlated in the first degree with MtGRF2. 


\begin{tabular}{|c|c|c|c|c|}
\hline Gene1 & Gene2 & $\rho$ & Nodule(TPM) & p.value \\
\hline Medtr1g064350.1 & Medtr5g063600.1-NCR88-TC38212 & 0.95 & 560.411 & c \\
\hline Medtr1g064350.1 & Medtr6g090485.1-NCR219-TC3396 & 0.94 & 316.068 & $\mathrm{c}$ \\
\hline Medtr1g064350.1 & Medtr7g056460.1 & 0.94 & 10.3232 & $\mathrm{c}$ \\
\hline Medtr1g064350.1 & Medtr1g068630.1 & 0.93 & 12.7759 & $\mathrm{c}$ \\
\hline Medtr1g064350.1 & Medtr5g043930.1 & 0.93 & 1.69487 & $\mathrm{C}$ \\
\hline Medtr1g064350.1 & Medtr8g069250.1 & 0.93 & 23.3169 & $\mathrm{C}$ \\
\hline Medtr1g064350.1 & Medtr2g048900.1 & 0.92 & 43.8192 & $\mathrm{C}$ \\
\hline Medtr1g064350.1 & Medtr2g090605.1 & 0.92 & 14.206 & $\mathrm{C}$ \\
\hline Medtr1g064350.1 & Medtr1g090820.3 & 0.91 & 3359.16 & $\mathrm{c}$ \\
\hline Medtr1g064350.1 & Medtr2g073170.1-NCR & 0.91 & 540.612 & $\mathrm{c}$ \\
\hline Medtr1g064350.1 & Medtr3g460850.1 & 0.91 & 6.78597 & $\mathrm{C}$ \\
\hline Medtr1g064350.1 & Medtr4g063735.1-WOX2 & 0.91 & 23.0564 & $\mathrm{C}$ \\
\hline Medtr1g064350.1 & Medtr6g066040.1 & 0.91 & 26.186 & $\mathrm{c}$ \\
\hline Medtr1g064350.1 & Medtr7g078060.2 & 0.91 & 9.04986 & $\mathrm{C}$ \\
\hline Medtr1g064350.1 & Medtr7g088470.1 & 0.91 & 9.2261 & $\mathrm{C}$ \\
\hline Medtr1g064350.1 & Medtr8g012680.1 & 0.91 & 95.0776 & $\mathrm{C}$ \\
\hline Medtr1g064350.1 & Medtr2g073670.1-NCR & 0.9 & 59.2457 & $\mathrm{C}$ \\
\hline Medtr1g064350.1 & Medtr4g019870.1 & 0.9 & 201.425 & $\mathrm{c}$ \\
\hline Medtr1g064350.1 & Medtr5g084260.1 & 0.9 & 1982.68 & $\mathrm{c}$ \\
\hline Medtr1g064350.1 & Medtr6g445080.1-NCR & 0.9 & 8000.15 & $\mathrm{c}$ \\
\hline Medtr1g064350.1 & Medtr6g066090.1 & 0.9 & 33.8277 & $\mathrm{C}$ \\
\hline Medtr1g064350.1 & Medtr8g097320.1-MtSYMREM1 & 0.9 & 183.723 & $\mathrm{C}$ \\
\hline Medtr1g064350.1 & Medtr8g103233.1 & 0.9 & 26.5023 & $\mathrm{C}$ \\
\hline Medtr8g097320.1-MtSYMREM1 & Medtr8g097320.2-MtSYMREM1 & 0.98 & 19.0302 & $c$ \\
\hline Medtr1g068630.1 & Medtr2g090605.1 & 0.97 & 14.206 & $\mathrm{C}$ \\
\hline Medtr2g090605.1 & Medtr1g068630.1 & 0.97 & 12.7759 & $\mathrm{C}$ \\
\hline Medtr8g097320.1-MtSYMREM1 & Medtr6g007160.1-MtN24 & 0.97 & 235.405 & $\mathrm{C}$ \\
\hline Medtr1g090820.3 & Medtr2g103303.1 & 0.96 & 631.826 & $\mathrm{c}$ \\
\hline Medtr5g084260.1 & Medtr2g103307.1 & 0.96 & 547.189 & $\mathrm{C}$ \\
\hline Medtr5g084260.1 & Medtr4g013270.1 & 0.96 & 204.653 & $\mathrm{C}$ \\
\hline Medtr6g066040.1 & Medtr2g007210.1 & 0.96 & 73.5612 & $\mathrm{C}$ \\
\hline Medtr6g066090.1 & Medtr3g465470.1 & 0.96 & 22.7632 & $\mathrm{C}$ \\
\hline Medtr6g066090.1 & Medtr4g060590.1-NCR & 0.96 & 288.245 & $c$ \\
\hline Medtr6g445080.1-NCR & Medtr1g079730.1 & 0.96 & 18.7348 & $\mathrm{C}$ \\
\hline Medtr6g445080.1-NCR & Medtr5g064980.1 & 0.96 & 91.2789 & $\mathrm{c}$ \\
\hline Medtr1g090820.3 & Medtr4g063735.1-WOX2 & 0.95 & 23.0564 & $\mathrm{C}$ \\
\hline Medtr1g090820.3 & Medtr4g094338.1 & 0.95 & 702.329 & $\mathrm{c}$ \\
\hline Medtr1g090820.3 & Medtr5g084260.1 & 0.95 & 1982.68 & $\mathrm{C}$ \\
\hline Medtr1g090820.3 & Medtr6g464450.1-NCR & 0.95 & 272.111 & $c$ \\
\hline Medtr2g073670.1-NCR & Medtr4g038665.1-NCR & 0.95 & 71.318 & 0 \\
\hline Medtr4g063735.1-WOX2 & Medtr1g090820.3 & 0.95 & 3359.16 & $\mathrm{c}$ \\
\hline
\end{tabular}

Table 1. First- and secondcorrelation degree of coexpression genes with MtGRF2. Pearson coefficient correlations (PCC) were generated with RNA-Seq normalized as transcripts per million (TPM). Significant correlations were considered $\varrho \geq 0.90$ for firstdegree associations, and $\varrho \geq 0.95$ for second-degree associations in the analysis. The Gene name is shown for each one that has been functionally annotated.

Expression of NCR peptides is highly abundant in indeterminate nodules of $M$. truncatula, including during bacterial infection and bacteroid differentiation. They define the species-specific relationships between legumes and rhizobia (Van de Velde et al., 2010; Farkas et al., 2014; Satgé et al., 2016; Yang et al., 2017; Wang et al., 2017).

The WUSCHEL homeobox-containing (WOX) gene MtWOX2 (Medtr4g063735.1) is a homolog of the Arabidopsis AtWOX2. WOX homeobox proteins are transcription factors involved in embryo apical patterning and cotyledon development (Gamas et al., 1996). AtWOX2 acts redundantly with STIMPY-LIKE (STPL/WOX8) on regulating the expression of CUC genes to promote the establishment of the cotyledon boundary, without affecting the primary shoot meristem (Lie et al., 2012). This indicates that MtWOX2 may 
be involved in a somewhat similar developmental role in root nodules during differentiation after cell duplication.

MtSYMREM1 (Medtr8g097320 in Mt4.0v2.1, previously named Medtr8g098650 in Mt3.5v1) is a remorin membrane protein that interacts with at least three essentials nodule receptor-like kinases (RLKs). MtSYMREM1 has a Lotus homologs (LjSYMREM1) that increase the nodulation when overexpressed. MtSYMREM1 is involved with infection and symbiosomes formation from the microarray-based analysis of transcription reprogramming of root nodule development (Moreau et al., 2011).

At the second-degree level, i.e. genes associated transcriptionally with those directly associated with MtGRF2 expression, we highlight the following: the nodulins MtN22 (Medtr3g055450.1), MtN24 (Medtr6g007160.1), MtN25 (Medtr0174s0090.1), the signal peptide peptidase (Medtr1g008280.2), the transcription factor MtNIN (Medtr5g099060.1), the leghemoglobins MtLB29 (Medtr1g049330.1), Medtr1g090810.1 and Medtr5g041610.1, MtLEC4 (Medtr1g090943.1), MtIPD3 (Medtr5g026850.1), MtIRE (Medtr5g069000.1), MtNIP1/N26 (Medtr8g087710.1), MtDAS25 (Medtr5g081900.1), MtDNF1 (Medtr3g027890.1), MtDNF2 (Medtr4g085800.3), MtSYMREM1 (Medtr8g097320.1), MtSNARP1 (Medtr4g011680.1), MtNOD25 (Medtr3g055440.5), the organic cation/carnitine transporter Mt2OS (Medtr5g082760.1), along with the nodule-specific cysteine-rich peptidases NCR126-TC355 (Medtr1g071880.1), NCR193-TC3461 (Medtr3g084910.1), NCR14-TC4943 (Medtr4g059900.1), NCR144-TC29276 (Medtr5g068810.1), NCR164-TC36556 (Medtr7g071720.2), NCR166-TC3742 (Medtr6g453200.1), NCR168-TC35186 (Medtr7g071690.1), NCR194-TC4662 (Medtr5g062510.1), NCR217-TC41315 (Medtr5g070295.1), NCR219-TC3396 (Medtr6g090485.1), NCR235-TC4595 (Medtr4g063690.1), NCR238-TC29155 (Medtr2g044330.1), NCR24-TC34386 (Medtr7g114890.1), NCR26-TC42818 (Medtr5g063580.1), NCR264-TC42927 (Medtr4g046807.1), NCR28-TC4257 (Medtr7g022430.1), NCR88-TC38212 (Medtr5g063600.1) plus 48 other NCRs.

The non-characterized nodulins MtN22, MtN24 and MtN25 (Gamas et al., 1996) show high and specific expression in nodule, with maxima at $45.7 \%$ of total expression confined to the IZ for MtN22, $39.3 \%$ at proximal side of FII (along with $18 \%$ to IZ) for MtN24, and 70.3\% to IZ for MtN25, (Roux et al., 2014). Congruently, along with $M t G R F 2$, these three nodulins also show maximum expression in the nodule zone 2 sample in the Medicago Gene Atlas (Benedito et al., 2008).

Moreover, MtSNARP1 (Medtr4g011680.1) is small nodulin coding for an acidic RNA-binding peptide that regulates the establishment of symbiosis between Medicago truncatula-Sinorhizobium meliloti. MtSNARP1 interacts with the early nodulin MtENOD40 (Laporte et al., 2010), which is possibly involved in reallocating nuclear proteins to the cytoplasm (Pan and Wang, 2017), although the exact mechanism remains unknown. MtNIN (Medtr5g099060.1) is a central important TF acting downstream of 
NF signaling pathway that coordinates nodule formation and SNF, also seen in Chapter 2 (Marsh et al., 2007; Vernié et al., 2015).

Surprisingly, leghemoglobins can be symbiotic or non-symbiotic, and their genes are present not only in legumes, but also non-nodulating species. For example, the Arabidopsis genome codes for two leghemoglobins (Trevaskis et al., 1997). In legumes, nodule leghemoglobins are crucial for sustaining SNF by protecting nitrogenase from $\mathrm{O}_{2}$ irreversible inactivation (Andersson et al., 1996). In our gene network centered on MtGRF2, three leghemoglobins were associated - MtLb29 (Medtr1g049330.1), Medtr1g090810.1 and Medtr5g041610.1. Among these, MtLb29 belongs to a legume-specific phylogenetic clade, while the other two are in clades containing non-legume proteins (Ott et al., 2005). The expression level of leghemoglobin Lb120-1 (Medtr5g066070), which is associated with MtGRF2 via an NCR peptide (Medtr6g445080) is quite remarkable.

The lectin MtLEC4 is a $\beta, 1-3$ endoglucanase (MtBGLU1) expressed in nodules starting at one week after inoculation with Sinorhizobium meliloti. Medicago mutants (bit1, rit1, and mtsym 1) are defective in the initial stages of invasion, whereas the bacterial mutants (exo $A$ and $e x o H$ ) were unable to induce $M t L E C 4$ expression, although nodules infected with the bacA mutant do express MtLEC4 (Mitra and Long, 2004). Nodules of plant mutants with defects in nitrogen fixation ( $d n f 1$ and $d n f 5$ ) also express MtLEC4 (Mitra and Long, 2004), indicating that MtLEC4 acts downstream of DNF1 and DNF5. Opposite results were found on the transcription reprograming analysis of nodule development, where the MtLEC4 present expression in exoA nodules, which are wild-type of M. truncatula inoculated with Rhizobium capable to colonized plant cells, but impaired to differentiate (Moreau et al., 2011).

MtDNF1 (SPC22, Medtr3g027890) is a subunit of a signal peptidase complex required for protein secretion during symbiosome development (Wang et al., 2010). MtDNF2 (PLC-like phosphodiesterase, Medtr4g085800) is a putative phosphatidylinositol phospholipase C-like enzyme involved with bacteroid differentiation since its down-regulation caused bacteria to not differentiate properly into bacteroids and generated non-functional nodules (Bourcy et al., 2013).

The nuclear protein IPD3 (called Cyclops in Lotus japonicus), encoded by MtIPD3, a phosphorylation substrate of DMI3 (CCaMK), is also essential for rhizobial colonization decoding of the calcium signal and the molecular events downstream required for symbiosis events in both rhizobial and mycorrhizal colonization (Yano et al., 2008; Horváth et al., 2011).

MtIRE an Arabidopsis thaliana homologous INCOMPLETE ROOT HAIR ELONGATION (IRE) gene encodes to AGC protein kinase expressed in inoculated roots and in a proximal part of the invasion zone (zone II) found in indeterminate nodules (Pislariu and Dickstein, 2007). MtNIP1, Nod 26-like, encodes to an aquaporin Nod intrinsic proteins (NIP), which was described as AM-induced and facilitate the cellular uptake of ammonia (Uehlein et al., 2007). MtDAS25 is been shown to be associated with DNF1 (Wang et 
al., 2010), and is been on expression profiles together with, with DNF1and DAS25 genes in cluster 11 (Moreau et al., 2011; Roux et al., 2014). MtNDO25 encodes for a signal peptide with high conserved modular nodulin in both $\mathrm{N}$-terminal and $\mathrm{C}$-terminus, that is also been localized in the symbiosome of infected cells. This modular conserved nodulins present one possible mechanism for the delivery of host proteins to the symbiosomes of infected root nodule cells, shown to be sufficient to translocate proteins across the peribacteroid membrane (Hohnjec et al., 2009).

Taken all together, we hypothesize that MtGRF2 is a novel nodulin with a putative transcription factor function apparently involved in the rhizobium differentiation and maturation, the required process for symbiotic nitrogen fixation in root nodule of M. truncatula.

\section{Analysis of cis-elements in the MtGRF2 gene promoter}

An important question regarding gene expression, is the presence of conserved cis-elements that interact with transcription factors and regulators. The very specific expression profile of MtGRF2 in nodule during rhizobial differentiation presents an opportunity to better understand the molecular mechanisms governing this transcriptional pattern. Known cis-elements present in the 2,062bp promoter region of the $M t G R F 2$ gene (Figure 6). We identified 63 cis-different elements, with 38 of them representing in multiple copies. Those represented at least seven times in this genomic interval are: ARRIAT (20 times), DOFCOREZM (17), CACTFTPPCA1 (14), GTFANTG10 (12), GATABOX (11), CAATBOX1 (10), MYCCONSENSUSAT (9), EBOXNNAPA (9), OSE2ROOTNODULE (7), NODCON2GM (7), and GT1CONSENSUS (7). 


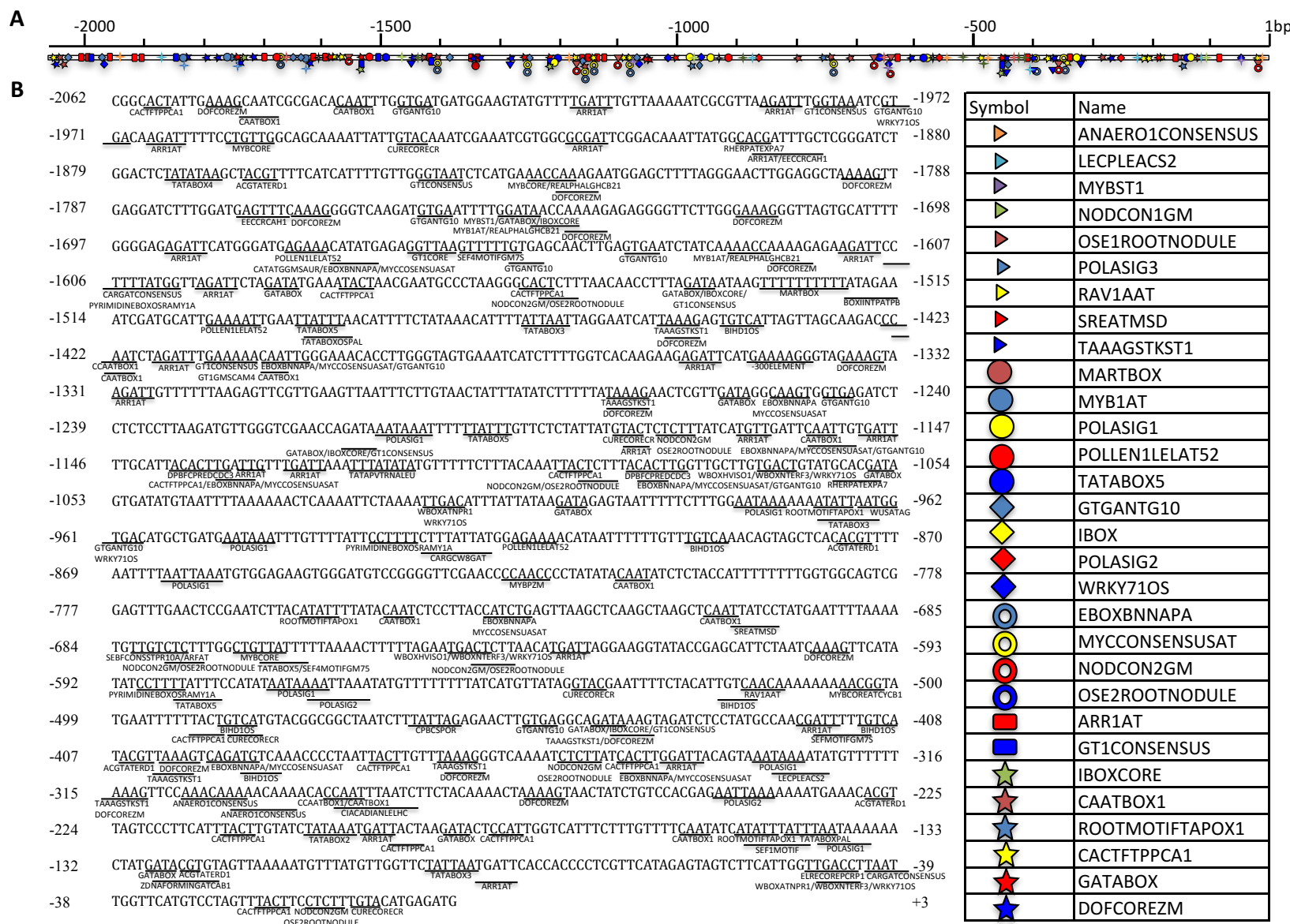

Figure 6. Cis-regulatory elements identified in the promoter region of MtGRF2 (Medtr1g064350). A 2,062-bp region upstream of the transcriptional start site (TSS) was analyzed in PLACE (Higo et al., 1999). Cis-elements repeated more than three times are represented in (A) with the symbols correspondence to each element shown on the right. Thes cis-elements are highlighted the promoter sequence in $(\mathbf{B})$.

Given the unique and distinct expression domains of MtGRF1 and MtGRF2 genes, a comparative analysis can be useful to elucidate their spatial regulation. It has not escaped our notice that two cis-elements are frequent, but similarly or uniquely represented in both or either in promoters of the GRF genes of this study. The MtN20/MtGRF1 promoter has five IBOX, while the MtGRF2 promoter has six BIHD1OS ciselements, neither of those cis-elements are present in the promoter of the other gene (Table 2). The biological significance of these elements to the unique expression patterns of each of our genes of interest has yet to be assessed.

In toto, MtGRF2 is a novel nodulin highly and specifically expressed in interzone tissues of $M$. truncatula indeterminate nodules. This gene encodes a protein from uncharacterized novel protein family, GRF-type zinc finger and it seems to have an important function on the bacteroid terminal maturation that occurs in the interzone, where the bacteroid type- 3 ceases its elongation and feature a high cytoplasmic heterogeneity. 
Table 2. Comparative analysis of promoter cis-elements of $M t N 20 / M t G R F 1$ and $M t G R F 2$ genes. Common and distinct promoter cis-elements found in $\sim 2 \mathrm{~kb}$ upstream of $M t N 20 / M t G R F 1$ and $M t G R F 2$. \#s indicates the number of times that cis-elements were founded in the promoter of each gene. Unique cis-elements in each gene promoter are shown on the right.

\begin{tabular}{|c|c|c|c|c|c|c|}
\hline \multicolumn{3}{|c|}{$\begin{array}{l}\text { Common Cis-element between pMtGRF1 and } \\
\text { pMtGRF2 followed by times that each one apears }\end{array}$} & \multicolumn{4}{|c|}{ Differential Cis-elements between pMtGRF1 and pMtGRF2 } \\
\hline \multirow{2}{*}{$\begin{array}{ll}\text { Cis-element } \\
\text { BOXIINTPATPB }\end{array}$} & \multicolumn{2}{|c|}{ pMtGRF1 \#s pMtGRF2 \#s } & \multicolumn{2}{|c|}{$\begin{array}{c}\text { pMtGRF1 } \\
\end{array}$} & \multicolumn{2}{|l|}{ pMtGRF2 } \\
\hline & 1 & 1 & cis-element & copies \# & cis-element & copies \# \\
\hline CARGCW8GAT & 1 & 1 & 2SSEEDPROTBANAPA & 1 & ABRELATERD1 & 1 \\
\hline CIACADIANLELHC & 1 & 1 & АMYBOX2 & 1 & ARFAT & 1 \\
\hline CPBCSPOR & 1 & 1 & CANBNNAPA & 1 & CATATGGMSAUR & 1 \\
\hline GT1CORE & 1 & 1 & IBOXCORENT & 1 & ELRECOREPCRP1 & 1 \\
\hline MYBCOREATCYCB1 & 1 & 1 & MYB26PS & 1 & MYBPZM & 1 \\
\hline CCAATBOX1 & 1 & 2 & MYCATRD22 & 1 & SEBFCONSSTPR10A & 1 \\
\hline PYRIMIDINEBOXOSRAMY1A & 1 & 3 & PRECONSCRHSP7OA & 1 & SEF1MOTIF & 1 \\
\hline REALPHALGLHCB21 & 1 & 3 & PROXBBNNAPA & 1 & TATAPVTRNALEU & 1 \\
\hline -300ELEMENT & 2 & 1 & SORLIP2AT & 1 & WUSATAg & 1 \\
\hline GT1GMSCAM4 & 2 & 1 & TATCCAYMOTIFOSRAMY3D & 1 & ZDNAFORMINGATCAB1 & 1 \\
\hline DPBFCOREDCDC3 & 2 & 2 & $-10 P E H V P S B D$ & 2 & CARGATCONSENSUS & 2 \\
\hline SEF4MOTIFGM7S & 2 & 3 & АМYBOX1 & 2 & EECCRCAH1 & 2 \\
\hline ACGTATERD1 & 2 & 5 & CCA1ATLHCB1 & 2 & MYBCORE & 2 \\
\hline CURECORECR & 2 & 5 & GAREAT & 2 & RHERPATEXPA7 & 2 \\
\hline LECPLEACS2 & 3 & 1 & INRNTPSADB & 2 & BIHD1OS & 6 \\
\hline MYBST1 & 3 & 1 & MYBGAHV & 2 & & \\
\hline RAV1AAT & 3 & 1 & RBCSCONSENSUS & 2 & & \\
\hline SREATMSD & 3 & 1 & TATCCAOSAMY & 2 & & \\
\hline ANAERO1CONSENSUS & 3 & 2 & IBOX & 5 & & \\
\hline MARTBOX & 4 & 1 & & & & \\
\hline MYB1AT & 4 & 3 & & & & \\
\hline POLLEN1LELAT52 & 4 & 4 & & & & \\
\hline POLASIG1 & 4 & 6 & & & & \\
\hline POLASIG2 & 5 & 3 & & & & \\
\hline GTGANTG10 & 5 & 12 & & & & \\
\hline NODCON2GM & 6 & 7 & & & & \\
\hline OSE2ROOTNODULE & 6 & 7 & & & & \\
\hline EBOXBNNAPA & 6 & 9 & & & & \\
\hline MYCCONSENSUSAT & 6 & 9 & & & & \\
\hline GT1CONSENSUS & 8 & 7 & & & & \\
\hline ARR1AT & 8 & 20 & & & & \\
\hline IBOXCORE & 10 & 4 & & & & \\
\hline ROOTMOTIFTAPOX1 & 12 & 3 & & & & \\
\hline СААТВОХ1 & 12 & 10 & & & & \\
\hline САCTFTPPCA1 & 15 & 14 & & & & \\
\hline GATABOX & 17 & 11 & & & & \\
\hline DOFCOREZM & 18 & 17 & & & & \\
\hline
\end{tabular}

\section{MATERIAL AND METHODS}

Plant growth conditions: Medicago truncatula plants (ecotype 'A17') were grown in turface:vermiculite (2:1) medium in 4" Azalea pots under 16:8-h (light:dark) photoperiod and $24^{\circ} \mathrm{C}: 22^{\circ} \mathrm{C}$ (day:night) temperature conditions in a Percival growth chamber. Plants received $50 \mathrm{~mL} \mathrm{1X} \mathrm{B \& D} \mathrm{(Broughton} \mathrm{and}$ Dilworth, 1971) fertilizer solution with low nitrogen (0.5mM ammonium nitrate) every other day, except at day of inoculation with rhizobium. 
Cloning of the MtGRF1 promoter: A 2,062-bp genomic region upstream the $M t G R F 2$ start codon (coordinates chr1:28315631...28316566 of the Medicago truncatula genome assembly v.4.0) was amplified and cloned into a binary vector to express the GUS reporter gene. Medicago genomic DNA (ecotype 'A17') was extracted from young leafs using the IDT Plant DNA Extraction Protocol (www.idtdna.com/pages/docs/educational-resources/plant-dna-extraction-protocol.pdf?sfvrsn=5). PCR was carried out with the high-fidelity KOD Extreme Hot-Start DNA polymerase (Toyobo, catalog \#71086) in an Mastercycler ep Gradient S Thermal Cycler (Eppendorf). The amplicon was run on a 1\% agarose gel, column purified and further cloned into the directional pENTR-D/ TOPO vector (ThermoFisher), followed by Gateway LR reaction, using Gateway LR Clonase II Enzyme Mix (ThermoFisher) for recombination it into the destination vector (pKGWFS7). All final cassettes were confirmed by Sanger sequencing at the WVU Genomics Core Facility. Plasmids were used to transform Agrobacterium rhizogenes strain 'ARqua1' for ex-vitro hairy-root transformation. All primer sequences used in this dissertation are provided in Annex 1.

Ex-vitro hairy-root transformation: A slightly modified version of the freeze-thaw method for Agrobacterium transformation protocol (http://openwetware.org/wiki/Maloof_Lab:Agro_Transformation) was used for transformation of Agrobacterium rhizogenes strain 'ARqua1' cells. Ex-vitro hairy root transformation of Medicago truncatula ecotype "A17" was performed as described by Boisson-Dernier et al. (2006). In brief, roots of four-day-old seedlings were diagonally cut out and the wound was inoculated with a three-day-old plate cultivated with ARqual transformed with the final destination on solid LB medium containing the respective selective antibiotic $(100 \mathrm{mg} / \mathrm{L}$ spectinomycin plus $100 \mathrm{mg} / \mathrm{L}$ streptomycin). The seedlings were then grown on modified Fahraeus medium ( $\mathrm{pH} 7.5)$ with $15 \mathrm{~g} / \mathrm{L}$ agar in tissue culture tubes for 2 weeks under 16:8-h light:dark photoperiod regimen at $24^{\circ} \mathrm{C}: 22^{\circ} \mathrm{C}$ day:night temperature before transplanting to a turface:vermiculite (2:1 ratio) under the same growth conditions. $0.5 \mathrm{mM}$ were provided $1 / 2$-strengh $\mathrm{B} \& \mathrm{D}$ fertilizer solution $(50 \mathrm{~mL})$ every other day 7 days before rhizobial inoculation. When applicable, transgenic roots and nodules were visualized under fluorescence stereoscope via expression of the fluorescent marker DsRed (excitation/emission 580/605 nm).

Rhizobial inoculation: Unless specified otherwise, roots of one week-old plants were inoculated with 50 $\mathrm{mL}$ suspension $\left(\mathrm{OD}_{600}=0.05\right)$ of Sinorhizobium meliloti rhizobial strain Sm1021 (Sm1021-lacZ) harboring the hemA::LacZ cassette in $1 \mathrm{X} \mathrm{B} \& \mathrm{D}$ solution without nitrogen to induce nodulation. One inoculation loop of Sinorhizobium meliloti rhizobial strain Sm1021 from glycerol stock was grown for three days in $3 \mathrm{~mL}$ YM medium supplemented with $6 \mathrm{mM} \mathrm{CaCl}_{2}$ and proper antibiotic, according to the destination vector (e.g., 
$10 \mathrm{mg} / \mathrm{L}$ Tetracycline or $100 \mathrm{mg} / \mathrm{L}$ Streptomycin). Sixteen hours before rhizobial inoculation, the 1-mL inoculum was regrown in $200 \mathrm{~mL}$ flask until $\mathrm{OD}_{600} \sim 1.0$. The suspension was centrifuged at $10,000 \mathrm{~g}$ for 10 minutes, the pellet washed by resuspension and centrifugation, and the clean pellet was then resuspended and diluted with $1 \mathrm{X}$ no-N $\mathrm{B} \& \mathrm{D}$ solution without nitrogen to an $\mathrm{OD}_{600}$ of 0.05 . Fifty milliliters of the rhizobial suspension were used to inoculate each plant.

Histochemical assay (tissue fixation and GUS staining): Sections were cut by hand from unfixed stems of plants grown in vitro, essentially as described (Jefferson et al., 1987) and fixed in $0.3 \%$ formaldehyde in $10 \mathrm{mM}$ MES, pH 5.6, 0.3 M D-mannitol for $45 \mathrm{~min}$ at room temperature, followed by several washes in 50 $\mathrm{mM} \mathrm{NaH}_{2} \mathrm{PO}_{4}, \mathrm{pH}$ 7.0. All fixatives and substrate solution were introduced into sections with a brief (1 $\mathrm{min}$ ) vacuum infiltration. Histochemical reactions with X-Gluc were performed with $1 \mathrm{mM}$ substrate in 50 $\mathrm{mM} \mathrm{NaH}{ }_{2} \mathrm{PO}_{4}, \mathrm{pH} 7.0$ at $37^{\circ} \mathrm{C}$ from 3 hours and 16 hours. After staining, sections were rinsed in $70 \%$ ethanol for $5 \mathrm{~min}$, and then mounted for microscopy (Jefferson et al., 1987). For anatomical analyses, transformed nodules at 28 dpi were embedded in 5\% low-melting agarose and sectioned on a vibratome with a $70-\mu \mathrm{m}$ thickness. The sections were extracted from agarose and kept in $1.5 \mathrm{~mL}$ tube with $\mathrm{NaH}_{2} \mathrm{PO}_{4}$, pH 7.0 for observation under light microscopy (Nikon Eclipse E600 microscope coupled with a Nikon DSRi1 camera).

Gene expression analyses: The gene expression profiling of $M t G R F 2$ in nodulating roots inoculated with Sinorhizobium meliloti strain Sm1021 in were performed with M. truncatula ecotype "A17" plants inoculated with the mutants fixJ, bacA, exoA or the functional strain hemA::LacZ strains, all in the same Sm1021 genetic background. For gene expression analyses via qRT-PCR, non-inoculated root samples provided full nitrogen fertilization ( $6 \mathrm{mMN}$ from $2 \mathrm{mM} \mathrm{KNO}_{3}$ and $2 \mathrm{mM} \mathrm{NH}_{4} \mathrm{NO}_{3}$ ) were used as a negative control. Whole root systems were harvested at $0,3,14,21$, and 28 dpi. RNA was extracted with mirVana mRNA Isolation kit (Life Technologies) followed by DNA removal with Turbo DNA-free kit (Applied Biosystems). First strand cDNA was synthesized with oligo-dT priming using the SuperScript III FirstStrand Synthesis Super mix (ThermoFisher), following the manual instructions. All primer sequences used are described cf. Annex 1.

SYBR green master mix (Applied Biosystems) we used for 5- $\mu \mathrm{L}$ reactions and ABI7500 Real Time qPCR System (Applied Biosystems) was used to run three biological and three technical replicates. A master mix containing SyBR green $(2.5 \mu \mathrm{L})$ and $\mathrm{cDNA}(1 \mu \mathrm{L} 1: 10)$ was plated with a solution of primer pair $\operatorname{mix}(0.5 \mu \mathrm{L}$ with $20 \mathrm{mM}$ each) and water $(0.5 \mu \mathrm{L})$. All templates were amplified using the same cycling conditions: $50^{\circ} \mathrm{C}$ for $2 \mathrm{~min}$; $95^{\circ} \mathrm{C}$ for $10 \mathrm{~min} ; 40$ cycles of $95^{\circ} \mathrm{C}$ for $15 \mathrm{sec}$, and $60^{\circ} \mathrm{C}$ for $1 \mathrm{~min}$. 
Melt curves were produced at the end of each run. Ct (threshold cycle) values were exported to Excel to organize data and the comparative analysis of gene expression. The housekeeping genes used as data normalizers for RT-qPCR were EFl $\alpha$ (Medtr6g021800) and Tub1 (Medtr7g089120). LinRegPCR was used to extract PCR efficiencies for each primer pair (http://linregpcr.nl/). The software NormFinder (Andersen, 2004) was used to confirm the chosen housekeeping genes as stably expressed. Relative expression was calculated according to the Pfaffl method (Pfaffl, 2001).

Light microscopy: At 28 days post-inoculation with Sm1021-LacZ, nodules were harvested and fixed under vacuum with $2.5 \%$ glutaraldehyde in $0.1 \mathrm{M}$ PIPES ( $\mathrm{pH} 7.2$ ) for one hour at room temperature, followed by two rinses with 0.1 M PIPES (pH 7.2). When applicable, samples were stained in fresh staining solution containing $50 \mathrm{mM}$ potassium ferricyanide, $50 \mathrm{mM}$ potassium ferrocyanide, $0.08 \%$ X-Gal $(0.08 \mathrm{mg} / \mathrm{mL})$ or $0.08 \%$ Red-Gal $(0.08 \mathrm{mg} / \mathrm{mL})$ and $0.1 \mathrm{M}$ PIPES $(\mathrm{pH} 7.2)$ for 16 hours at room temperature (Boivin et al., 2016), followed by two rinses with 0.1M PIPES (pH 7.2), and stored at 70\% ethanol until processing. After fixation (and staining), tissues were cleared with $2.4 \%$ sodium hypochlorite for 5 min and dehydrated with an ethanol series $(50 \%, 70 \%, 90 \%, 95 \%$, and 100\% twice for 45 minutes each). Samples were then transferred to $100 \%$ xylene for 15 minutes or until translucent. The completely dehydrated samples were embedded in fresh $60^{\circ} \mathrm{C}$ xylene:paraplast $(1: 1)$ mix for two hours at $60^{\circ} \mathrm{C}$ and transferred to melted $\left(60^{\circ} \mathrm{C}\right) 100 \%$ paraplast and incubated at $60^{\circ} \mathrm{C}$ for at least three hours. Each sample were blocked and cut in $7-\mu \mathrm{m}$ section with a conventional microtome. The slices were placed on glass slides and incubated overnight at $37^{\circ} \mathrm{C}$. On the next day, the slides were washed twice with $100 \%$ xylene for three minutes and twice with $100 \%$ ethanol, followed by the hydration process using submersion in $95 \%$ ethanol and then water for five minutes each. The samples were then ready to accept water-based dyes. The slides were observed under bright field microscope (Nikon Eclipse E600 microscope coupled with a Nikon DSRi1 camera). Often, X-gal staining was used to visualize lacZ bacteria and the tissue was counterstained with chloramphenicol to visualize lignin in the plant cell wall.

Regulatory gene network analysis: SRA files of 72 publicly available Medicago truncatula RNA-Seq samples were chosen for this study: 33 files with high sequencing depth totaling triplicates of five treatments (Roux et al., 2014: NCBI BioProject Accession PRJNA213402), 15 files for five treatments in triplicates collected at different times points of nodule development (Satgé et al., 2016: PRJNA188524), 36 files of nodules with triplicates of eight treatments plus four root controls (unpublished, PRJNA327225) and six files of major organs of the mature Medicago truncatula plant (Young et al., 2011: PRJNA80163). The raw files were submitted to quality check using the FastQC software (www.bioinformatics.babraham.ac.uk/projects/fastqc/), and then mapped onto the M. truncatula reference 
transcriptome (Mt4.0v2) with the Salmon Transcript Quantification v.0.8.2 software (Patro et al., 2015) in the Galaxy platform (Afgan et al., 2016). All data were normalized as transcript per million (TPM). A gene expression matrix was created in the format a gene-per-row (57,585 genes models) and a sample-percolumn (72 samples).

Pearson coefficient correlation (PCC) was performed with MtGRF2 expression values against all Medicago genes. A $\rho \geq|0.9|$ threshold was imposed in first-degree correlations with MtGRF2, producing 23 genes with significant correlation. Following, the 23 co-expressed genes were used to generate a seconddegree correlation set with a $\rho \geq|0.90|$. The correlation analysis was processed in $\mathrm{R}$ in a Linux platform on the WVU Spruce high-performance computer (HPC) cluster using the R-package agricolae in R environment ( $\mathrm{R}$ Development Core Team, 2016). The correlation datasets for all selected genes were imported to Cytoscape for the genetic network visualization (Smoot et al., 2011).

Identification of cis-elements in promoter region: known cis-elements present in the 2-kb promoter region of the $M t G R F 2$ gene was performed using the PLACE online tool (www.dna.affrc.go.jp/htdocs/PLACE: Higo et al., 1999) using Arabidopsis as the default plant species.

\section{REFERENCES}

Adesemoyea, A., H. Torbertb and J. Kloeppera (2010) Increased plant uptake of nitrogen from 15Ndepleted fertilizer using plant growth- promoting rhizobacteria. Applied Soil Ecology 56(1): 54-58.

Afgan E, Baker D, van den Beek M, Blankenberg D, Bouvier D, Čech M, Chilton J, Clements D, Coraor N, Eberhard C, et al (2016) The Galaxy platform for accessible, reproducible and collaborative biomedical analyses: 2016 update. Nucleic Acids Res 44: W3-W10

Andersen CL (2004) Normalization of real-time quantitative reverse transcription-PCR data: A modelbased variance estimation approach to identify genes suited for normalization, applied to bladder and colon cancer data sets. Cancer Res 64: 5245-5250

Andersson CR, Jensen EO, Llewellyn DJ, Dennis ES, Peacock AWJ (1996) A new hemoglobin gene from soybean: A role for hemoglobin in all plants (nonsymbiotic/leghemoglobin/evolution). Plant Biol 93: 5682-5687

Andrews S FastQC a quality control tool for high throughput sequence data.

de Bang T, Lundquist PK, Dai X, Boschiero C, Zhuang Z, Pant P, Torres-Jerez I, Roy S, Nogales J, Veerappan V, et al (2017) Genome-wide identification of Medicago peptides involved in macronutrient responses and nodulation. Plant Physiol 175: pp.01096.2017

Berrabah F, Ratet P, Gourion B (2015) Multiple steps control immunity during the intracellular 
accommodation of rhizobia. J Exp Bot 66: 1977-1985

Boivin S, Fonouni-Farde C, Frugier F (2016) How auxin and cytokinin phytohormones modulate root microbe interactions. Front Plant Sci 7: 1-12

Bourcy M, Brocard L, Pislariu CI, Cosson V, Mergaert P, Tadege M, Mysore KS, Udvardi MK, Gourion B, Ratet P (2013) Medicago truncatula DNF2 is a PI-PLC-XD-containing protein required for bacteroid persistence and prevention of nodule early senescence and defense-like reactions. New Phytol 197: 1250-1261

Brameier M, Krings A, MacCallum RM (2007) NucPred - Predicting nuclear localization of proteins. Bioinformatics 23: 1159-1160

Broughton WJ, Dilworth MJ (1971) Control of leghaemoglobin synthesis in snake beans. Biochem J 125: $1075-1080$

Czernic P, Gully D, Cartieaux F, Moulin L, Guefrachi I, Patrel D, Pierre O, Fardoux J, Chaintreuil C, Nguyen P, et al (2015) Convergent evolution of endosymbiont differentiation in Dalbergioid and inverted repeat-lacking clade legumes mediated by nodule-specific cysteine-rich peptides. Plant Physiol 169: 1254-1265

Emerich DW, Krishnan HB (2014) Symbiosomes: temporary moonlighting organelles. Biochem J 460: $1-11$

Farkas A, Maroti G, Durg H, Gyorgypal Z, Lima RM, Medzihradszky KF, Kereszt A, Mergaert P, Kondorosi E (2014) Medicago truncatula symbiotic peptide NCR247 contributes to bacteroid differentiation through multiple mechanisms. Proc Natl Acad Sci 111: 5183-5188

Ferguson GP, Roop II RM, Walker GC (2002) Deficiency of a Sinorhizobium meliloti bacA mutant in alfalfa symbiosis correlates with alteration of the cell envelope. J Bacteriol 184: 5625-5632

Gamas P, Niebel F de C, Lescure N, Cullimore J (1996) Use of a subtractive hybridization approach to identify new Medicago truncatula genes induced during root nodule development. Mol Plant Microbe Interact 9: 233-42

Higo K, Ugawa Y, Iwamoto M, Korenaga T (1999) Plant cis-acting regulatory DNA elements (PLACE) database: 1999. Nucleic Acids Res 27: 297-300

Hohnjec N, Lenz F, Fehlberg V, Vieweg MF, Baier MC, Hause B, Küster H (2009) The signal peptide of the Medicago truncatula modular nodulin MtNOD25 operates as an address label for the specific targeting of proteins to nitrogen-fixing symbiosomes. Mol Plant-Microbe Interact 22: 63-72

Horváth B, Yeun LH, Domonkos Á, Halász G, Gobbato E, Ayaydin F, Miró K, Hirsch S, Sun J, Tadege M, et al (2011) Medicago truncatula IPD3 is a member of the common symbiotic signaling pathway required for rhizobial and mycorrhizal symbioses. Mol Plant-Microbe Interact 24: 13451358 
Jones KM, Kobayashi H, Davies BW, Taga ME, Walker GC (2007) How rhizobial symbionts invade plants: the Sinorhizobium-Medicago model. Nat Rev Microbiol 5: 619-633

Kereszt A, Mergaert P, Kondorosi E (2011) Bacteroid development in legume nodules: evolution of mutual benefit or of sacrificial victims? Mol Plant-Microbe Interact 24: 1300-1309

Laporte P, Satiat-Jeunemaître B, Velasco I, Csorba T, Van De Velde W, Campalans A, Burgyan J, Arevalo-Rodriguez M, Crespi M (2010) A novel RNA-binding peptide regulates the establishment of the Medicago truncatula-Sinorhizobium meliloti nitrogen-fixing symbiosis. Plant J 62: 24-38

Lie C, Kelsom C, Wu X (2012) WOX2 and STIMPY-LIKE/WOX8 promote cotyledon boundary formation in Arabidopsis. Plant J 72: 674-682

Maróti G, Kondorosi É (2014) Nitrogen-fixing Rhizobium-legume symbiosis: Are polyploidy and host peptide-governed symbiont differentiation general principles of endosymbiosis? Front Microbiol 5: $1-6$

Marsh JF, Rakocevic A, Mitra RM, Brocard L, Sun J, Eschstruth A, Long SR, Schultze M, Ratet P, Oldroyd GED (2007) Medicago truncatula NIN is essential for rhizobial-independent nodule organogenesis induced by autoactive calcium/calmodulin-dependent protein kinase. Plant Physiol 144: $324-335$

Marx H, Minogue CE, Jayaraman D, Richards AL, Kwiecien NW, Sihapirani AF, Rajasekar S, Maeda J, Garcia K, Del Valle-Echevarria AR, et al (2016) A proteomic atlas of the legume Medicago truncatula and its nitrogen-fixing endosymbiont Sinorhizobium meliloti. Nat Biotechnol advance on: $1198-1205$

Mitra RM, Long SR (2004) Plant and bacterial symbiotic mutants define three transcriptionally distinct stages in the development of the Medicago truncatula/Sinorhizobium meliloti symbiosis. Plant Physiol 134: 595-604

Moreau S, Verdenaud M, Ott T, Letort S, de Billy F, Niebel A, Gouzy J, de Carvalho-Niebel F, Gamas P (2011) Transcription reprogramming during root nodule development in Medicago truncatula. PLoS One 6: e16463

Mortier V, Den Herder G, Whitford R, Van de Velde W, Rombauts S, D'haeseleer K, Holsters M, Goormachtig S (2010) CLE peptides control Medicago truncatula nodulation locally and systemically. Plant Physiol 153: 222-237

Ott T, van Dongen JT, Günther C, Krusell L, Desbrosses G, Vigeolas H, Bock V, Czechowski T, Geigenberger P, Udvardi MK (2005) Symbiotic leghemoglobins are crucial for nitrogen fixation in legume root nodules but not for general plant growth and development. Curr Biol 15: 531-535

Pan H, Wang D (2017) Nodule cysteine-rich peptides maintain a working balance during nitrogen-fixing symbiosis. Nat Plants. doi: 10.1038/nplants.2017.48 
Patro R, Duggal G, Love MI, Irizarry RA, Kingsford C (2017) Salmon provides fast and bias-aware quantification of transcript expression. Nature Methods 14, 417-419

Penterman J, Abo RP, De Nisco NJ, Arnold MFF, Longhi R, Zanda M, Walker GC (2014) Host plant peptides elicit a transcriptional response to control the Sinorhizobium meliloti cell cycle during symbiosis. Proc Natl Acad Sci 111: 3561-3566

Pfaffl MW (2001) A new mathematical model for relative quantification in real-time RT-PCR. Nucleic Acids Res 29: e45

Pislariu CI, Dickstein R (2007) An IRE-like AGC kinase gene, MtIRE, has unique expression in the invasion zone of developing root nodules in Medicago truncatula. Plant Physiol 144: 682-694

Ribeiro CW, Baldacci-Cresp F, Pierre O, Larousse M, Benyamina S, Lambert A, Hopkins J, Castella C, Cazareth J, Alloing G, et al (2017) Regulation of differentiation of nitrogen-fixing bacteria by microsymbiont targeting of plant Thioredoxin s1. Curr Biol 27: 250-256

Roux B, Rodde N, Jardinaud M-F, Timmers T, Sauviac L, Cottret L, Carrère S, Sallet E, Courcelle E, Moreau S, et al (2014) An integrated analysis of plant and bacterial gene expression in symbiotic root nodules using laser-capture microdissection coupled to RNA sequencing. Plant J 77: $817-837$

Satgé C, Moreau S, Sallet E, Lefort G, Auriac M-C, Remblière C, Cottret L, Gallardo K, Noirot C, Jardinaud M-F, et al (2016) Reprogramming of DNA methylation is critical for nodule development in Medicago truncatula. Nat Plants 2: 16166

Sibley CR, Blazquez L, Ule J (2016) Lessons from non-canonical splicing. Nat Rev Genet 17: 407-421

Sinharoy S, Torres-Jerez I, Bandyopadhyay K, Kereszt A, Pislariu CI, Nakashima J, Benedito VA, Kondorosi E, Udvardi MK (2013) The $\mathrm{C}_{2} \mathrm{H}_{2}$ transcription factor REGULATOR OF SYMBIOSOME DIFFERENTIATION represses transcription of the secretory pathway gene VAMP721a and promotes symbiosome development in Medicago truncatula. Plant Cell 25: 35843601

Smoot ME, Ono K, Ruscheinski J, Wang P-L, Ideker T (2011) Cytoscape 2.8: new features for data integration and network visualization. Bioinformatics 27: 431-432

Trevaskis B, Watts RA, Andersson CR, Llewellyn DJ, Hargrove MS, Olson JS, Dennis ES, Peacock WJ (1997) Two hemoglobin genes in Arabidopsis thaliana: the evolutionary origins of leghemoglobins. Proc Natl Acad Sci U S A 94: 12230-4

Uehlein N, Fileschi K, Eckert M, Bienert GP, Bertl A, Kaldenhoff R (2007) Arbuscular mycorrhizal symbiosis and plant aquaporin expression. Phytochemistry 68: 122-129

Vasse J, De Billy F, Camut S, Truchet G (1990) Correlation between ultrastructural differentiation of bacteriods and nitrogen fixation in alfalfa nodules. J Bacteriol 172: 4295-4306 
Van de Velde W, Zehirov G, Szatmari A, Debreczeny M, Ishihara H, Kevei Z, Farkas A, Mikulass K, Nagy A, Tiricz H, et al (2010) Plant peptides govern terminal differentiation of bacteria in symbiosis. Science 327: 1122-1126

Vernié T, Kim J, Frances L, Ding Y, Sun J, Guan D, Niebel A, Gifford ML, de Carvalho-Niebel F, Oldroyd GED (2015) The NIN transcription factor coordinates diverse nodulation programs in different tissues of the Medicago truncatula root. Plant Cell 27: 3410-3424

Wang D, Griffitts J, Starker C, Fedorova E, Limpens E, Ivanov S, Bisseling T, Long S (2010) A nodule-specific protein secretory pathway required for nitrogen-fixing symbiosis. Science 327: $1126-1129$

Wang Q, Yang S, Liu J, Terecskei K, Ábrahám E, Gombár A, Domonkos Á, Szűcs A, Körmöczi P, Wang T, et al (2017) Host-secreted antimicrobial peptide enforces symbiotic selectivity in Medicago truncatula. Proc Natl Acad Sci 114: 201700715

Yamaya-Ito H, Shimoda Y, Hakoyama T, Sato S, Kaneko T, Hossain MS, Shibata S, Kawaguchi M, Hayashi M, Kouchi H, et al (2017) Loss-of-function of ASPARTIC PEPTIDASE NODULEINDUCED 1 (APN1) in Lotus japonicus restricts efficient nitrogen-fixing symbiosis with specific Mesorhizobium loti strains. Plant J 38: 42-49

Yang S, Wang Q, Fedorova E, Liu J, Qin Q, Zheng Q, Price PA, Pan H, Wang D, Griffitts JS, et al (2017) Microsymbiont discrimination mediated by a host-secreted peptide in Medicago truncatula. Proc Natl Acad Sci 114: 201700460

Yano K, Yoshida S, Muller J, Singh S, Banba M, Vickers K, Markmann K, White C, Schuller B, Sato S, et al (2008) CYCLOPS, a mediator of symbiotic intracellular accommodation. Proc Natl Acad Sci 105: 20540-20545 
CHAPTER 5 


\section{INVOLVEMENT OF TWO NOVEL GRF-TYPE ZINC FINGER NODULINS DURING RHIZOBIAL SYMBIOTIC ESTABLISHMENT IN MEDICAGO TRUNCATULA NODULES}

\section{CONCLUSIONS AND PERSPECTIVES}

Although a detailed picture has been compiled regarding the first stages of interaction between root cells and free-living rhizobia that triggers nodule development, very little remains known about the molecular players during cell infection, symbiosome formation and bacteroid differentiation that will ultimately produce a fully functional nodule capable of supporting SYMBIOTIC NITROGEN FIXATION (SNF). One major gaps in knowledge on SNF, is the involved of plant genes that participate in the regulation of bacteroid differentiation.

In this dissertation, we shed some light on the function of two novel putative transcription factor during the development of root nodules for symbiotic nitrogen fixation in the model legume Medicago truncatula. Both genes of interest are highly expressed but in distinct zones of the indeterminate nodule. Both genes encode related proteins that belong to a largely non-characterized protein family of potential transcription factors, the GRF-type zinc finger.

The nodulin MtN20/MtGRF1 is highly expressed at 4dpi, a stage when the symbiosome starts forming in newly infected cells of the developing nodule. More precisely, MtN20 is expressed in the distal side of the infection zone. An insertional Tnt1 mutant line for this gene indicates MtN20 may be crucial for symbiotic nitrogen fixation, but not for nodule formation. From the experiments with mutant rhizobial, $M t N 20$ requires infection for transcription induction, but not necessarily bacteroid differentiation per se. We conclude that MtN20 is potentially involved during the early events of rhizobial infection of nodule cells. MtN20 belongs to a regulatory gene network participating with bona fide symbiotic genes, such as EFD, the EFD target Nod19, NIN and several nodule-specific cysteine-rich (NCR) peptides. In order to further our understanding about this gene and reveal its exact molecular function during nodule development, some experiments need to be performed. 1) Gene knock-out of MtN20 (e.g., via CRISPR/Cas9 system) will resolve its essentiality for symbiotic nitrogen fixation in Medicago truncatula; 2) Transcriptional profiling (e.g., RNA-Seq) of MtN20 knock-out and overexpressing nodules will help determine which genes that transcriptionally connected with our gene of interest; 3) Expression of MtN20 fused with a fluorescent marker (e.g., GFP) will reveal its subcellular localization. If this protein acts as a transcription factor, it is expected to localize in the nucleus. In this regard, given the putative nuclear localization signal is position at the C-terminus, it is important to test this fusion with fluorescent tag fused at the N-terminus of the protein of interest; 4) If MtN20 is a transcription factor, it also needs to interact 
with cis-elements in the DNA or target genes. This question can be addressed with ChIP-Seq, ChIP-PCR, or motif assay, in which a pull-down approach is used to identify which molecule or DNA sequence the protein is able to interact with. Additional confirmation will require alternate approaches, such as yeastone-hybrid, and electrophoretic mobility shift assay (EMSA) to help elucidate the exact MtN20 target DNA sites; 5) A refined bioinformatics analysis to identify and compare cis-elements in all co-regulated genes of the MtN20 transcriptional network may render a selection of common cis-element responsible for the spatial-temporal resolution of plant genes during cell infection; 6) the significance of the post-translational modifications experimentally verified in MtN20 also requires some consideration. Expression of MtN20 variants with the phosphorylated Ser residues replaced by a tolerable non-phosphorylated substitute residue (e.g., Ala) (Betts and Russell, 2003) compared to the wild-type allele and a variant with those Ser replaced by phosphomimetic mutations residue (Glu, which works as a mimic of constitutive phosphorylated Ser). In this experiment, it is advisable to use the native promoter of MtN20 to avoid its mis-expression that could lead to pleiotropic effects in nodule development. The potential roles of protein phosphorylation on protein localization or DNA-binding properties are intriguing questions; 7) finally, the protein-protein interactions involving MtN20 is highly significant in this process. This question can be addressed by yeasttwo-hybrid (Y2H) screening of co-expressed proteins, bimolecular fluorescence complementation (BiFC) assay, and fluorescence resonance energy transfer (FRET). Altogether, focusing not only on MtN20, but on other nodule-specific (or nodule zone-specific) genes throughout symbiosis maturation, from cell infection to full bacteroid differentiation, could lead us to a much better dynamic picture of the process.

Furthermore, we also showed that $M t G R F 2$ is another nodule-specific gene but distinctly expressed specifically in the interzone of the nodule. This result indicates that MtGRF2 may play an essential role during bacteroid differentiation, when many nodule cysteine-rich (NCRs) peptides are essential for normal symbiotic nitrogen fixation in root nodules of Medicago truncatula. Indeed, the genetic network generated around MtGRF2 contains several NCRs and other important symbiotic genes, such as MtNCR88-TC38212 (Medtr5g063600.1), NCR219-TC3396 (Medtr6g090485.1). The same follow-up experiments suggested for MtN20 also applies to MtGRF2. Additionally, a comparative approach using the cis-elements overrepresented in both genes connected with MtN20 and MtGRF2, or uniquely overrepresented in only one of them, will enable identify relevant regulatory sequences and create testable hypotheses for molecular biology experiments to understand how the genes are sequentially regulated during the process that goes from cell infection into full bacteroid differentiation in a nodule cell that is mature to symbiotically fix nitrogen.

Those two M. truncatula GRF-type zinc finger possibly are involved in the processed of bacteroid differentiation. Very few genes have been identified in the process of bacteroid differentiation, e.g. as Regulator of Symbiosome Differentiation (RSD) controlling the expression of vesicle-associated 
membrane protein 721a, Does Not Fix (DNF1) and DNF2, Trx s1, Glycine-Rich Protein (GRP), Symbiotic Cysteine-rich Receptor-like Kinase (SymCRK) and many NCRs specific of the Inverted Repeat-Lacking Clade (IRLC) legume group (Alunni and Gourion, 2016). And this dissertation opens up new ideas in that plant genes present fundamental control on the bacteroid initial and terminal differentiation. There are possibilities that those two putative transcription factors GRF-type zinc finger, coordinate the genetic machinery reprogramming, positioning the legume, macrosymbiont, acting as the major regulator of the bacteroid differentiation and sustainment of SNF.

A set of experiments aiming at better understanding the process of mutualistic cell infection and bacteroid differentiation is needed. For that, a batch of knock-out mutant nodule for genes specifically expressed in these stages could be generated, transcriptionally profiled, and phenotypically analyzed by microscopy, for the nodule anatomy by a light or via transmission electron microscopy for bacteroid features. Altogether, these data will determine which (non-redundant) genes are essential and at which stage the process is interrupted by each gene knockout. High-throughput analysis of cis-elements overrepresented in nodule-induced genes would also help elucidate the molecular mechanisms by which genes are induced and which transcription factors are responsible for each step of the process.

Overall, this study could provide valuable information about the nodulation and symbiotic nitrogen fixation in terms of reprogramming the genetic machinery required to normal root nodulation and symbiotic nitrogen fixation, as well as important evolutionary events that enabled the occurrence of endosymbiosis. With all the knowledge gathered on molecular genetics and physiology of legumes so far, we are closer than ever, albeit so far yet, of fully understanding nodulation and symbiotic nitrogen fixation in order to introduce this trait in non-legume crops. Only a greater investment in research and education, and substantially more funding to agricultural sciences will enable this ambition to be fulfilled.

\section{REFERENCE}

Alunni B, Gourion B (2016) Terminal bacteroid differentiation in the legume-rhizobium symbiosis: nodule-specific cysteine-rich peptides and beyond. New Phytol 211: 411-417

Betts MJ, Russell RB (2003) Amino acid properties and consequences of substitutions. in: bioinformatics for geneticists, pp 289-316. John Wiley \& Sons, Ltd. Available at: http://dx.doi.org/10.1002/0470867302.ch14. 